\title{
RESISTÊNCIA AO DESGASTE DE CIMENTOS RESINOSOS SUBMETIDOS À CICLAGEM DE pH E ESCOVAÇÃO SIMULADA
}

\section{ANURADHA PRAKKI}

Dissertação apresentada à Faculdade de Odontologia de Bauru, da Universidade de São Paulo, como parte dos requisitos para obtenção do título de Mestre em Odontologia, área Dentística.

(Edição Revisada) 


\section{RESISTÊNCIA AO DESGASTE DE CIMENTOS RESINOSOS SUBMETIDOS À CICLAGEM DE pH E ESCOVAÇÃO SIMULADA}

\section{ANURADHA PRAKKI}

Dissertação apresentada à Faculdade de Odontologia de Bauru, da Universidade de São Paulo, como parte dos requisitos para obtenção do título de Mestre em Odontologia, área Dentística.

(Edição Revisada)

Orientador: Prof. Dr. Rafael Francisco Lia Mondelli

\section{BAURU}

2003 


\begin{tabular}{|c|}
\hline Prakki, Anuradha \\
P84ristência ao desgaste de cimentos resinosos \\
$\begin{array}{l}\text { Rubmetidos à ciclagem de pH e escovação simulada./ } \\
\text { Anuradha Prakki - Bauru, 2003. 100p.; il.; } 30 \mathrm{~cm} .\end{array}$ \\
Dissertação (Mestrado) - Faculdade de Odontologia \\
de Bauru. USP \\
Orientador: Prof. Dr. Rafael Francisco Lia Mondelli
\end{tabular}

Autorizo, exclusivamente para fins acadêmicos e científicos, a reprodução total ou parcial desta dissertação/tese, por processos fotocopiadores e/ou meios eletrônicos.

Assinatura do Autor:

Data: 


\section{ANURADHA PRAKKI}

\section{DADOS CURRICULARES}

26 de Março de 1975

São José dos Campos, SP

Filiação

1993-1996

$1999-2000$

2001-2003

Associações

\author{
Nascimento
}

Prakki Satyamurty

Prakki Alivelu Mangatayaru

Graduação em Odontologia

Faculdade Estadual de Campinas

(FOP/UNICAMP)

Especialização Dentística Restauradora Fundação Bauruense de Estudos Odontológicos (FUNBEO/USP)

Curso de Pós Graduação em Dentística, nível mestrado - Faculdade de Odontologia de Bauru - USP

GBPD: Grupo Brasileiro de Professores de Dentística

SBPqO: Sociedade Brasileira de Pesquisa Odontológica

IADR: International Association for Dental Research 
"If we discover a complete theory, it should in time be understandable in broad principle by everyone, not just a few scientists. Then we shall all, philosophers, scientists, and just ordinary people, be able to take part in the discussion of why we and the universe exist. If we find the answer to that, it would be the ultimate triumph of human reason for then we would truly know the mind of God".

\footnotetext{
STEPHEN HAWKING Concluding sentence of "A Brief History of Time"
} 
Sempre que consultamos uma dissertação, existe uma grande curiosidade em ler as dedicatórias e agradecimentos do autor. Entretanto, tenho notado que elas são muito semelhantes, todas utilizam "chavões" muito parecidos como: gostaria de dividir essa vitória com e etc., ou obrigada por terem acreditado e etc., enfim, não tomem isso como uma crítica maldosa, mas é que quando sentei para escrever essas palavras, meditei sobre elas e resolvi fazer um pouco diferente. Resolvi contar a vocês (que tiverem paciência de ler), um pouco da minha história (...)

(...) Tudo começou há algumas décadas atrás na pequena cidade de Nidadavolu, no estado de Andhra Pradesh, ao sulda Índia.Meus pais vieram de famílias extremamente simples. Só para se ter uma idéia, meu pai ganhou o seu primeiro calçado aos 7 anos de idade. O tragicômico aconteceu em seguida, ele foi inaugurar esse chinelinho em uma festa e não acostumado a se calçar tirou-os do pé e foi brincar. Quando retornou, haviam the roubado o chinelo e isso ainda rendeu dias de castigo. Fiquem tranqüilos os traumas já foram superados.

Meus pais (Satyamurty e Alivelu) se casaram de uma forma inconcebível para a cultura ocidental, o casamento foi arranjado pelas duas famílias e o meu av $\hat{o}$ materno pagou ao paterno um dote em dinheiro, e isso é ainda extremamente comum lá, até os dias de hoje. Em uma situação dessas, tudo parece conspirar contra, mas o fruto dessa relação foi super positivo e originou três filhas. A Aruna nascida na Índia, Anuradha e Purnima, Grasileiras.

O motivo que trouxe meu pai ao Brasil foi profissional, mas eles se apaixonaram pela terrinha e se tornaram brasileiros. Hoje o meu pai é na minha suspeitíssima opinião um grande pesquisador, e a minha mãe uma verdadeira fera, que deu ao papai todo o suporte para progredir.

Uma das maiores gratidões que nós (aqui eu falo também em nome das minhas irmãs) temos por eles está no fato de terem se adaptado da forma mais sábia possível às divergências culturais. Hoje, somos formadas no Brasil, a Aru é médica, eu e a Pu, dentistas. E o que parecia impossível aos olhos de alguns familiares e "amigos" mais radicais aconteceu, eu tenho dois cunhados brasileiros; um mineiro também 
médico e o outro joseense, advogado. Bem, segundo a Purnima "se cunhado fosse coisa boa não começava com c +u!!!!!!!" Ћá! há! há! Mas eu sou a primeira a contestar essa maldade, os meus são como irmãos para mim. A família não parou de crescer aí, eu tenho dois sobrinhos (Luisa e Henrique) que são literalmente como filhos para mim, eu os mimo, mimo, mimo e o que é melhor, sou muito mimada por eles também.

O terceiro aspirante a genro da família é o Renato. Outro dia eu disse brincando ao Rafael (meu orientador) que daqui há 1 ano, nós completaríamos 10 anos de namoro e que eu achava que estava no direito de reivindicar uma pensão alimentícia!!! Aí o Rafael disse o seguinte: "Noão vem não que eu estou sabendo que vocês andaram uns tempos terminados, se você me chamar para depor, é causa perdida". Amigo da onça! Brincadeiras à parte, isso de certa forma mostra como a vida pode dar voltas e que ofuturo é sempre uma grande incógnita. Mas hoje, eu posso afirmar com todas as letras que o Renato é uma das melhores coisas que poderia ter me acontecido.

Um dia quem sabe, e u terei a oportunidade de continuar essa história, por hora eu gostaria de dizer que me sinto muito orgulhosa e feliz pela família que tenho, que eu os amo muito, muito, muito. Eu os agradeço por cada momento de ternura, de "quebra-pau" às vezes, de conquistas, afeto, dedicação, renúncia... Nossa!! Só agora me dei conta que não teve mesmo jeito, acabei usando todos aqueles "chavões" que tentei evitar!! Pois é, agora eu entendo. Como poderia escapar disso se o maior de todos os "chavões" é o próprio amor?

A todos vocês dedico este trabalho 


\section{AGRADECIMENTOS}

Ao meu orientador Rafael, que me proporcionou dois anos de excelente convivência, sempre acreditando no meu trabalho, mais que um simples orientador, hoje um grande amigo.

Á Faculdade de Odontologia de Bauru, na pessoa da Diretora Profa. Dra. Maria Fidela de Lima Navarro e do coordenador da pós-graduação Prof. Dr. José

Carlos Pereira.

Aos amigos, de São José dos Campos (Unesp), Piracicaba (Unicamp), pósgraduandos de outras disciplinas, doutorandos de Dentística e Materiais Dentários e em especial, aos colegas, Bruno, Leonardo, Diego, Natália, Terezinha, Flávia, Luís, Eduardo, Nádia, Carla, Anderson, Daniela, Heitor, Luisa, Rosa, Cris e

Maria Carmen. Daqui a alguns anos, eu dificilmente me lembrarei dos temas das suas teses, e provavelmente, todos esses materiais que utilizamos nesses estudos nem existam mais. O que fica mesmo é a amizade e a lembrança dos bons momentos. 
Aos professores de Materiais Dentários e do Departamento de Dentística. Ao Prof. César, pelo excentrismo; ao Paulinho, pela sua acessibilidade, ao Prof. Paulo Amarante, um poço de cultura, ao Prof. José Mondelli, pelas lições de humildade, ao Prof. Mario, pela sua 6ondade e tranqüilidade, ao Prof. Aquira, pela sua criatividade, ao Prof. Francischone pela sua altivez, à Profa. Teresa pela sua jovialidade, ao Prof. Eduardo, pela sua sistemática, ao Prof. Ricardo, pela sua sabedoria e ah! por ter me salvado do terremoto! Ao Prof. Pereira, pela sua ternura, e à Profa. Fidela, uma verdadeira Fortaleza. Cada um com seu jeito peculiar contribuíram para o meu aprendizado profissional e pessoal

Aos professores, Zé Roberto, Dora, Lauro, que me estimularam a estudar

Dentística.

Ao Prof. Dr. José Roberto Pereira Lauris pela colaboração na análise estatística desse trabalho.

Aos funcionários e amigos, Lô, Sandrinha, Alcides, Edimauro, Odemir, Telma, Ovídio, Karen, Elo, Ângela, Rita, Nelson, Dito, Junior, Ziley, Zuleika, Aurélio, Aninha, Cleusa, Giane, Solange, Vera, Valéria, Rita, Cybelle, Ademir, César e Salvador. 


\section{SUMÁRIO}

Lista de abreviaturas e símbolos...................................................... ix

Lista de figuras........................................................................

Lista de tabelas.............................................................................. $\quad$ xiv

Lista de Anexos............................................................................ XV

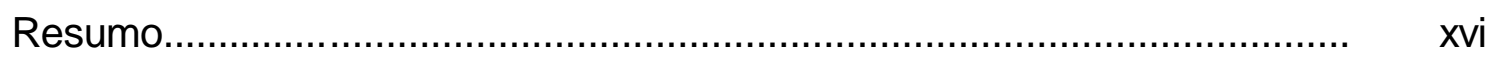

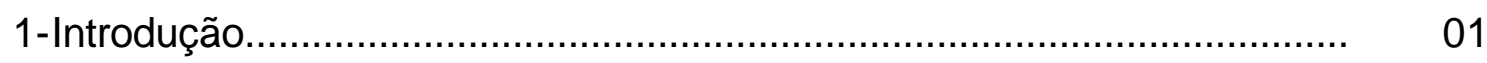

2-Revisão da Literatura.............................................................. 05

3-Proposição......................................................................... 28

$4-$ Material e métodos..................................................................... $\quad 30$

$5-$ Resultados.......................................................................... 46

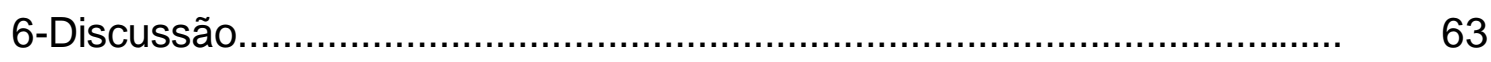

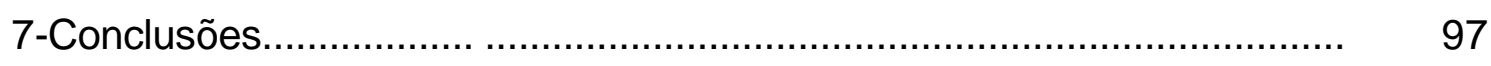

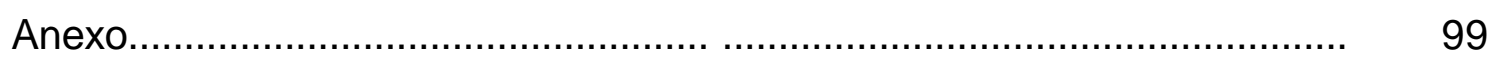

Referências bibliográficas.............................................................. 102

Abstract.......................................................................... 118 


\section{LISTA DE ABREVIATURAS E SÍMBOLOS}

Bis-GMA: Bisfenol glicidil metacrilato

TEGDMA: trietilenoglicol de dimetacrilato

UDMA: Uretano dimetacrilato

g: Grama

Kg: Quilograma

TMPT: Trimetilol propano trimetacrilato

$\mathrm{mm}$ : Milímetro

$\mathrm{mm}^{2}$ : Milímetro ao quadrado

ml: Mililitro

$\mathrm{pH}$ : Potencial hidrogeniônico

$\mathrm{X}$ : Indica o número de vezes

$\%$ : Porcentagem

MEV: Microscopia eletrônica de varredura

$\mathrm{N}$ : Unidade química $=$ Normal

${ }^{\circ} \mathrm{C}$ : Graus Celsius

Mpa: Mega Pascal

ìm: Micrômetro

Ra: Rugosidade aritmética

$\mathrm{P}^{32}$ : Isótopo de fósforo

r.p.m.: Rotações por minuto

$\mathrm{SiO}_{2}$ : Sílica

$\mathrm{CaCO}_{3}$ : carbonato de Cálcio

PMMA: Polimetilmetacrilato

\pm : Mais ou menos

$\mathrm{Hz}$ : Hertz

$\mathrm{PO}_{4}$ : Fosfato 
Ca: Cálcio

ppm: parte por milhão

MFP: Máximo Flúor Prote tor

\#: number (número na língua inglesa)

$\mathrm{mM}$ : Milimolar

DP: Desvio padrão

Ms: Milisegundos 


\section{LISTA DE FIGURAS}

FIGURA 1 Apresentação comercial dos materiais restauradores empregados.

FIGURA 2 Apresentação comercial do dentifrício e escova dental empregado.

FIGURA 3 Apresentação do equipamento Rugosímetro Hommel Tester T1000.......

FIGURA 4 Rugosímetro Hommel Tester T 1000...................................... 37

FIGURA 5 Ponta ativa do Rugosímetro Hommel Tester T 1000................... 38

FIGURA 6 Máquina de escovação utilizada nos testes de escovação simulada.

FIGURA 7 Disposição do espécime na base metálica do equipamento......... 40

FIGURA 8 Disposição do espécime em relação à escova dental................... 41

FIGURA 9 Posicionamento da escova dental sobre o espécime.................... 41

FIGURA 10 Escovação do espécime............................................................... 42

FIGURA 11 Escovação simultânea dos espécimes........................................ 42

FIGURA 12 Gráfico representativo da alteração de massa (\%) dos materiais avaliados

FIGURA 13 Gráfico representativo da alteração de rugosidade $(\mu \mathrm{m})$ dos materiais avaliados.

FIGURA 14 Padrão perfilométrico de rugosidade superficial. Enforce inicial (A), Enforce final sem ciclagem de $\mathrm{pH}(\mathrm{B})$, Enforce final com ciclagem de $\mathrm{pH}(\mathrm{C})$.

FIGURA 15 Padrão perfilométrico de rugosidade superficial. Rely $X$ inicial (A), Rely $X$ final sem ciclagem de $\mathrm{pH}(\mathrm{B})$, Rely final com ciclagem de $\mathrm{pH}(\mathrm{C})$. 
FIGURA 16 Padrão perfilométrico de rugosidade superficial. Variolink II inicial (A), Variolink II final sem ciclagem de $\mathrm{pH}(\mathrm{B})$, Variolink II final com ciclagem de $\mathrm{pH}(\mathrm{C})$.

FIGURA 17 Padrão perfilométrico de rugosidade superficial. Artglass inicial (A), Artglass final sem ciclagem de $\mathrm{pH}(\mathrm{B})$, Artglass final com ciclagem de $\mathrm{pH}(\mathrm{C})$

FIGURA 18 Padrão perfilométrico de rugosidade superficial. Duceram Plus inicial (A), Duceram Plus final sem ciclagem de pH (B), Duceram Plus final com ciclagem de $\mathrm{pH}(\mathrm{C})$

FIGURA 19 Fotomicrografia da superfície do cimento Enforce antes da escovação (MEV original 500X)

FIGURA 20 Fotomicrografia da superfície do cimento Enforce após escovação (MEV original 500X).

FIGURA 21 Fotomicrografia da superfície do cimento Enforce após ciclagem de pH e escovação (MEV original 500X)

FIGURA 22 Fotomicrografia da superfície do cimento Rely $X$ antes da escovação (MEV original 500X).

FIGURA 23 Fotomicrografia da superfície do cimento rely $\mathrm{X}$ após escovação (MEV original 500X)

FIGURA 24 Fotomicrografia da superfície do cimento Enforce após ciclagem de $\mathrm{pH}$ e escovação (MEV original 500X)

FIGURA 25 Fotomicrografia da superfície do cimento Variolink II antes da escovação (MEV original 500X).

FIGURA 26 Fotomicrografia da superfície do cimento Variolink II após escovação (MEV original 500X).

FIGURA 27 Fotomicrografia da superfície do cimento Variolink II após ciclagem de pH e escovação (MEV original 500X).

FIGURA 28 Fotomicrografia da superfície do Artglass antes da escovação (MEV original 500X).

FIGURA 29 Fotomicrografia da superfície do Artglass após escovação (MEV 
original 500X)

FIGURA 30 Fotomicrografia da superfície do Artglass após ciclagem de pH e escovação (MEV original 500X)................................................ 61

FIGURA 31 Fotomicrografia da superfície da Duceram Plus antes da escovação (MEV original 500X)......................................... 62

FIGURA 32 Fotomicrografia da superfície da Duceram Plus após escovação (MEV original 500X)....................................................... 62

FIGURA 33 Fotomicrografia da superfície da Duceram Plus após escovação (MEV original 500X) ........................................................... 62 


\section{LISTA DE TABELAS}

TABELA 1 Materiais utilizados e seus fabricantes........................................ 31

TABELA 2 Composição dos materiais empregados..................................... 32

TABELA 3 Composição do dentifŕ́cio Colgate MFP..................................... 33

TABELA 4 Valores das médias iniciais, finais, desvio padrão e a diferença (gramas) entre os grupos testados................................................

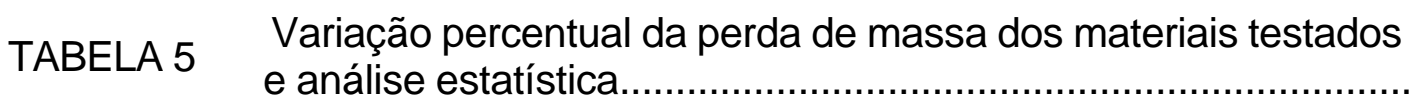

TABELA 6 Valores das médias iniciais, finais, desvio padrão, alteração de rugosidade e análise estatística dos grupos estudados (îm)....... 


\section{ANEXOS}

Médias das massas iniciais, médias das massas finais, diferença entre MF e Ml, porcentagem da alteração de massa, médias das ANEXO 1 rugosidades iniciais, médias das rugosidades finais e a diferença entre $\mathrm{RF}$ e RI de todos os materiais e condições experimentais

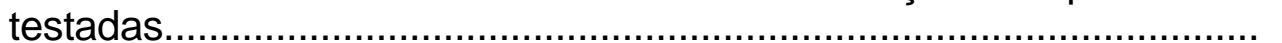

ANEXO 2 Teste estatístico para alteração de massa (ANOVA e Tukey) 102

ANEXO 3 Teste estatístico para alteração de rugosidade (ANOVA e Tukey) 102 
RESUMO 


\section{Resumo}

\section{RESUMO}

A importância da avaliação da resistência ao desgaste de cimentos resinosos se justifica, uma vez que estes podem ser expostos ao meio bucal em função do grau de desadaptação das restaurações estéticas indiretas, tornando-os susceptíveis às degradações físicas, químicas e mecânicas. Neste contexto, o objetivo deste trabalho foi avaliar a resistência ao desgaste, por meio da escovação simulada, de três cimentos resinosos, Enforce (Dentsply), Rely X (3M) e Variolink II (Vivadent) quando comparados a dois materiais de restauração indireta, Artglass (Heraeus Kulzer) e Duceram Plus (Ducera), através da alteração de massa e rugosidade superficial. Foram confeccionados 100 corpos de prova, 20 para cada material testado, onde metade foi submetida aos ciclos dinâmicos de $\mathrm{pH}$ previamente à escovação simulada. Os espécimes foram submetidos a 100.000 ciclos de escovação, utilizando-se escovas dentais macias (Oral B) e pasta dental (Colgate) diluída em água deionizada. A alteração de massa foi verificada pela diferença entre massa inicial (antes da escovação) e final (após escovação) em balança analítica. A alteração da rugosidade superficial (Ra) foi determinada pela diferença entre a média de cinco leituras iniciais (antes da escovação) e cinco leituras finais (após escovação) com rugosímetro Hommel Tester T 1000. Os resultados foram submetidos à análise de variância e teste de Tukey $(p<0,05)$.

A porcelana Duceram Plus não foi influenciada pela ciclagem de $\mathrm{pH}$ e, apresentou o melhor comportamento frente ao teste de escovação simulada. Entre os materiais resinosos, o Artglass e o Variolink II apresentaram os melhores 
comportamentos para alteração de massa e rugosidade superficial, seguidos do

Rely X e Enforce. A ciclagem de pH não influenciou estatisticamente no desgaste dos materiais avaliados. 
1-INTRODUÇÃO 


\section{1-INTRODUÇÃO}

Os últimos anos vêm sendo caracterizados por uma verdadeira revolução no âmbito dos materiais odontológicos restauradores e, protagonizando esse processo, encontram-se as resinas compostas e os sistemas adesivos. Inúmeros problemas relacionados a esses materiais ainda desafiam a ciência, entre eles, a resistência ao desgaste, principalmente nas regiões de contato oclusal, degradação hidrolítica, dificuldades em se obter contatos e contornos interproximais efetivos ${ }^{44,71}$, sensibilidade pós-operatória ${ }^{30,35}$ e a contração de polimerização ${ }^{16}$.

Nesse contexto, a confecção de restaurações estéticas indiretas é, em algumas situações clínicas, uma excelente alternativa a fim de minimizar esses problemas $^{122,22}$, pelo fato de serem confeccionadas e, principalmente, polimerizadas fora da cavidade oral.

Os materiais de fixação associados a essas restaurações também evoluíram muito e, com o advento de cimentos a base de resina, problemas como resistência de união e resistência à compressão, puderam ser contornados principalmente em relação ao tradicional cimento de fosfato de zinco, que proporciona adequada retenção mecânica porém, solubilidade relativamente alta em ambiente ora ${ }^{94}$ e uma opacidade extremamente indesejada em restaurações estéticas.

Pouca atenção está sendo despendida, no entanto, ao desempenho do desgaste dos cimentos resinosos, que é de crucial importância para garantir a longevidade destes procedimentos clínicos. Este desgaste por sua vez, pode estar diretamente relacionado à sua composição ${ }^{37,68}$ (porcentagem, tipo e quantidade de carga inorgânica), ao seu grau de polimerização, silanização das suas partículas 
inorgânicas ${ }^{37}$, bem como a espessura da linha de cimento ${ }^{44}$, ao material restaurador empregado em conjunto ${ }^{115}$ e parafunção do paciente.

A exposição do cimento na margem da restauração torna-o susceptível à degradação por ação de substâncias abrasivas (escova e pasta dental), alimentos e fluidos bucais (degradação hidrolítica) ${ }^{37}$. A alteração de rugosidade na linha de cimento pode facilitar a adesão e retenção de placa dental, implicando em maior risco do desenvolvimento de cáries secundárias e doenças periodontais ${ }^{9,96}$, descoloração e manchamento das restaurações ${ }^{45}$ e até mesmo a perda da restauração indireta ${ }^{84}$. KAWAI; ISENBERG; LEINFELDER ${ }^{62}$ (1993), observaram em seus estudos que linhas de cimentos resinosos equivalentes a 50ìm j á são susceptíveis ao desgaste.

A adaptação marginal de restaurações estéticas indiretas pode apresentar uma expressiva variação, podendo chegar até $300 \mu \mathrm{m}^{98,111}$. De acordo com PASHLEY et al. $^{88}$ (1992), a espessura exclusivamente de agentes adesivos polimerizados varia de 60 a 350 $4 \mathrm{~m}$, o que poderia interferir na adaptação de restaurações indiretas, onde a linha de cimento desejada é de 50 a $100 \mu \mathrm{m}$. FANUSCU; SORENSEN ${ }^{33}$ (1992) demonstraram que a adaptação marginal do material restaurador IPS-

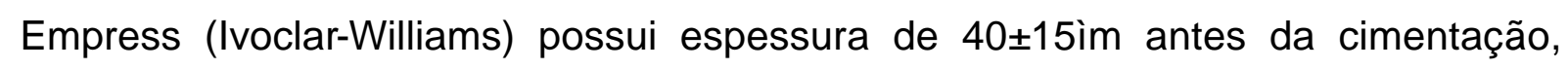
podendo atingir espessura de $60 \pm 25 i ̀ m$ após o procedimento de cimentação.

Segundo ASMUSSEN ${ }^{6}$ (1984) polímeros experimentais à base de Bis-GMA e TEGDMA apresentaram queda na dureza e "amolecimento" de polímeros após seu armazenamento em condições ácidas. Também, a lisura superficial de restaurações de resina composta pode ser influenciada por uma condição de alto desafio cariogênico, por expô-las a ácidos na cavidade oral. Esta constatação foi averiguada 
por alguns autores ${ }^{118,11}$, quando esses materiais eram simplesmente imersos em soluções ácidas ou ainda, submetidos a protocolos dinâmicos de ciclagem de $\mathrm{pH}^{34}$.

Sabendo-se que a utilização de escovas de dente associada a dentifrícios é a maior ferramenta de higiene oral utilizada ${ }^{73}$ e da possibilidade da lisura superficial de restaurações submetidas à escovação também ser influenciada por uma condição de desafio ácido ${ }^{118,11,6}$, este trabalho tem como objetivo avaliar laboratorialmente 0 comportamento de cimentos resinosos em comparação a uma porcelana e uma resina composta de uso indireto quando submetidos à escovação simulada ${ }^{39,}{ }^{119}$ e ciclagem de $\mathrm{pH}$. A avaliação foi realizada através da perda de massa e alteração da rugosidade superficial. 
2-REVISÃO DE LITERATURA 


\section{2-REVISÃO DE LITERATURA}

\section{$\underline{2.1-D E S G A S T E}$}

Idealmente o material restaurador deveria, ao ser inserido na cavidade dentária, apresentar longevidade clínica compatível à vida cronológica do paciente. No entanto, esses materiais quando levados à cavidade oral estão sujeitos a uma série de degradações: a atrição, abfração, erosão e abrasão ${ }^{51}$. MILLER $^{82}$ (1907) define desgaste como perda de substância, podendo ser do material restaurador ou do próprio elemento dental, sem considerar a etiologia envolvida. Outra conceituação é atribuída a desgaste pelos autores JONES; JONES; WILSON ${ }^{59}$ (1972), estes associam desgaste a uma perda progressiva de substância de uma determinada superfície através de uma ação mecânica. Especificamente no caso da abrasão, essa perda de material é causada pela ação cortante de um abrasivo, podendo ser o esforço mastigatório ${ }^{46,93}$, a movimentação do bolo alimentar ${ }^{65}$ e a escovação dentária ${ }^{39,119,118}$.

O desgaste de um material restaurador pode levar a conseqüências indesejadas tais como: alteração da rugosidade superficial facilitando a adesão e retenção de placa dental, implicando em maior risco do desenvolvimento de cáries secundárias e doenças periodontais ${ }^{9,96}$, além da descoloração e manchamento das restaurações ${ }^{45,62}$; desadaptação marginal que implica em infiltração bacteriana ${ }^{88}$, e alteração da anatomia da restauração, podendo causar problemas de oclusão.

Diante desses contratempos, metodologias adequadas para se avaliar a resistência ao desgaste das próprias estruturas dentais, bem como dos materiais 
odontológicos restauradores, vêm sendo desenvolvidas e aprimoradas ao longo dos $\operatorname{anos}^{96,27,78,94,57}$.

\section{2 - QUAIS SÃO OS TESTES EMPREGADOS PARA SE AVALIAR A}

\section{RESISTÊNCIA AO DESGASTE DE MATERIAIS RESTAURADORES?}

Duas diferentes abordagens são geralmente relacionadas aos testes laboratoriais de desgaste ${ }^{64}$, sendo elas: desgaste abrasivo de 3 ou 2 corpos.

O desgaste de 3 corpos ocorre quando um abrasivo é inserido entre duas superfícies que apresentam movimentos independentes. Enquanto no desgaste de 2 corpos, as partículas abrasivas encontram-se agregadas a uma das superfícies.

O precursor de testes de resistência abrasiva, utilizando dentifrícios, foi MILLER $^{82}$ no ano de 1907. Através da escovação manual de dentes recém extraídos, este curioso pesquisador percebeu a ocorrência de desgaste.

A partir de então, vários estudos laboratoriais também foram realizados com o intuito de se verificar a resistência ao desgaste de estruturas dentais e materiais restauradores. Com a aplicação de feixes de laser de hélio-neônio (medindo assim a intensidade de luz refletida), a abrasividade de dentifrícios em placas de polimetilmetacrilato (PMMA) foi investigada em 1979 por RELDMALM; RYDÉN77. Seis dentifrícios contendo diferentes abrasivos foram testados: polimetilmetacrilato, dióxido de sílica, bicarbonato de sódio, silicato de alumínio e carbonato de cálcio. Os espécimes foram submetidos ao laser anteriormente à abrasão. A escovação foi efetuada com ciclos de $85 \mathrm{~mm}$, com 2.000 movimentos por minuto sob carga de $2,35 \mathrm{KN}$. A cada hora as placas eram removidas para as mensurações, antes de 
recolocadas eram lavadas com água e secas. Após as escovações foi notado um decréscimo na intensidade de luz refletida. Para o PMMA, foi verificado leve aumento na intensidade de luz. O dióxido de silicone e o bicarbonato de cálcio diminuíram a intensidade inicialmente, mas após algum tempo de escovação também se verificou um aumento significante nesta intensidade. As placas escovadas com os demais abrasivos apresentaram contínua redução da intensidade da luz. Pelos resultados, a metodologia apresentada pode ser utilizada para estudos tanto de resistência abrasiva quanto de efeitos de limpeza na higiene oral.

Outro artifício para a avaliação da abrasão de materiais restauradores foi descrito em 1980 por EHNFORD et al. $^{28}$, por meio de um sistema que permitia o contato da superfície do espécime com pequenas pérolas de vidro $(1 \mathrm{~mm}$ de diâmetro) e pasta abrasiva. Os materiais utilizados foram o amálgama, uma resina composta e uma resina sem carga. Para o teste, utilizaram $500 \mathrm{~g}$ de pérolas de vidro, $100 \mathrm{~g}$ de óxido de alumínio em pó como abrasivo e $120 \mathrm{~g}$ de água. Diferentes granulações de óxido de alumínio foram empregadas: 800, 400, 240, 120 e 80 . A uma temperatura constante de $37 \pm 2 \mathrm{C}$ os corpos de prova foram rotacionados por um motor por 2,5 minutos em cada direção com pausa a cada 15 segundos em uma velocidade de 1,4m/s. Após 4 repetições, uma média por desgaste de 1 hora foi calculada. O desgaste foi verificado pela alteração da espessura dos espécimes e as superfícies foram analisadas em MEV. A granulação de 240 causou a maior abrasão sobre o amálgama. A resina composta sofreu maior abrasão com as granulações 240, 120 e 80. Para a granulação 120 foi estabelecida uma comparação de desgaste entre os materiais, em ordem crescente: amálgama, compósito e resina sem carga. 
Houve subseqüentemente a proposta de se submeter materiais restauradores, no caso o amálgama, a resina composta e uma resina acrílica sem partículas, a uma vibração com papel carbide abrasivo a base de sílica ${ }^{79}$. O teste foi realizado por 320 minutos, utilizando separadamente diferentes granulações 180, 280, 500 e 800 do papel abrasivo a velocidade de $43 \mathrm{~Hz}$. A avaliação foi feita através da diferença de volume, calculada a partir da massa e densidade dos espécimes. Houve uma perda linear de material por volume e quanto maior a granulação maior o desgaste verificado.

Uma das metodologias comumente encontradas na remota literatura relacionase à utilização de isótopos radioativos. De acordo com a descrição de GRABENSTETTER et al. $^{43}$ (1958), os dentes são irradiados pela exposição a nêutrons. Durante a reação, as porções $\mathrm{P}^{31}$ da hidroxiapatita são convertidas em $\mathrm{P}^{32}$. O cálcio após exposição aos nêutrons, origina isótopos que passam a emitir uma fraca radiação. A abrasão é verificada através da alteração de radiação emitida pelas amostras. Assim, BULL et al. ${ }^{12}$ (1968) avaliaram cortes de esmalte e dentina, previamente irradiados do qual isótopos são formados. As amostras foram escovadas por 6 tipos de pastas com diferentes abrasivos, empregando-se uma máquina do tipo Pepsodent modificada. Para a dentina foram efetuadas 5 seqüências de 400 ciclos e para o esmalte 5 escovações de 4000 ciclos. Os resultados da escovação por quantificação dos isótopos liberados em cada solução demonstraram menor abrasividade do fosfato dicálcio hidratado comparado ao carbonato de cálcio. HARTE; MANLY ${ }^{48}$ (1975) também irradiaram espécimes de substrato de dentina de dentes humanos que foram escovados utilizando-se duas diferentes marcas comerciais de escovas de dente. Os resultados demonstraram 
forte influência das escovas, dos abrasivos, das interações entre escovas e abrasivos e, finalmente, das concentrações dos abrasivos nos resultados. Ainda na mesma linha de pesquisa e um ano depois, HARTE; MANLY ${ }^{48}$ (1976) estudaram a influência dos fatores relacionados aos estudos de determinação da abrasividade dos dentifrícios. Nesta etapa, verificaram a interferência de diferentes marcas comerciais de escovas dentárias, dureza da escova, concentração de abrasivo, temperatura do teste e tipo de diluente na abrasão da dentina. Os espécimes obtidos foram previamente irradiados. Os autores concluíram que a consistência da escova foi mais importante que o abrasivo utilizado. Esta mesma técnica também foi empregada sobre amostras de esmalte e dentina que foram submetidas a teste de escovação simulada após terem sido irradiadas, um medidor de reflexão foi aplicado para avaliar o brilho das superfícies abrasionadas. Neste estudo, STOOKEY; MUHLER $^{13}$ (1968) avaliaram suas amostras também através da perda de suas massas encontrando correlação entre os dois métodos empregados.

A proposta de se graduar o desgaste sofrido por diferentes substratos pela medição da sua alteração de massa iniciou-se na década de $70^{59}$. Neste primeiro trabalho os autores confeccionaram esferas de resinas compostas (através das palmas das mãos) da ordem de $0,4 \mathrm{~g}$ por material. O abrasivo provocava abrasão por vibração em um período de 3 minutos. A abrasão foi avaliada através das medições de massa inicial e final. Da mesma forma, MCCABE; SMITH ${ }^{79}$ (1981) testaram abrasão de uma série de materiais (amálgama, resina composta e acrílica) e PRAMPERO et al. ${ }^{95}$ (1992) também avaliaram o desgaste de resinas acrílicas, pela alteração de massa, submetidas à escovação com diversas durezas de cerdas. 
$\mathrm{Na}$ literatura essa forma de avaliação é geralmente associada a avaliações onde se analisa também a alteração da rugosidade superficial dos substratos estudados, através de perfilômetros ${ }^{39,47,118,119,39,125}$.

Métodos laboratoriais para determinação da abrasividade de dentifrícios foi o alvo de estudo de HEFFEREN ${ }^{52}$ ainda em 1976. A dentina (neutralizada em formaldeído) seria o principal substrato a ser utilizado para a comparação das abrasividades e cuidados que deveriam ser tomados na sua obtenção, limpeza e preparo para o teste. Várias formas de análise foram propostas para verificar as superfícies abrasionadas, como a perda de massa, a irradiação, a perfilometria e a MEV. Foi sugerido o uso da irradiação de nêutrons (através de reator nuclear) para medir a quantidade de material abrasionado. Empregando-se metodologia semelhante HARRINGTON et al. ${ }^{47}$ (1982), avaliaram o comportamento de diferentes materiais restauradores frente ao processo de abrasão por escovação. Diferentes resinas compostas, cimentos de ionômero de vidro, cimento de silicato e amálgama foram submetidos à teste in vitro. As superfícies das amostras foram avaliadas por um rugosímetro Talysurf 4, os pesos determinados por uma balança e as espessuras medidas por um micrômetro. A perda em espessura das amostras foi calculada através da seguinte fórmula:

Perda de espessura $=$ Perda de peso $\times$ Espessura original

\section{Peso original}

As resinas sem carga apresentaram a maior perda de estrutura e quanto à análise da superfície, a melhor lisura. O amálgama apresentou superfície melhorada ao final do processo. 
JONES; FISHER; WILSON ${ }^{58}$ (1985) investigaram o desgaste produzido por diferentes marcas comerciais de dentifrícios (20 marcas comerciais) em dois materiais restauradores: uma resina convencional (Delphic) e outra de micropartículas (Orion). Foi realizado um estudo de escovação em laboratório e verificourse a perda de massa dos materiais. Os pesos, as espessuras (micrômetros) e os valores de rugosidade superficial (Talysurf 4) foram registrados. Nenhum grupo apresentou perda significante de massa ou de espessura.

Recentemente, três trabalhos de similar metodologia foram realizados, WANG $^{119}$ (2001) comparou o desgaste de algumas marcas comerciais de resinas condensáveis através de um teste in vitro de escovação simulada, GARCIA ${ }^{39}$ (2001) e XU; XIN; WEATHERSBY; BURGESS ${ }^{125}$ (2002) compararam o desgaste de resinas compostas fluidas. Em todos, a alteração da massa e a análise da rugosidade superficial $(\mathrm{Ra})$ foi determinada.

Por fim, outros métodos (utilizados em menor escala) também se encontram descritos nos documentos literários. Sendo assim, DALY; CHAPPLE; CAMERON ${ }^{19}$ (1996) se propuseram a avaliar, por meio de um computador, o desgaste de escovas dentais. Vinte e dois voluntários, sendo 11 do sexo masculino e 11 do feminino, foram submetidos a uma avaliação de 3 em 3 semanas, em um total de 9 semanas. A cada retorno, uma reavaliação era feita utilizando-se o índice de placa de Quingley e Hein modificado por Turesky e a análise do desgaste das escovas dentárias foi realizada pela medição da área das mesmas. Os resultados mostraram um aumento progressivo de área das cerdas das escovas, refletindo a ocorrência de desgaste neste período. Para a avaliação simultânea da resistência à abrasão e à atrição (em um mesmo teste), CONDON; FERRACANE ${ }^{17}$ (1996) introduziram uma técnica 
diferente. Um amálgama dental e onze diferentes resinas compostas foram submetidos a um aparelho, especialmente desenvolvido, utilizando um fragmento de esmalte de molar humano como antagonista. Um perfilômetro foi utilizado para avaliação, em direção perpendicular, dos movimentos de atrição e abrasão provocados, medindo a profundidade de desgaste.

Outro recurso que é também amplamente utilizado e difundido relaciona-se à verificação dos padrões de desgaste através de microscopia eletrônica de varredura. Trabalhos como o de HEATH; WILSON ${ }^{51}$ (1976); AKER $^{1}$ (1982); PANZERI et al. ${ }^{86}$ (1978); WANG ${ }^{119}$ (2001) e GARCIA ${ }^{39}$ (2001) utilizaram a microscopia das superfícies abrasionadas, visando acrescentar detalhes com respeito ao padrão de desgaste de materiais empregados na odontologia.

Análises clínicas também são realizadas através de inspeções diretas, fotografias e através da duplicação de modelos. Podemos citar como exemplo o estudo de BULL et al. ${ }^{12}$ (1968) que realizaram trabalho clínico onde pacientes colaboradores foram recrutados, submetidos a um preparo prévio, com profilaxia, estabelecendo-se uma condição inicial ("baseline"). Fotografias padronizadas foram feitas dos dentes anteriores e seus negativos obtidos. A cada semana uma nova avaliação foi realizada totalizando 4 semanas. Nestes intervalos, os pacientes utilizaram dentifrícios em teste. Ao final dos testes, novas fotografias padronizadas foram registradas. Por comparação das fotografias iniciais e finais, foi estabelecida uma avaliação através de manchas que surgiram durante as avaliações.

Nos últimos tempos, HAYASHI et al. ${ }^{50}$ (2000) publicaram um trabalho de oito anos de acompanhamento clinico de inlays de porcelana. Quarenta e cinco inlays de porcelana (G-Cera Cosmotech II, GC Co) foram confeccionadas em 25 pacientes e 
avaliadas imediatamente após cimentação e após períodos de 6 meses, 1, 2, 4, 6 e 8 anos. Para observação da degradação marginal e desgaste do material, replicas das restaurações foram levadas à microscopia eletrônica de varredura. A sua longevidade pode ser constatada em $80 \%$ dos casos após período de oito anos, no entanto, em seis anos de observação esse valor era de $92 \%$.

\section{3-CICLAGEM DE $p H$}

Como anteriormente citado um dos trabalhos pioneiros a realizar estudos sobre a ação abrasiva dos dentifrícios sobre restaurações e estruturas dentárias, demonstrando, contudo, a preocupação sobre a ação dos ácidos sobre elas, aconteceu em 1907 por MILLER ${ }^{82}$. Neste o autor apresentou casos clínicos avaliando, através de ensaios laboratoriais, a ação de vários agentes químicos, físicos e biológicos sobre os dentes e materiais restauradores. De acordo com estas observações o autor concluiu que os ácidos, nas concentrações encontradas na boca, não são capazes de produzir desgaste, sendo que o processo mecânico de escovação foi o responsável pelo desgaste dos tecidos duros orais. Houve um interessante estudo realizado por ASMUSSEM $^{6}$ (1984), onde polímeros experimentais a base de Bis-GMA e TEGDMA em variadas concentrações e, posteriormente, ambos em concentração constante, porém, com variadas concentrações do agente catalisador foram testados em relação a condições ácidas de armazenamento. Os agentes estudados foram o etanol, ácido acético, ácido propiônico e o ácido láctico, sendo a armazenagem em água utilizada como controle. Após duas semanas a dureza das amostras foi avaliada. O etanol, o ácido acético e 
propiônico causaram considerável queda na dureza dos monômeros, o que não foi averiguado em relação ao ácido láctico. Além disso, esse "amolecimento" do polímero esteve relacionado ao aumento de duplas ligações não reagidas na solução.

Certamente foi em 1986 que FEATHERSTONE et al. $^{34}$ ao expor um modelo de ciclos de mineralização e desmineralização in vitro obtidos através de experimentos realizados in vivo, fez mudar a concepção de muitos autores engajados em aperfeiçoar suas pesquisas aproximando-as da realidade clínica. O regime de ciclagem consistia em 14 dias onde diariamente os dentes eram designados à um desafio cariogênico através de uma solução desmineralizadora ácida $(2.0 \mathrm{mmol} / \mathrm{l} \mathrm{Ca}$, $2.0 \mathrm{mmol} / \mathrm{I} \mathrm{PO}_{4}, 0.075 \mathrm{~mol} / \mathrm{l}$ acetato ao $\mathrm{pH} 4.3,37 \mathrm{C}$ ) por 6 horas e 17horas de remineralização por saliva artificial $(1.5 \mathrm{mmol} / /$ de cálcio, $0.9 \mathrm{mmol} / /$ de fosfato, 150 $\mathrm{mmol} / /$ de cloreto de potássio e $20 \mathrm{mmol} / \mathrm{l}$ ao $\mathrm{pH} 7.0$ de solução tampão). Durante os finais de semana (ao longo dos 14 dias de ciclagem) os espécimes eram mantidos em saliva artificial apenas. Os dentes foram em seguida seccionados transversalmente e sua microdureza (perda de mineral) foi avaliada. Os resultados mostraram que este modelo de ciclagem de $\mathrm{pH}$ para simulação de desafio cariogênico mostrou-se qualitativa e quantitativamente semelhante aos encontrados nos testes in vivo. A partir de então muitos outros trabalhos passaram a adotar o modelo de ciclagem de pH para simular condições clinicas. SERRA; CURY'101 (1992) realizaram um trabalho cujo objetivo foi avaliar diferenças na iniciação e progressão de lesões cariosas em esmalte adjacente a diferentes materiais restauradores. Para a indução de cáries secundárias (experimentais) ao redor de restaurações de cimento de ionômero de vidro ou de resina composta, o modelo de ciclagem de pH 
foi utilizado. Os efeitos desses materiais foram comparados através de testes de microdureza. Os resultados demonstraram que os modelo experimental adotado aproximava-se da realidade clínica.

Posteriormente, CARVALHO; CURY'15 (1999) propuseram um novo modelo de simulação de ciclagem de $\mathrm{pH}$, associando uma solução desmineralizante $(\mathrm{pH} 4,3)$ a uma remineralizante $(\mathrm{pH} 7,0)$. Para efeitos comparativos, a água deionizada e uma saliva artificial corresponderam a dois meios de imersão para quantificação da liberação de flúor de materiais restauradores. Foram avaliados um cimento de ionômero de vidro (Chelon-Fil), resinas compostas modificadas por poliácidos (Dyract e Variglass), um cimento de ionômero de vidro modificado por resina (Vitremer) e uma resina composta (Tetric). Em 15 dias consecutivos, a cada 24 horas era realizada troca de solução, sendo que para o sistema cíclico de $\mathrm{pH}$, as amostras permaneciam por 6 horas em solução desmineralizadora e 18 horas em solução remineralizadora. As leituras foram procedidas utilizando-se um eletrodo e o medidor de $\mathrm{pH}$ digital Orion e solução TISAB, este na mesma proporção do material de leitura. Segundo os autores esse modelo cíclico de pH é de extrema relevância cientifica por, de fato, simular a realidade clínica. Este mesmo padrão de repetições foi incorporado nos estudos de $\operatorname{GARCEZ}^{38}$ (2001) que se dispôs a verificar a liberação de flúor de materiais restauradores, em dois meios de imersão. A água deionizada o sistema de ciclos de $\mathrm{pH}$ por 15 dias.

TURSSI $^{18}$ (2001) avaliou o efeito de diferentes soluções de armazenamento na micromorfologia de materiais restauradores resinosos. Os materiais submetidos ao estudo foram, Fuji II LC, Dyract AP, Durafill VS e Filtek Z250. Estes foram inicialmente submetidos ao teste de rugosidade. Espécimes de cada material (15) 
foram armazenados em água deionizada, outros 15 em saliva artificial e os demais submetidos à ciclagem de $\mathrm{pH}$. Após 10 dias de armazenagem a rugosidade final foi avaliada. Tem se como resultado a íntima relação entre alteração da micromorfologia superficial dos materiais frente à situação de alto desafio cariogênico. Um modelo de ciclagem de pH conduzido por 10 dias foi aplicado no recente estudo de PEREIRA et al. ${ }^{91}$ (2002). O efeito da simulação de alto desafio cariogênico, através de ciclagem de $\mathrm{pH}$, na rugosidade superficial de materiais restauradores foi verificado. A alteração da rugosidade superficial $(\mathrm{Ra})$ foi obtida através das diferenças entre as médias de 3 leituras iniciais e finais realizadas em cada corpo de prova. Apesar de ter sido verificado diferença de rugosidade superficial entre os materiais analisados, esta não foi significantemente afetada após o desafio cariogênico.

Variados cimentos, entre eles, resinosos, ionoméricos, policarboxilato, modificado por resina, poliácido e cimento de fosfato de zinco, também tiveram sua resistência à abrasão testada quando armazenados em meio neutro e ácido ${ }^{11}$. Diferente dos trabalhos que adotam protocolos iguais ou semelhantes ao de FEATHERSTONE ${ }^{34}$ (1986), aqui 12 amostras de cada material foram simplesmente armazenados por 24 horas em solução tampão pH 6.8. As demais (12) foram armazenadas em solução tampão pH 3.0. Todas as amostras foram submetidas ao teste de escovação simulada (2000 ciclos). Posteriormente, a rugosidade das amostras foi analisada através de um perfilômetro computadorizado. Os maiores índices de abrasão foram registrados para os cimentos de policarboxilato, com exceção de três cimentos resinosos, o pH baixo determinou menor resistência à abrasão para os demais materiais. 


\section{4 - CARACTERISTICAS E RESISTÊNCIA AO DESGASTE DOS MATERIAIS EM}

\section{ESTUDO}

\subsubsection{CARACTERÍSTICAS}

A base composicional dos cimentos resinosos é um sistema monomérico BisGMA (Bisfenol - A metacrilato de glicidila) ou UEDMA (Uretano dimetacrilato) em combinação a monômeros de baixa viscosidade (TEGDMA, UDMA), além de cargas inorgânicas (lítio, alumínio e Óxido de silício) tratadas com silano (agentes de união) $)^{2,90}$. A adoção de grupamentos funcionais hidrófilos modificou a composição orgânica dos sistemas resinosos de cimentação em relação às resinas compostas e ainda, propiciou possibilidade de adesão com a superfície dentinária. Para completar a composição, a resina aglutinante foi combinada com partículas cerâmicas e sílica coloidal. As partículas inorgânicas se apresentam nas formas angulares, esféricas ou arredondadas, com conteúdo de peso variando entre 36 a $77 \%{ }^{53}$ e diâmetro variável entre 10 a 15 ìm, dependendo do produto.

O Artglass é um polividro cuja parte inorgânica é formada por partículas de sílica e microvidros (vidro de bário) ${ }^{25}$. De acordo com SILVA e SOUZA Jr. et al. ${ }^{107}$ (2001) são nada mais que resinas compostas. Ainda, os "polividros" são a mistura de dois elementos (óxidos vitrosos), correspondendo aproximadamente $70 \%$ em peso do produto $^{32}$. A porção orgânica é composta de metacrilatos multifuncionais em combinação com monômeros bifuncionais, formando uma matriz entrelaçada (crosslinked). 
As cerâmicas são compostos formados por elementos metálicos e não metálicos. A sua maior parte é formada por óxidos, pela união entre oxigênio e metais como alumínio e magnésio ${ }^{34}$. O vidro, o concreto e o cristal são exemplos de cerâmicas. Os átomos que formam as cerâmicas são unidos por ligações iônicas e covalentes. Trata-se de materiais extremamente friáveis e são também pobres condutores térmicos e elétricos.

Já a porcelana é um tipo específico de cerâmica. A Duceram Plus é uma cerâmica convencional, cuja base feldspática é enriquecida com óxido de silício, óxido de sódio e outros óxidos de metais utilizados para sua pigmentação.

\subsubsection{FATORES RELACIONADOS À RESISTÉNCIA AO DESGASTE DE CIMENTOS RESINOSOS}

Há muitos anos notamos na literatura uma intensa preocupação em se avaliar a resistência ao desgaste dos materiais empregados para cimentação. Neste sentido, OSBORNE et al. ${ }^{84}$ (1978) realizaram um interessante estudo in vivo com quatro materiais de cimentação (cimento de silicato, cimento de policarboxilato, cimento de fosfato de Zinco e cimento de óxido de Zinco e eugenol) sendo avaliados em dois testes. No primeiro, 15 pacientes tiveram restaurações indiretas de ouro cimentadas provisoriamente por seis meses. Em cada uma dessas restaurações foram realizados oito pequenos orifícios em duas de suas faces (gengival e oclusal) que foram preenchidas com os materiais em estudo. Seis meses depois, essas restaurações foram removidas e as espessuras dos materiais analisados com um paquímetro digital. No segundo, a força de compressão desses mesmos materiais foi 
avaliada após períodos de armazenamento em água a 37 C após 24 horas, 1 semana e 1 mês. Como resultado, não houve para os materiais diferença estatisticamente significante entre os resultados de desgaste dos cimentos inseridos nos orifícios oclusais e gengivais das restaurações provisórias. Também, independente da sua localização, o cimento de óxido de zinco e eugenol foi o material que isoladamente apresentou o maior desgaste. Esses resultados não foram condizentes com o do teste laboratorial, uma vez que neste último, os resultados de desgaste para o óxido de zinco e eugenol se aproximaram do cimento de fosfato de zinco.

$\mathrm{Na}$ década de 50, BUONOCORE ${ }^{13}$ introduzia a odontologia a clássica técnica de condicionamento ácido ao esmalte. Desde então, as resinas compostas e os sistemas de união à estrutura dental sofreram indubitavelmente várias transformações.

Os materiais utilizados na ancoragem de restaurações indiretas também evoluíram culminando com o surgimento de resinas compostas para cimentação. Estes materiais apresentam menor percentual volumétrico de partículas que é incorporado à matriz orgânica, com o objetivo de adequar sua viscosidade às condições específicas e desejáveis de cimentação ${ }^{24}$.

Entretanto, sabemos que as resinas compostas restauradoras, em seu processo de contração de polimerização podem gerar microtrincas estruturais sendo um importante coadjuvante na causa de desgaste generalizado desses materiais ${ }^{103}$. Para minimizar estes problemas alguns autores indicam a aplicação de um selante de superfície ao término do seu procedimento restaurador e de polimento. Seguindo este raciocínio, SHINKAI et al. ${ }^{103}$ (1994) avaliaram a possibilidade de redução no 
desgaste generalizado dos cimentos resinosos quando da aplicação dos selantes superficiais. Para este estudo 5 materiais foram utilizados (Duatcement; Twinlook cement; Super-Bond C\&B; Fuji II LC e Fuji BOND). Preparos cavitários foram então realizados em molares humanos e restaurações de resina composta indireta foram cimentados sobre eles. Um grupo de restaurações diretas com resina composta foi realizado como controle. Em seguida, dois espécimes de cada grupo tiveram a superfície condicionada com ácido fosfórico a 37\% e o selante de superfície (Fortify) foi aplicado. Os espécimes foram submetidos a um teste de desgaste de três corpos. O desgaste foi avaliado através de um perfilômetro e também microscopia eletrônica de varredura. Não houve diferença estatisticamente significante para o desgaste entre os grupos que receberam ou não o selante de superfície. $O$ desgaste da resina indireta associada aos selantes superficiais foi, no entanto, inferior ao grupo que não recebeu este tratamento.

Estes mesmos autores ${ }^{104}$, posteriormente, realizaram um estudo sobre a correlação entre a espessura de cimentos resinosos ou à base de ionômero de vidro associados a inlays de resina indireta e seus desgastes. Orifícios cilíndricos foram realizados sobre superfícies oclusais de molares. Estes foram submetidos a 400.000 ciclos de teste de resistência ao desgaste (3 corpos). Os valores de desgaste, dos cimentos e da resina indireta, foram obtidos com auxílio de um perfilômetro. A relação entre a espessura de cimento e o seu desgaste foi confirmada através da análise de regressão linear. O cimento de micropartículas demonstrou desgaste consideravelmente menor em relação aos demais materiais estudados.

A relação direta entre espessura da linha de cimento resinoso e o seu desgaste também foram confirmados por vários outros trabalhos ${ }^{62,56,55}$. Em um deles, 
GUZMAN; MOORE; ANDRES ${ }^{44}$ (1997) investigaram o efeito da fenda marginal, cimento aplicado e o material restaurador na resistência ao desgaste dos cimentos em áreas onde o contato oclusal não estava presente. Três cimentos resinosos (Variolink, Vita-Duo e Enforce) e um cimento ionomérico modificado por resina (Duet) foram empregados em dois sistemas de inlays, uma resina composta e uma porcelana. Dentes bovinos associados à abrasão por escovação foram utilizados para este estudo. Três espessuras de fendas (de cimentação) foram pré-

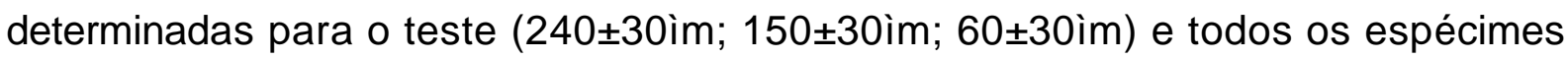
foram termociclados. O desgaste dos materiais de cimentação aumentou linearmente de acordo com a sua espessura. No seguinte, KRÄMER; FRANKENBERGER ${ }^{66}$ (2000) cimentaram 39 inlays classe II de IPS Empress (16 pacientes) com o material resinoso Variolink Low. As restaurações foram avaliadas após períodos de 6, 12, 24, 36, 48 e 72 meses através de replicas obtidas por moldagens. As áreas livres de contato dos modelos foram escaneadas através de um perfilômetro controlado por um computador. Após 6 meses todas as restaurações apresentaram leve alteração nas margens e a porcentagem de fenda do cimento causada por abrasão foi aumentando a cada reavaliação. Uma relação positiva foi observada entre a espessura da linha de cimento e a perda de material.

Quando PASHLEY et al. ${ }^{88}$ (1992) avaliaram a habilidade de seis diferentes sistemas de união em selar dentina preparada para coroas totais, através de microinfiltração por nitrato de prata e da quantificação da infiltração de fluido pela dentina em períodos de 1 hora, 1 dia, 1 semana e 1 mês, antes e depois de realizar termociclagem, observaram que um dos melhores seladores foi o Superbond sistema pó e líquido, claramente superior ao Superbond quando se empregou 
somente o líquido. Os autores advogaram sobre o fato do sistema pó e líquido ter proporcionado uma linha de cimento significativamente maior em relação ao sistema exclusivamente líquido, que foi prejudicado pela ação do oxigênio que presumivelmente inibiu a sua adequada polimerização. Esta ocorrência é esperada em linhas de cimento entre 20 e 40ìm. Como conclusão a variação desejada da linha de cimento é de 50 a 100 ìm $^{88}$.

O grau de dureza alcançada por cimentos a base de resina polimerizada quimicamente (exclusivamente) ou de forma dual (química e física), e a sua relação de dureza com a espessura de inlays de cerâmica foi investigado em 1999 por ELMOWAFY; RUBO; EL-BADRAWY ${ }^{31}$. Os resultados mostraram significante diferença entre a dureza dos cimentos químicos e duais. Diferenças na dureza também foram constatadas entre espécimes duais sob placas de cerâmica de espessura equivalente ou superior a $3 \mathrm{~mm}$. Os autores concluíram que, para os cimentos que apresentam as duas formas de ativação, a polimerização química exclusiva não é suficiente para se alcançar a dureza necessária. De acordo com PEUTZFELDT ${ }^{92}$ (1995) a quantidade de duplas ligações livres em cimentos resinosos duais relaciona-se não apenas à sua forma de polimerização, mas também às características da sua composição, por exemplo, os tipos de monômeros resinosos e as concentrações entre eles. A quantidade de duplas ligações remanescentes interfere diretamente sobre as propriedades mecânicas dos materiais resinosos.

Assim, fica clara a necessidade do conhecimento da resistência à abrasão e o grau de conversão de polimerização de materiais resinosos utilizados em restaurações indiretas. 
Os cimentos resinosos proporcionam atualmente um grande leque de indicações. Podem ser aplicadas para colagem de "brackets" ortodônticos, próteses adesivas e sob restaurações indiretas parciais e/ou totais ${ }^{94}$. Já os cimentos resinosos que apresentam polimerização dual, foram desenvolvidos para ser utilizados sob restaurações estéticas, pois estes materiais restauradores permitem a passagem de luz, que é responsável por parte da sua polimerização, cabendo à reação química a função de complementar a reação em regiões profundas, de difícil acesso à luz ${ }^{85}$.

Provavelmente pelos cimentos resinosos estarem usualmente associados à resinas indiretas, a sua correlação foi avaliada em 1995 por SUZUKI; LEINFELDER; SHINKAI ${ }^{115}$. Quatro cimentos resinosos (Adhesive cement; Twinlook cement; DCR Cement e Panavia 21) e um ionomérico (Fuji LC) foram utilizados para o estudo. Molares humanos hígidos tiveram sua superfície planificada onde preparos foram realizados $(4 \mathrm{~mm} \times 3 \mathrm{~mm})$; um grupo recebeu restauração de resina composta direta (Charisma) e o outro grupo restaurações indiretas que foram cimentadas com os materiais citados. Após os testes de desgaste os espécimes foram submetidos à análise perfilométrica (Surfanalyzer 4000). Moldagens e a obtenção de moldes em resina epóxica foram realizadas para avaliação da superfície em microscopia eletrônica de varredura. O material que se mostrou menos resistente foi o cimento ionomérico. Os cimentos resinosos, por sua vez, se mostraram menos resistentes que a resina composta seja direta ou indireta. 


\subsubsection{RESISTÊNCIA AO DESGASTE DE RESINAS INDIRETAS E PORCELANAS ODONTOLÓGICAS}

A influência da escovação mecânica na rugosidade de superfície de resinas indiretas, Artglass, Targis e Sculpture, foi avaliada por CORRER SOBRINHO et al. ${ }^{18}$ (2001), onde confeccionaram oito amostras para cada material e os armazenaram em água destilada a 37 C por 24 horas. Quatro espécimes de cada material receberam acabamento e polimento e os outros não, atuando como controle. A rugosidade foi verificada com o aparelho Surf Corder após 30.000 ciclos de escovação simulada. Para os três materiais submetidos ao polimento, nenhuma diferença estatística foi observada, antes ou após a escovação. Os resultados indicaram que a escovação promoveu aumento na rugosidade de superfície para as amostras sem polimento e redução nas amostras com polimento. Resinas indiretas também tiveram a sua resistência à abrasão testada através de escovação simulada, seguida de teste de dureza Vickers ${ }^{78}$. Os materiais selecionados foram Concept, Artglass, BelleGlass, Sculpture e Targis e o esmalte humano também foi testado como controle. Um espectroscópio (EDX) foi utilizado para determinação da composição elementar de carga do material. Concept foi o material que apresentou resistência ao desgaste e dureza superiores aos demais materiais e a menor rugosidade superficial. Significante relação foi observada entre desgaste e dureza e também entre desgaste e rugosidade. $\mathrm{O}$ esmalte foi a estrutura que apresentou maior resistência ao desgaste. O espectroscópio EDX demonstrou que a composição (carga) dos materiais analisados era praticamente idêntica. 
Como já aludido, além das resinas indiretas, os cimentos resinosos são habitualmente empregados em conjunto com restaurações de porcelana. Existem alguns interessantes trabalhos que retratam a relação de desgaste destes materiais aos dos cimentos resinosos.

Baseado nos achados de SUZUKI; LEINFELDER; SHINKAI ${ }^{15}$ (1995), o valor de desgaste do agente cimentante depende diretamente do desgaste do material usado para a confecção da restauração. Os cimentos exibiram menor desgaste quando utilizados junto a restaurações de resina composta, em outras palavras, o desgaste foi menor quando utilizados sob restaurações de menor resistência ao desgaste. Isto ocorreu pois, as restaurações de resina absorveram mais as tensões mastigatórias quando comparadas à porcelana odontológica, que são materiais friáveis, e não absorvem as tensões transmitindo-as para o material de cimentação.

O desgaste de cerâmicas em comparação a antagonistas em esmalte e cimentos resinosos foi verificado por $\mathrm{KREJCl}$ et al. $^{67}$ (1993). Cada grupo foi composto por 6 dentes que tiveram restaurações MOD (inlays) de porcelana cimentadas com materiais à base de resina. Cerâmica fundida, feldspática e prensada foram utilizadas para as restaurações. Como materiais de cimentação empregou-se um cimento resinoso microhíbrido e um de micropartículas. As restaurações foram submetidas a testes dinâmicos e associados de desgaste (degradação química, abrasão por escovação, ciclos de mastigação simulada e termociclagem) correspondendo, segundo os autores, a cinco anos de desempenho clínico. O desgaste na região oclusal foi quantificado durante e ao final do teste através de um scanner tridimensional. Os desgastes dos materiais de cimentação foram quantificados através de um perfilômetro (Talysurf 50). Como resultado, as 
cerâmicas polidas fundidas e feldspáticas apresentaram índices de abrasão semelhantes ao esmalte quando submetidas às mesmas condições de desgaste. Os cimentos de micropartículas apresentaram desgaste maior que os microhíbridos. Ainda, o desgaste das cúspides de esmalte parece depender da combinação entre dureza e rugosidade da restauração antagonista.

A resistência ao desgaste de porcelanas odontológicas e a sua relação com a perda de espessura dos espécimes, considerando-se também as durezas e alteração de rugosidade, foi testada por DERAND; VEREBY²6 (1999). A resistência ao desgaste foi menor para a porcelana Finesse e maior para a Creation. Os valores de dureza superficial foram similares para todos os materiais. A porcelana de baixa fusão Finesse mostrou a menor resistência à abrasão comparada a Ducera Gold e Ti-Ceram. Dentre as porcelanas de alta fusão, a Vita Alpha foi a mais resistente. 
3-PROPOSIÇÃO 


\section{3 - PROPOSIÇÃO}

Avaliar a resistência ao desgaste de três cimentos resinosos comparados a uma porcelana odontológica e uma resina composta para restaurações indiretas, submetendo-os a ensaios de ciclos de pH e testes de escovação simulada, em função da análise da alteração de massa e da rugosidade superficial. 
4-MATERIAL E MÉTODOS 


\section{4- MATERIAL E MÉTODOS}

\section{1- MATERIAL EMPREGADO}

Para a execução deste estudo foram selecionadas três marcas comerciais de cimentos resinosos duais, uma marca comercial de resina composta restauradora indireta e uma porcelana odontológica, sendo eles, Enforce Sure Cure (Dentsply), Rely X (3M/ESPE), Variolink II (Ivoclair/Vivadent); Artglass (Heraeus Kulzer) e Duceram Plus (Degussa).

Foram confeccionados 100 corpos de prova, distribuídos em dez grupos, dois para cada material a ser analisado (submetidos ou não à ciclagem de pH). A tabela a seguir ilustra as marcas comerciais dos materiais utilizados.

TABELA 1 - Materiais utilizados e seus fabricantes

\begin{tabular}{lcccc}
\hline Material & Fabricante & Abreviatura & Lote & Validade \\
& & & & \\
\hline Enforce & Dentsply & $\mathrm{E}$ & 176 & $2003-07$ \\
Rely X & 3M/ESPE & $\mathrm{R}$ & 27071 & $2003-05$ \\
Variolink II & Ivoclair/Vivadent & $\mathrm{V}$ & $\mathrm{C} 55626$ & $2003-07$ \\
Artglass & Heraeus Kulzer & $\mathrm{A}$ & 010110 & $2004-03$ \\
Duceram Plus & Degussa & $\mathrm{D}$ & $0090 / 22$ & $2002-11$ \\
\hline
\end{tabular}




\section{Material e Métodos}

A tabela 2 ilustra a composição básica dos materiais utilizados neste estudo: para os materiais a base de resina - matriz orgânica, carga inorgânica, porcentagem em peso de carga e o tamanho médio das partículas; e a composição da porcelana odontológica.

TABELA 2 - Composição dos materiais empregados

\begin{tabular}{|c|c|c|c|c|}
\hline Material & $\begin{array}{c}\text { Matriz } \\
\text { Orgânica }\end{array}$ & $\begin{array}{c}\text { Partícula } \\
\text { inorgânica }\end{array}$ & Peso (\%) & $\begin{array}{c}\text { Tamanho } \\
\text { Médio da } \\
\text { Partícula (ìm) }\end{array}$ \\
\hline Enforce & $\begin{array}{l}\text { Bis-GMA } \\
\text { TEGDMA }\end{array}$ & $\begin{array}{l}\text { Sílica, Vidro Boro } \\
\text { Silicato, Alumínio, Bário }\end{array}$ & 66 & 1,0 \\
\hline Rely X & $\begin{array}{l}\text { Bis-GMA } \\
\text { TEGDMA }\end{array}$ & $\begin{array}{c}\text { Zircônia } \\
\text { Sílica }\end{array}$ & 67,5 & 1,5 \\
\hline Variolink II & $\begin{array}{l}\text { Bis-GMA } \\
\text { TEGDMA }\end{array}$ & $\begin{array}{l}\text { Vidro de Ba, trifluoreto } \\
\text { de itérbio, vidro de } \\
\text { fluorsilicato Ba-Al e } \\
\text { óxidos mistos } \\
\text { esferoidais. }\end{array}$ & 73,4 & 0,7 \\
\hline Artglass & $\begin{array}{l}\text { Dimetacrilatos } \\
\text { e Metacrilatos }\end{array}$ & $\begin{array}{l}\text { Vidro de Bário } \\
\text { aluminosilicato }\end{array}$ & 70 & 1 \\
\hline Duceram Plus & \multicolumn{4}{|c|}{ Base de Feldspato, Quartzo, Óxido de Sódio. } \\
\hline
\end{tabular}




\title{
Material e Métodos
}

O procedimento de escovação simulada foi realizado com a escova dental Orat B 35 (Gillete do Brasil Ltda., Manaus-AM, Brasil) e dentifrício dental Colgate MFP (Colgate Palmolive - Divisão da Kolynos do Brasil Ltda, Osasco-SP, Brasil). A composição do dentifrício é apresentada na tabela 3.

TABELA 3 - Composição do dentifrício Colgate MFP

\author{
Composição básica do dentifrício Colgate MFP \\ Monofluorfosfato de Sódio (1500ppm) \\ Carbonato de Cálcio \\ Lauril Sulfato de Sódio \\ Umectante / Espessante / Aromas / Água
}

Todos os materiais empregados neste estudo estão disponíveis no mercado nacional (FIGURAS 1 e 2).

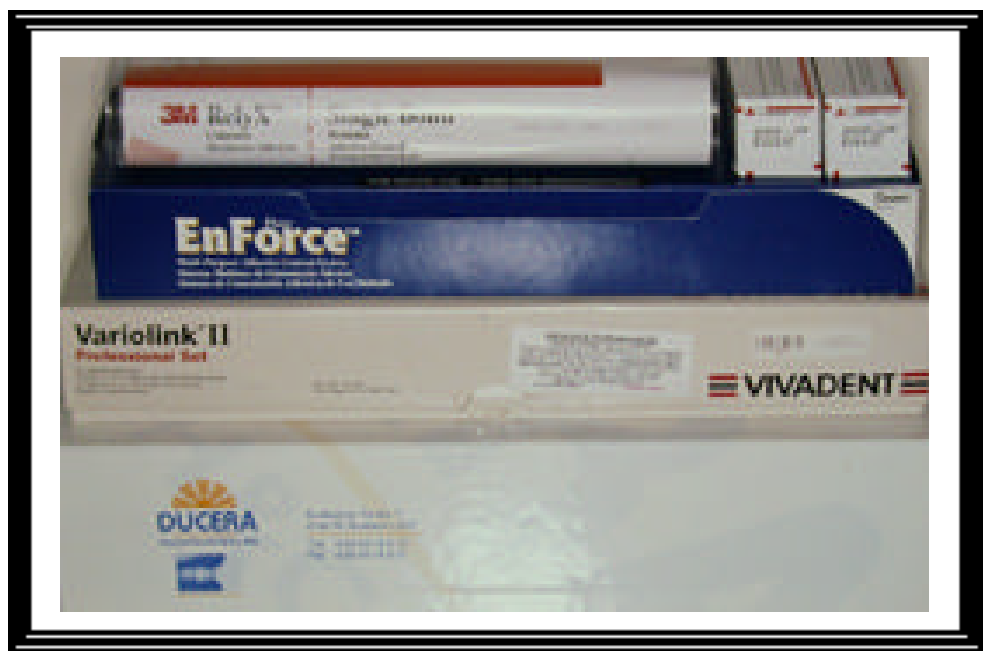

FIGURA 1- Apresentação comercial dos materiais restauradores empregados 


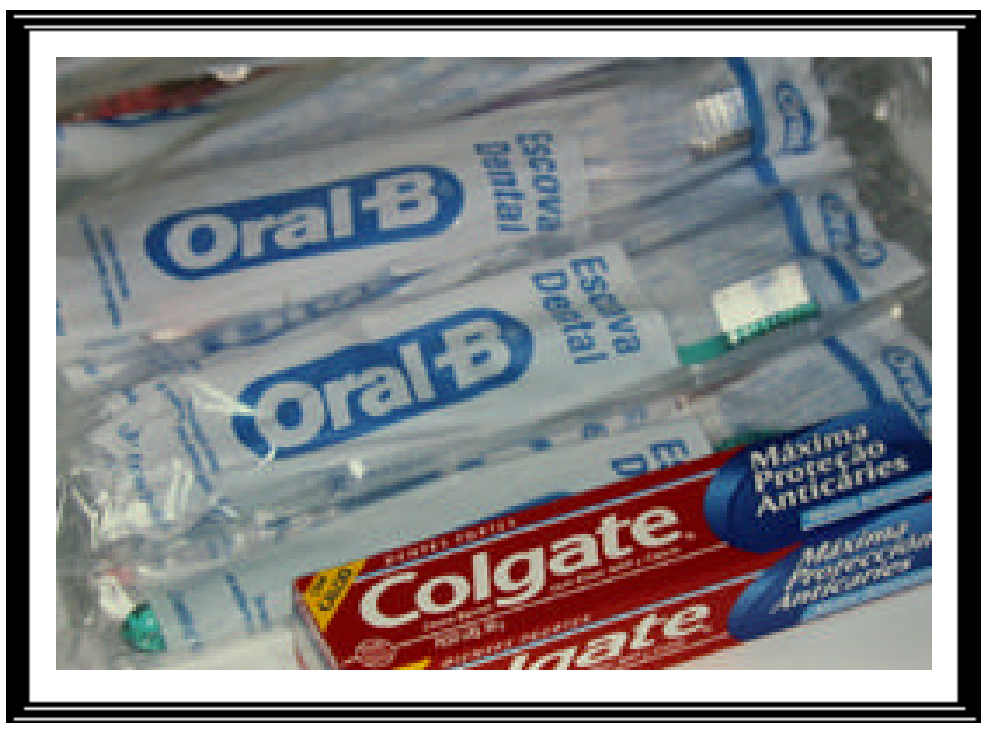

FIGURA 2- Apresentação comercial do dentifrício e escova dental empregados

\section{2 - MÉTODOS}

\subsection{1 - CONFECCÃO DOS CORPOS DE PROVA}

Os materiais foram manuseados conforme as especificações dos respectivos fabricantes. Os corpos de prova dos cimentos resinosos (20 para cada material) foram obtidos através de um molde de silicona de adição com dimensão de $5 \mathrm{~mm}$ de diâmetro por 3mm de espessura, proporcionando assim, estabilidade dimensional e melhor padronização dos mesmos. Depois do proporcionamento em placa de vidro, espatulação e inserção dos cimentos no molde com auxílio de seringa tipo centrix (Centrix Inc, Shelton - USA), foram cobertos por uma tira de poliéster (TDV Dental Ltda, Santa Catarina) e sobre esta uma lâmina de vidro (Corning Mexicana, S.A, $25 \times 75 \mathrm{~mm}$ e espessura de $0,8-1,1 \mathrm{~mm}$ ), que foi submetida a uma carga axial de $500 \mathrm{~g}$ por 30 segundos para causar extravasamento do excesso de material. Em seguida 
realizou-se a fotopolimerização (Optilight 600, Gnatus, Ribeirão Preto, Brasil) por 60 segundos através da tira de poliéster. A intensidade da luz $\left(500 \mathrm{~mW} / \mathrm{cm}^{2}\right)$ foi aferida por um radiômetro (Curing radiometer: model 100 P/N - 10503/Demetron Research Corp.). Ao ser removido do interior do molde, realizourse outra fotopolimerização por mais 60 segundos na superfície oposta do corpo de prova. Após remoção das arestas, o acabamento foi obtido utilizando-se discos de lixa Sof-lex (3M do Brasil Ltda, Sumaré) de granulação maior à menor (grossa, média, fina e superfina) seqüencialmente. Este polimento foi realizado através de um contra ângulo (KAVO), sem refrigeração, por 15 segundos para cada granulação.

Para os corpos de prova (20) de Artglass (confeccionados pelo técnico Nélson Queiroz do laboratório de produção do departamento de Dentística) foi utilizada a mesma matriz descrita. Cada incremento foi fotopolimerizado por 90 segundos seguindo instruções do fabricante, utilizando-se o forno fotopolimerizador UniXS (Heraeus/Kulzer - Germany). O polimento se deu através de uma politriz (Fortel) utilizando-se três granulações de lixa d'água (120, 360 e 600).

Os corpos de prova de porcelana (20 no total) foram levados ao forno para sua queima a uma temperatura inicial de $650 \mathrm{C}$ (confeccionados pelo técnico Nélson Queiroz do laboratório de produção do departamento de Dentística), que se elevou gradativamente a 940 C, sob vácuo. O polimento foi realizado através de uma politriz (Fortel) utilizando-se três granulações de lixa d'água (120, 360 e 600).

Após os procedimentos de acabamento e polimento, os corpos de prova foram divididos em dois grupos e acondicionados individualmente em recipiente plástico identificado e preenchido com água destilada a temperatura de $37^{\circ} \mathrm{C}$. 


\section{Material e Métodos}

Um orifício foi realizado, através de ponta diamantada esférica (KG Sorensen Ind. Com. Ltda - Barueri - São Paulo), em cada um dos corpos de prova na superfície contrária ao lado de trabalho, para que este fosse facilmente identificado.

\subsection{2 - DETERMINACÃO DA MASSA INICIAL}

Após a obtenção dos corpos de prova, estes foram pesados em uma balança analítica Sartorius (tipo 2002, fabricada pela Sartorius - Werke A.G., Alemanha, fabricação 147359 , precisão de $0,0001 \mathrm{~g}$ ) e os valores registrados. Essa balança foi escolhida por possibilitar maior precisão. A cada intervalo de 24 horas, uma nova pesagem foi realizada até que não houvesse mais alteração da massa do corpo de prova. Quando eram obtidos valores estáveis após quatro pesagens consecutivas, a média destas foi registrada como a média inicial da massa - MMi (Anexo 1). Antes das pesagens, os espécimes eram secos com um papel absorvente de celulose (Grand Hotel, Klabin Kimberly S. A, Mogi das Cruzes) por 5 segundos cada e manipulados com pinça clínica universal.

\subsection{3 - DETERMINACÃO DA RUGOSIDADE SUPERFICIAL INICIAL}

Para realização das leituras de rugosidade superficial (após sete dias da confecção dos corpos de prova) foi utilizado o rugosímetro Hommel Tester T1000 basic (Hommelwerke GmbH ref. \# 240851 - Schwenningem - Germany) que constitui um aparelho (Figuras 3 e 4) de alta sensibilidade com ponta ativa de diamante (Figura 5), utilizado para medir rugosidade superficial quantitativamente. 


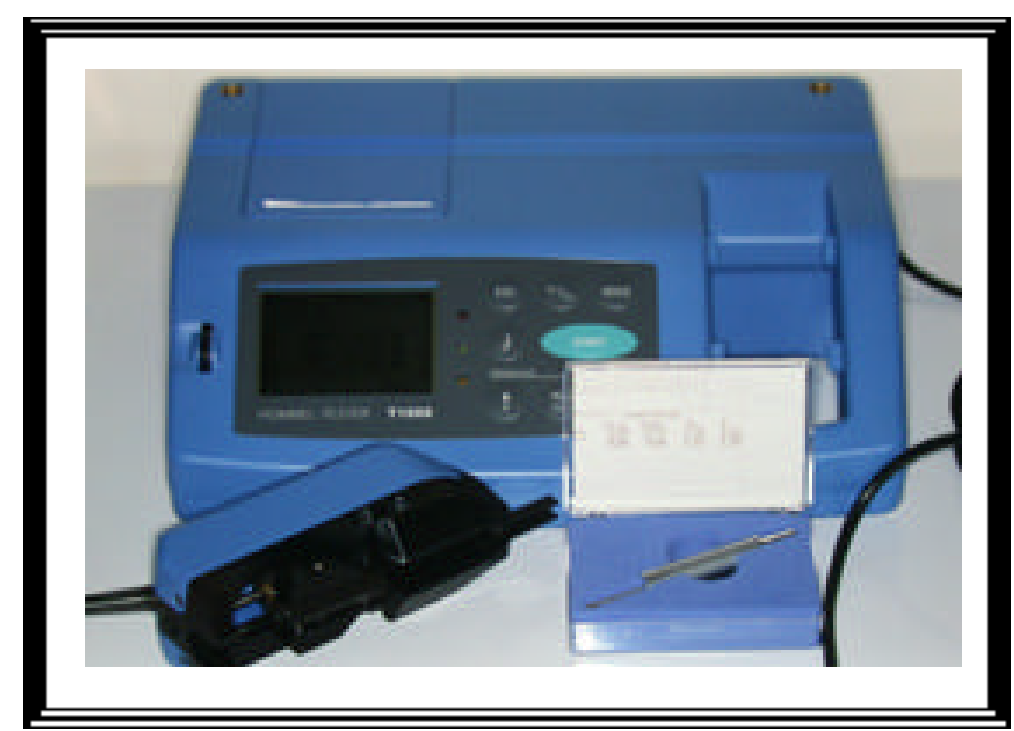

FIGURA 3- Apresentação do equipamento Rugosímetro Hommel Tester T1000

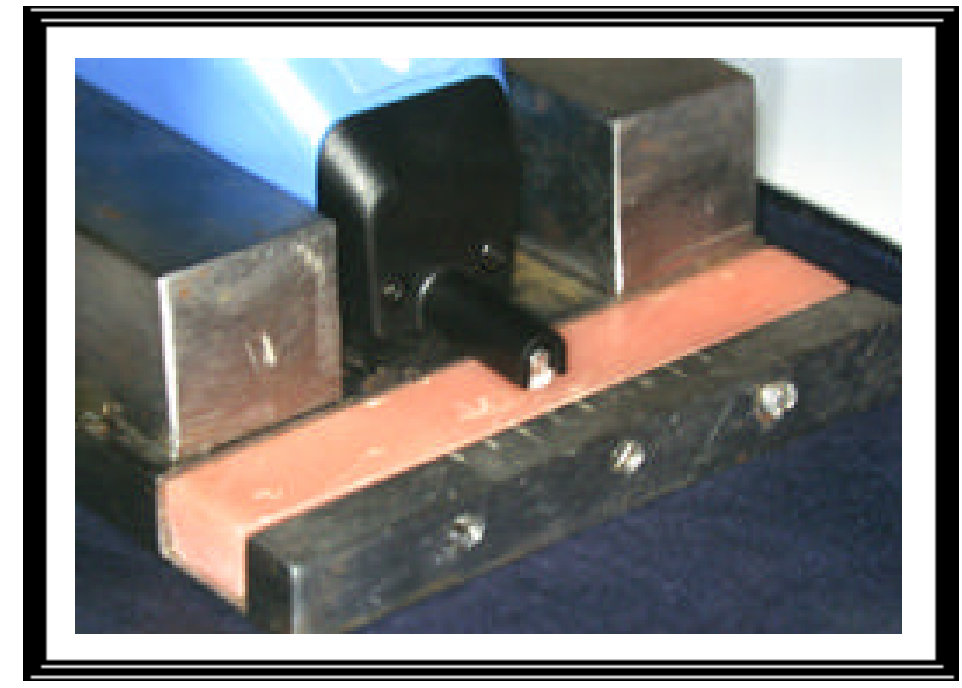

FIGURA 4- Pick up do rugosímetro durante o procedimento de leitura 


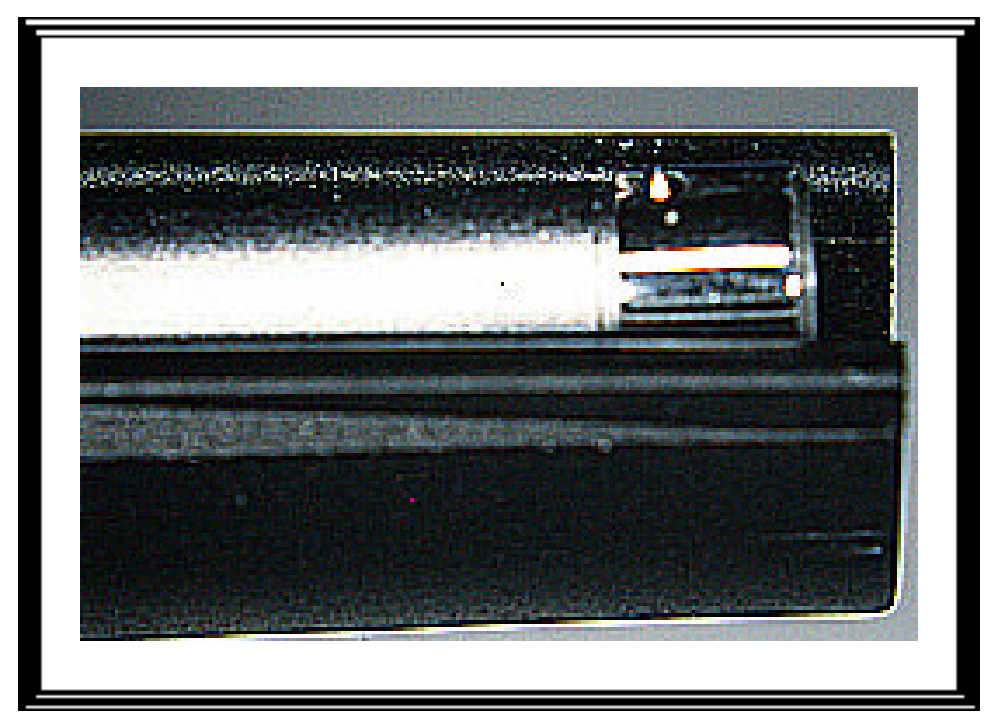

FIGURA 5- Ponta ativa do Rugosímetro Hommel Tester T1000

Para cada superfície do corpo de prova foram realizadas cinco leituras aleatórias passando sempre pelo centro do corpo de prova. O valor de rugosidade superficial foi obtido através da sua média aritmética (Anexo 1).

O parâmetro utilizado para obtenção da rugosidade superficial foi o $\mathrm{Ra}$, este traduz o valor da média aritmética de todas as distâncias absolutas do perfil de rugosidade $(R)$ desde a linha central dentro da extensão de medida $\operatorname{Lm}(1,25 \mathrm{~mm})$.

Os parâmetros escolhidos foram:

T mínima $=0,01$ ìm $\quad L t=1,5 \mathrm{~mm} \quad \mathrm{Lm}=1,25 \mathrm{~mm}$

T máxima $=8,00$ ìm $\quad$ Lc $=0,25 \mathrm{~mm}$ (cutt-off)

Sendo: $\quad \mathrm{T}=$ tolerância $\quad \mathrm{Lm}=$ limite de medição

$\mathrm{Lt}=$ limite de tracejamento $\quad \mathrm{Lc}=$ cut-off (filtragem) 


\subsection{4 - CICLAGEM DE $p H$}

De acordo com o protocolo proposto por FEATHERSTONE et al. ${ }^{34}$ (1986) e modificado por CARVALHO; CURY'15 (1999), metade dos espécimes de cada material avaliado (10) foi submetido a ciclos dinâmicos de $\mathrm{pH}$. Cada espécime foi primeiramente imerso em $75 \mathrm{ml}$ de solução ácida por 6 horas a $37 \pm 2^{\circ} \mathrm{C}$, que consiste em 2,0mM de cálcio e 2,0mM de fosfato em solução de 74,0mM de acetato ao pH igual a 4,3. Foram em seqüência lavados com água destilada e imersos em $75 \mathrm{ml}$ de saliva artificial por um período de 18 horas a $37 \pm 2^{\circ} \mathrm{C}$, que consiste em $1,5 \mathrm{mM}$ de cálcio e 0,9mM de fosfato em solução de $0,1 \mathrm{mM}$ de hidroximetil-aminometano em $\mathrm{pH}$ 7,0. Esse padrão de ciclagem foi repetido por 15 dias consecutivos.

\subsection{5 - PROCEDIMENTO DE ABRASÃO}

Para a realização dos testes de abrasão foi utilizada a máquina para simulação de escovação idealizada para esse propósito (Figura 6), através do protocolo descrito em 2001 por TURSSI ${ }^{18}$ (Figuras 7, 8, 9, 10 e 11). 


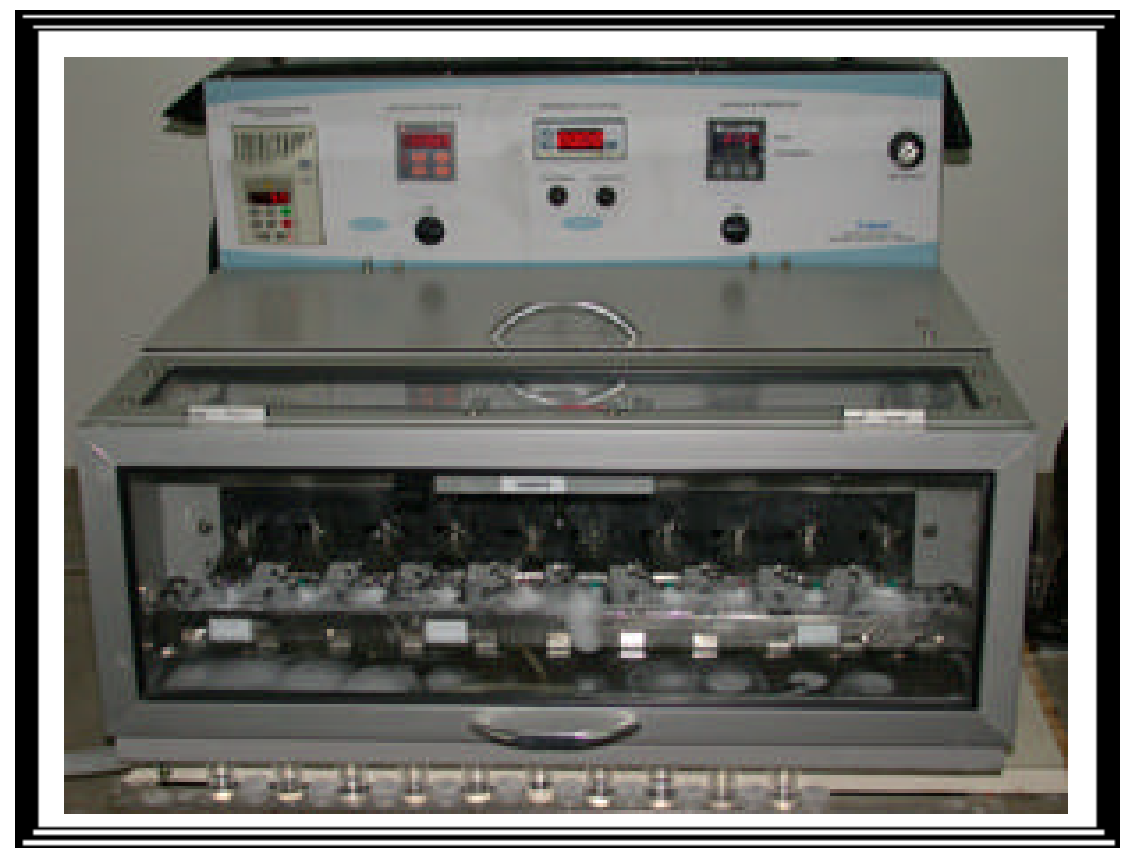

FIGURA 6 - Máquina de escovação utilizada nos testes de escovação simulada

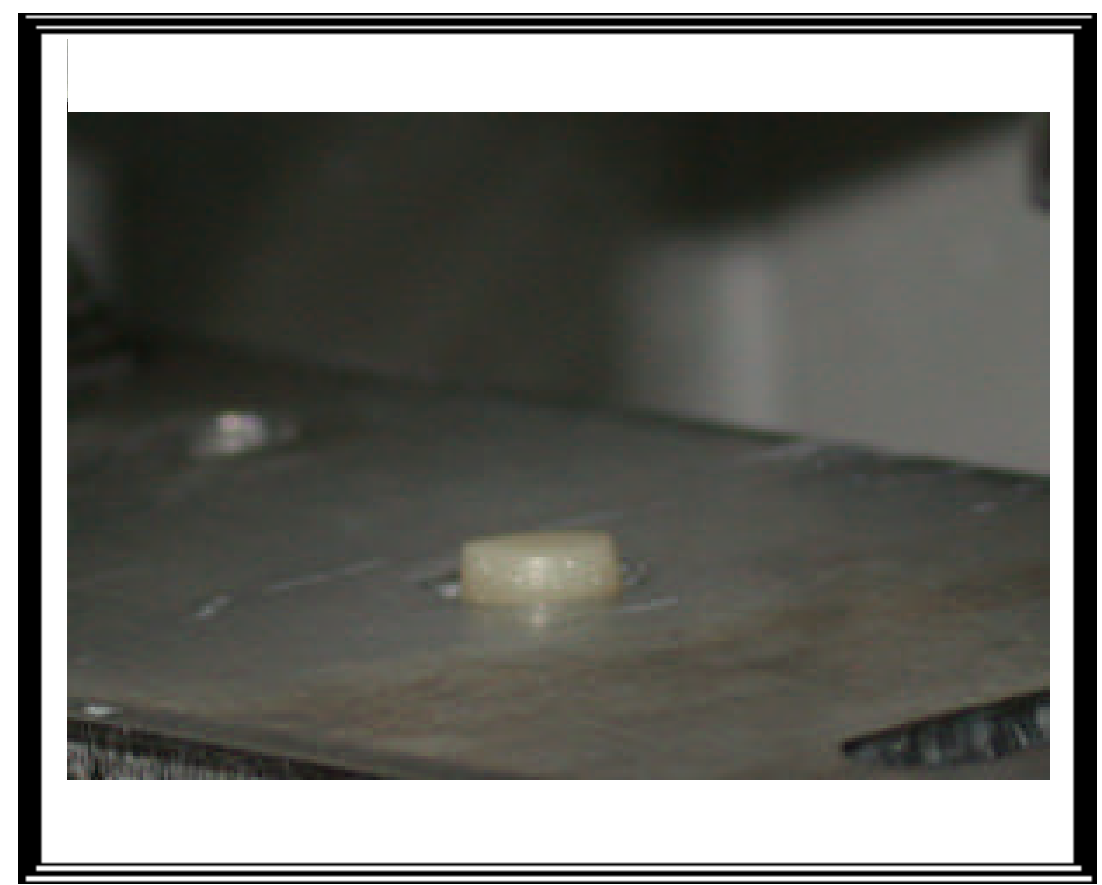

FIGURA 7 - Disposição do espécime na base metálica do equipamento 


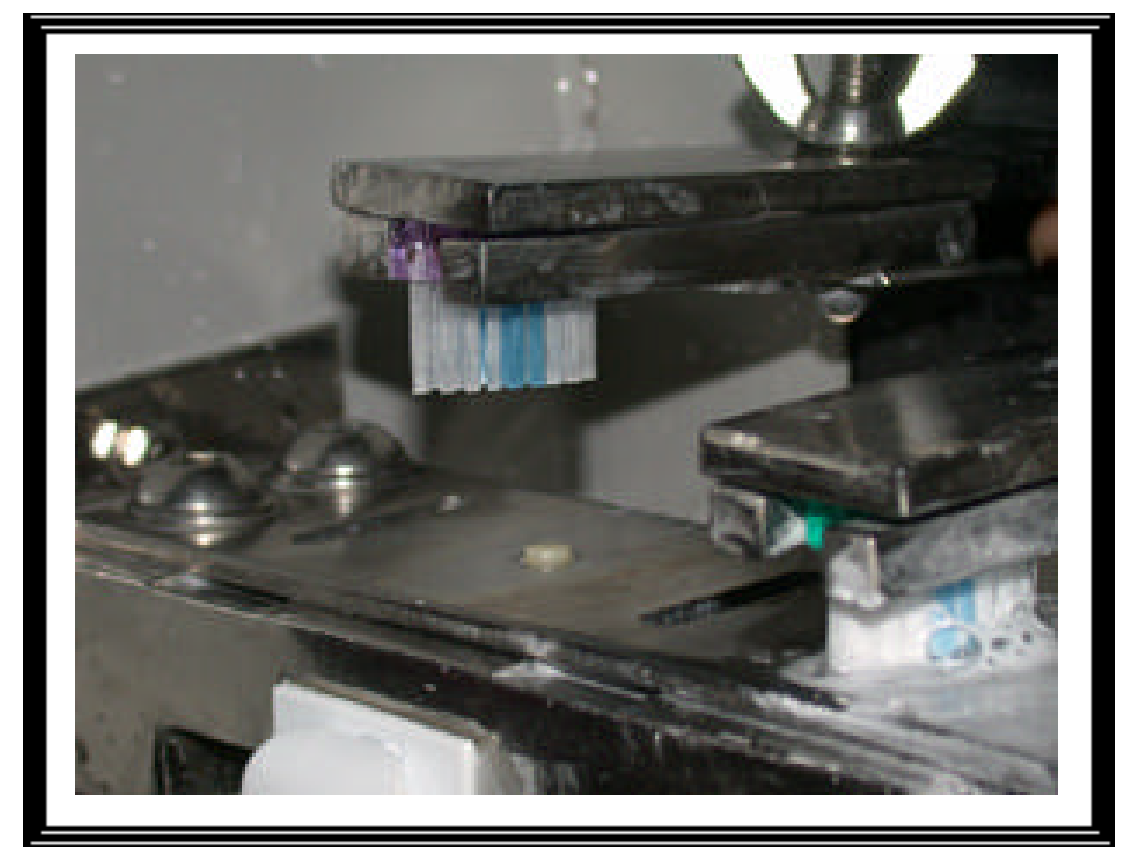

FIGURA 8 - Disposição do espécime em relação à escova dental

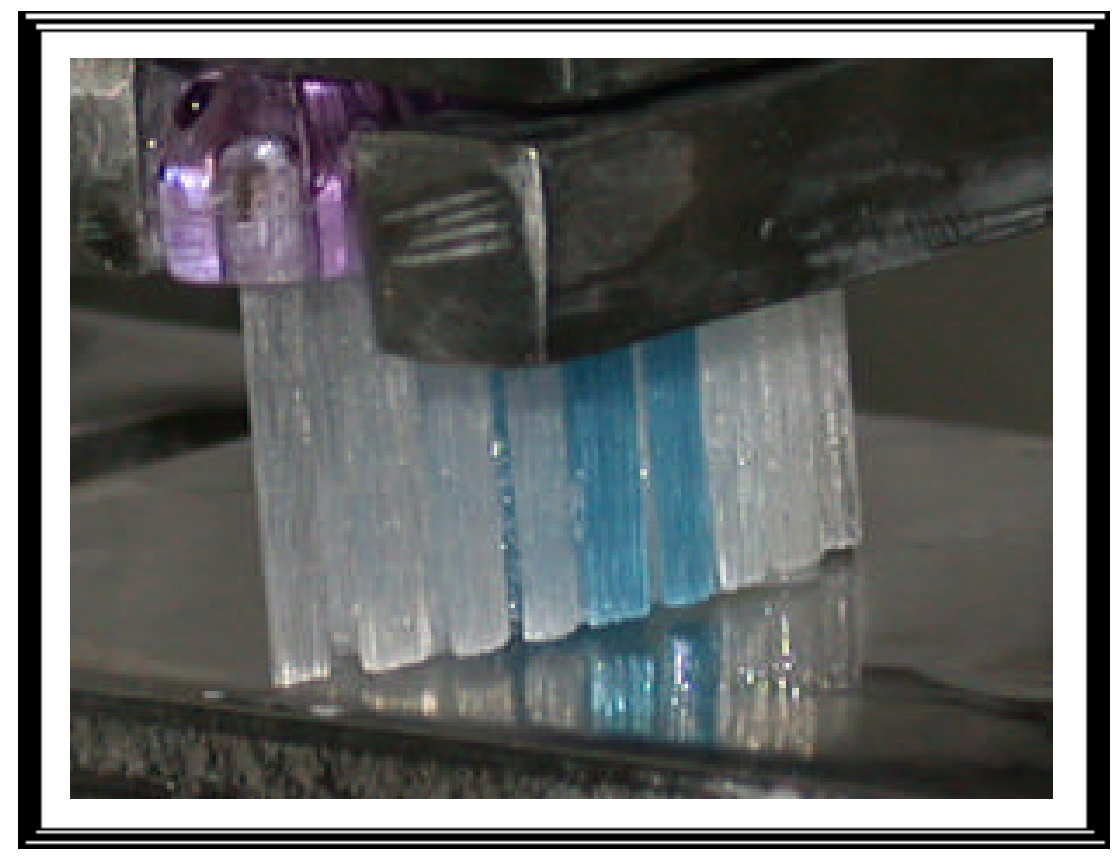

FIGURA 9 - Posicionamento da escova dental sobre o espécime 


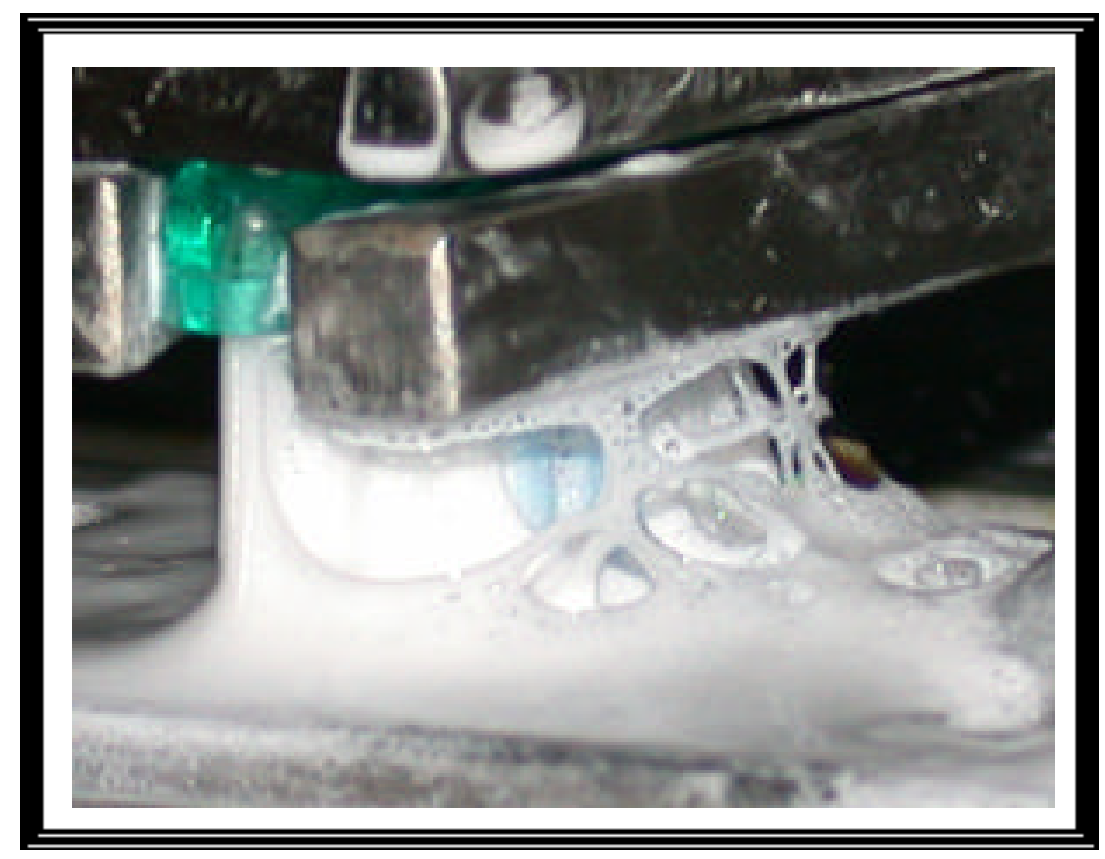

FIGURA 10 - Escovação do espécime

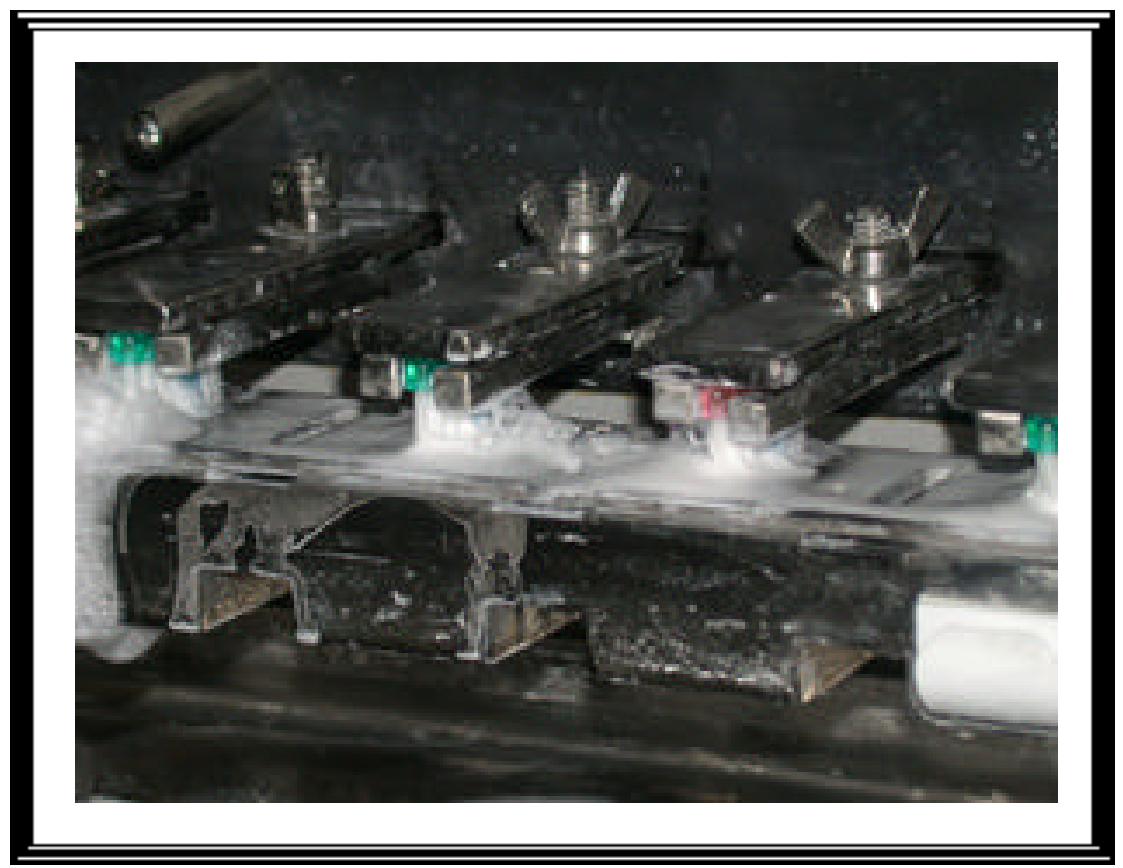

FIGURA 11- Escovação simultânea dos espécimes 


\section{Material e Métodos}

O equipamento consiste em um motor que produz movimentos de vai-vem em dez braços, nos quais são fixadas as "cabeças" das escovas dentais (Oral B 35), viabilizando simulação simultânea da escovação em dez corpos de prova. A base do equipamento é de aço inoxidável e possui dez dispositivos independentes para o posicionamento dos espécimes (Figura 7). As cabeças das escovas dentais foram fixadas de forma a garantir seu alinhamento paralelo à base (Figuras 8 e 9).

O equipamento é dotado de um sensor de temperatura que viabiliza a escovação a temperatura de $37 \pm 2$ C através de um monitoramento preciso e livre de interferências externas através de uma cúpula de vidro. A amplitude da excursão dos movimentos de escovação foi ajustada em $20 \mathrm{~mm}$, compatível com a dimensão dos espécimes. Cada ciclo, movimento completo de vai-vem, foi ajustado em um sensor específico do equipamento e adaptado a velocidade de 4,5 ciclos por segundo com carga de 300g. Durante a escovação, a máquina foi ajustada para injetar freqüentemente, em cada corpo de prova, $0,4 \mathrm{ml}$ da solução a cada dois minutos (Figuras 10 e 11).

A suspensão consistiu de dentifrício dental (Colgate MFP) e água destilada na proporção de 1:2 em peso e foi pesada e diluída no interior de um Becker com água destilada, de acordo com a especificação $I S O^{54}$. O preparo da solução foi realizado imediatamente antes da sua utilização, com a finalidade de preservar suas características. Monitorou-se o pH da solução no ato do seu preparo através de um pHmetro (B 371, MicroNal S.A, São Paulo) sendo registrado um valor de 8,4, sem variações significantes ${ }^{86}$.

Para o procedimento em si, os grupos foram escolhidos aleatoriamente e já haviam sido demarcados com uma broca (previamente à pesagem) que serviu de 
guia para o seu posicionamento. As escovas de dente foram trocadas ao fim de cada 50.000 ciclos, em um total de 100.000 ciclos de escovação para cada corpo de prova. O tempo de ensaio para cada grupo (100.000 ciclos) foi de aproximadamente oito horas.

\subsection{6 - LIMPEZA DOS CORPOS DE PROVA}

Após o término dos 100.000 ciclos de escovação, os corpos de prova foram lavados com água corrente com auxílio de uma pinça clínica. Em seguida, foram colocados no interior de um aparelho de vibração ultra-sônica (Tempo ultrasonic Ind.Com. Ltda, Taboão da Serra - SP, modelo T-14) por 10 minutos, cujo compartimento central continha água destilada para que as partículas abrasivas do creme dental fossem removidas. Posteriormente foram secados com papéis absorventes, pesados e armazenados em água destilada no interior de recipientes individualizados e identificados a temperatura de $37^{\circ} \mathrm{C}$ e umidade absoluta de $100 \%$.

\subsection{7-DETERMINACÃO DA MASSA FINAL}

Logo após a realização dos testes de escovação, os corpos de prova foram pesados utilizando-se a mesma metodologia descrita no item 4.2.2. As diferenças dos valores entre as médias iniciais e finais foram reportadas como a alteração final de massa (Anexo 1). 


\section{Material e Métodos}

\subsection{8 - DETERMINACÃO DA RUGOSIDADE SUPERFICIAL FINAL}

As leituras de rugosidade superficial final foram realizadas seguindo-se a mesma metodologia descrita anteriormente no item 4.2.3. As diferenças dos valores entre as médias iniciais e finais foram reportadas como a alteração final da rugosidade (Anexo 1).

\subsection{9 - OBSERVACÃO EM MICROSCOPIA ELETRÔNICA DE VARREDURA}

Esta etapa foi realizada com finalidade ilustrativa. Um elemento de cada material e em cada condição experimental, isto é, antes da escovação, após escovação e após ciclagem de pH e escovação, foram fixados em base de latão com esmalte de unha (Risque, Niasi, Taboão da Serra) e metalizados (Hammer VI sputtering system - Anatech Ltd, Alexandria, U.S.A) com partículas de ouro, possibilitando o registro das fotomicrografias em aumento de 500X (JEOL JSM T220A, Japan).

\subsubsection{0 - ANÁLISE ESTATÍSTICA}

Os resultados obtidos neste estudo, foram submetidos à Análise de Variância (ANOVA) a dois critérios e posteriormente, ao Teste de Tukey, para comparações individuais entre os grupos. O nível de significância empregado foi de 5\%, com $\mathrm{p}<0,05$ 
5-RESULTADOS 


\section{$\underline{5-R E S U L T A D O S}$}

\section{1- ALTERACÃO DA MASSA}

A análise de variância a dois critérios (ciclagem de $\mathrm{pH}$ e diferentes materiais) sobre a perda de massa em porcentagem não mostrou haver diferença estatisticamente significante para a condição de ciclagem de $\mathrm{pH}$, no entanto, houve diferença estatisticamente significante para os diferentes materiais estudados, onde $F=39,5 ; p=0,00$ (Anexo 2).

TABELA 4- Valores das médias iniciais, finais, desvio padrão e a diferença da alteração de massa (gramas) dos grupos testados

\begin{tabular}{lccc}
\hline Material & Média Inicial (DP) & Média Final (DP) & Diferença (DP) \\
\hline Enforce & $0,1184(0,0055)$ & $0,1164(0,0056)$ & $-0,0019(0,0004)$ \\
Enforce ${ }^{*}$ & $0,1178(0,0077)$ & $0,1156(0,0074)$ & $-0,0021(0,0005)$ \\
Rely X & $0,1147(0,0148)$ & $0,1133(0,0146)$ & $-0,0013(0,0003)$ \\
Rely X* & $0,1143(0,0053)$ & $0,1125(0,0053)$ & $-0,0018(0,0005)$ \\
Variolink II & $0,1354(0,0059)$ & $0,1335(0,0059)$ & $-0,0018(0,0003)$ \\
Variolink II & $0,1404(0,0074)$ & $0,1391(0,0075)$ & $-0,0013(0,0004)$ \\
Artglass & $0,1037(0,0099)$ & $0,1018(0,0098)$ & $-0,0018(0,0007)$ \\
Artglass ${ }^{*}$ & $0,1005(0,0053)$ & $0,0991(0,0050)$ & $-0,0014(0,0004)$ \\
Duceram Plus & $0,1359(0,0107)$ & $0,1355(0,0109)$ & $-0,0004(0,0002)$ \\
Duceram Plus ${ }^{*}$ & $0,1426(0,0132)$ & $0,1421(0,0134)$ & $-0,0005(0,0003)$ \\
\hline$\quad{ }^{*}$ Ciclagem de pH & & &
\end{tabular}




\section{Resultados}

$\mathrm{Na}$ tabela abaixo está relacionada a variação em porcentagem das massas dos materiais avaliados e os resultados da análise estatística (Teste de Tukey) utilizado para comparações entre os grupos avaliados.

TABELA 5- Variação percentual da perda de massa dos materiais testados, desvio padrão e análise estatística

\begin{tabular}{|c|c|c|c|c|c|}
\hline Material & Variação (DP) & \multicolumn{4}{|c|}{ Tukey** } \\
\hline Enforce & $-1,643(0,382)$ & á & è & & \\
\hline Enforce* $^{*}$ & $-1,850(0,457)$ & á & & & \\
\hline Rely X & $-1,211(0,291)$ & & è & â & \\
\hline Rely X* & $-1,568(0,471)$ & á & è & & \\
\hline Variolink II & $-1,345(0,268)$ & á & è & â & \\
\hline Variolink II* & $-0,973(0,364)$ & & & $\hat{a}$ & \\
\hline Artglass & $-1,821(0,649)$ & á & & & \\
\hline Artglass* & $-1,381(0,383)$ & á & è & â & \\
\hline Duceram Plus & $-0,340(0,201)$ & & & & $\tilde{a}$ \\
\hline Duceram Plus* & $-0,361(0,219)$ & & & & $\tilde{a}$ \\
\hline
\end{tabular}

A porcelana Duceram Plus apresentou a menor perda de massa, tendo sofrido ou não a ciclagem de $\mathrm{pH}, 0,36 \%$ e $0,34 \%$ respectivamente. As maiores variações de massa ocorreram para os grupos Enforce (E: 1,64\% e $\left.E^{*}: 1,85 \%\right)$; Rely X com ciclagem de $\mathrm{pH}\left(\mathrm{R}^{*}: 1,56 \%\right)$; Artglas (A: 1,82\% e $\left.A^{*}: 1,38 \%\right)$; Variolink II sem 
ciclagem de $\mathrm{pH}$ (V:1,34\%); Rely X sem ciclagem de $\mathrm{pH}(\mathrm{R}: 1,21 \%)$ e VariolinK II com ciclagem de $\mathrm{pH}\left(\mathrm{V}^{*}: 0,97 \%\right)$; onde * indica ciclagem de $\mathrm{pH}$.

$\mathrm{Na}$ figura abaixo, encontra-se a representação ilustrativa da alteração de massa dos materiais estudados (Figura 12).

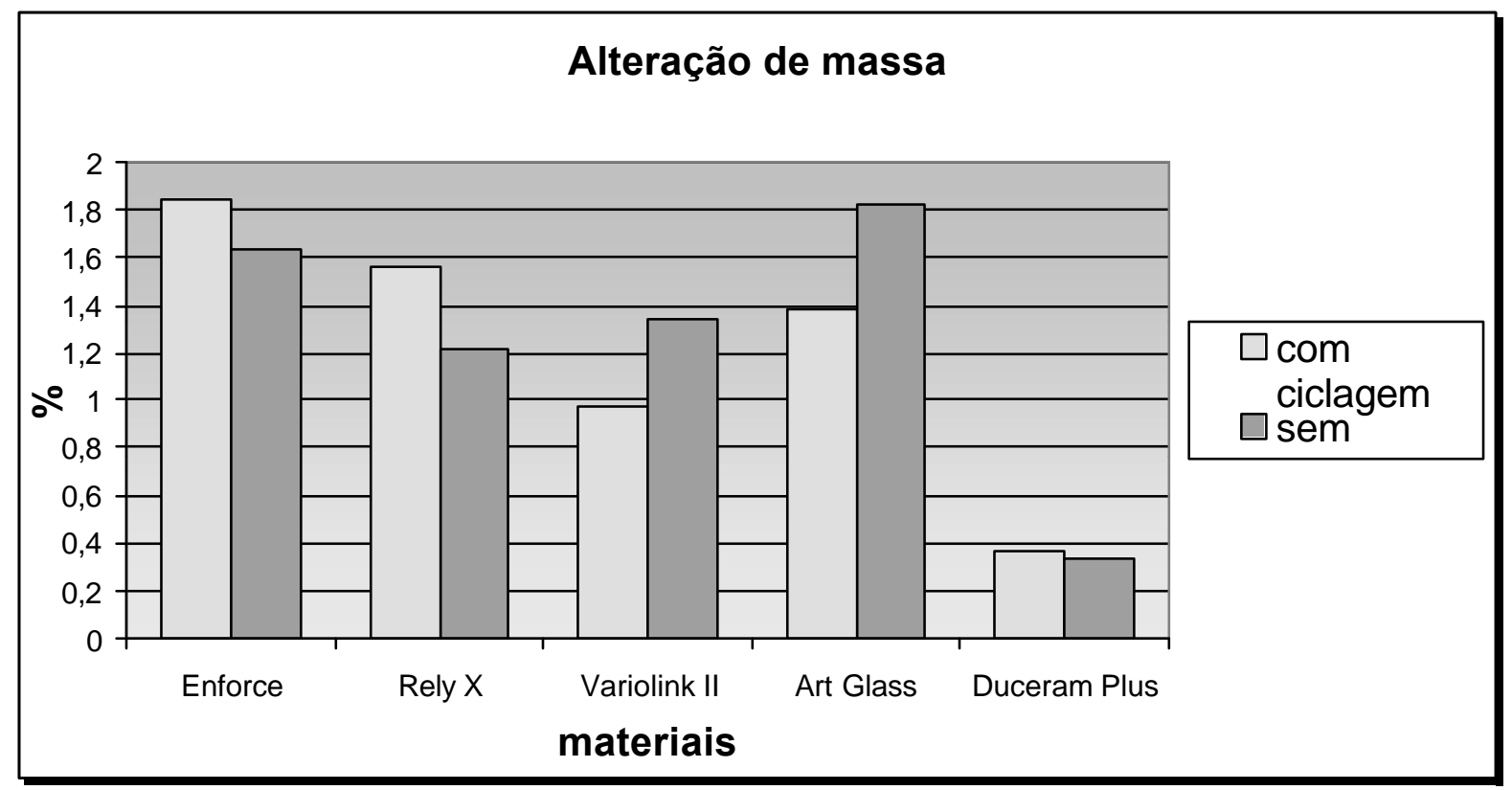

FIGURA 12 - Gráfico representativo da alteração de massa (\%) dos materiais avaliados 


\section{2-RUGOSIDADE SUPERFICIAL}

A análise de variância a dois critérios (ciclagem de pH e diferentes materiais) sobre a alteração de rugosidade superficial não mostrou haver diferença estatisticamente significante para a condição de ciclagem de $\mathrm{pH}$, no entanto, houve diferença estatisticamente significante para os diferentes materiais estudados, onde $F=76,4 ; p=0,00$. Aplicou-se teste de Tukey para comparações individuais entre os materiais (Anexo 3)

TABELA 6- Valores das médias iniciais, finais, desvio padrão, alteração de rugosidade e análise estatística dos grupos estudados (ìm).

\begin{tabular}{|c|c|c|c|c|c|c|c|c|}
\hline Material & Média I (DP) & Média F(DP) & Diferença (DP) & & \multicolumn{4}{|c|}{ Tukey** } \\
\hline Enforce & $0,077(0,023)$ & $0,289(0,085)$ & $0,211(0,100)$ & á & â & & & \\
\hline Enforce* & $0,057(0,011)$ & $0,311(0,061)$ & $0,253(0,064)$ & á & & & & \\
\hline Rely X & $0,111(0,054)$ & $0,340(0,061)$ & $0,229(0,084)$ & á & â & & & \\
\hline Rely X* & $0,089(0,042)$ & $0,378(0,066)$ & $0,288(0,084)$ & á & & & & \\
\hline Variolink II & $0,057(0,022)$ & $0,211(0,038)$ & $0,154(0,044)$ & & â & ã & & \\
\hline Variolink II* & $0,061(0,039)$ & $0,181(0,039)$ & $0,119(0,019)$ & & & ã & è & \\
\hline Artglass & $0,096(0,020)$ & $0,170(0,056)$ & $0,074(0,058)$ & & & ã & è & \\
\hline Artglass* & $0,094(0,014)$ & $0,130(0,034)$ & $0,036(0,032)$ & & & & è & $\ddot{e}$ \\
\hline Duceram Plus & $0,173(0,094)$ & $0,141(0,084)$ & $-0,031(0,041)$ & & & & & ë \\
\hline Duceram Plus* & $0,155(0,045)$ & $0,124(0,055)$ & $-0,033(0,041)$ & & & & & ë \\
\hline
\end{tabular}




\section{Resultados}

Os materiais testados apresentaram variações quanto à rugosidade superficial após a escovação simulada. A ordem crescente de variação em valores absolutos dos materiais foi: Duceram Plus, Duceram Plus*, Artglass*, Artglass, Variolink*, Variolink, Enforce, Rely X, Enforce*, Rely $\mathrm{X}^{*}$ (onde * indica ciclagem de $\mathrm{pH}$ ). Verificou-se diferença de comportamento entre os materiais frente ao procedimento de abrasão. O material Duceram Plus apresentou superfície mais lisa que verificada inicialmente, enquanto os demais materiais aumento da rugosidade superficial.

$\mathrm{Na}$ figura abaixo, encontra-se a representação ilustrativa da alteração de rugosidade dos materiais estudados (Figura 13).

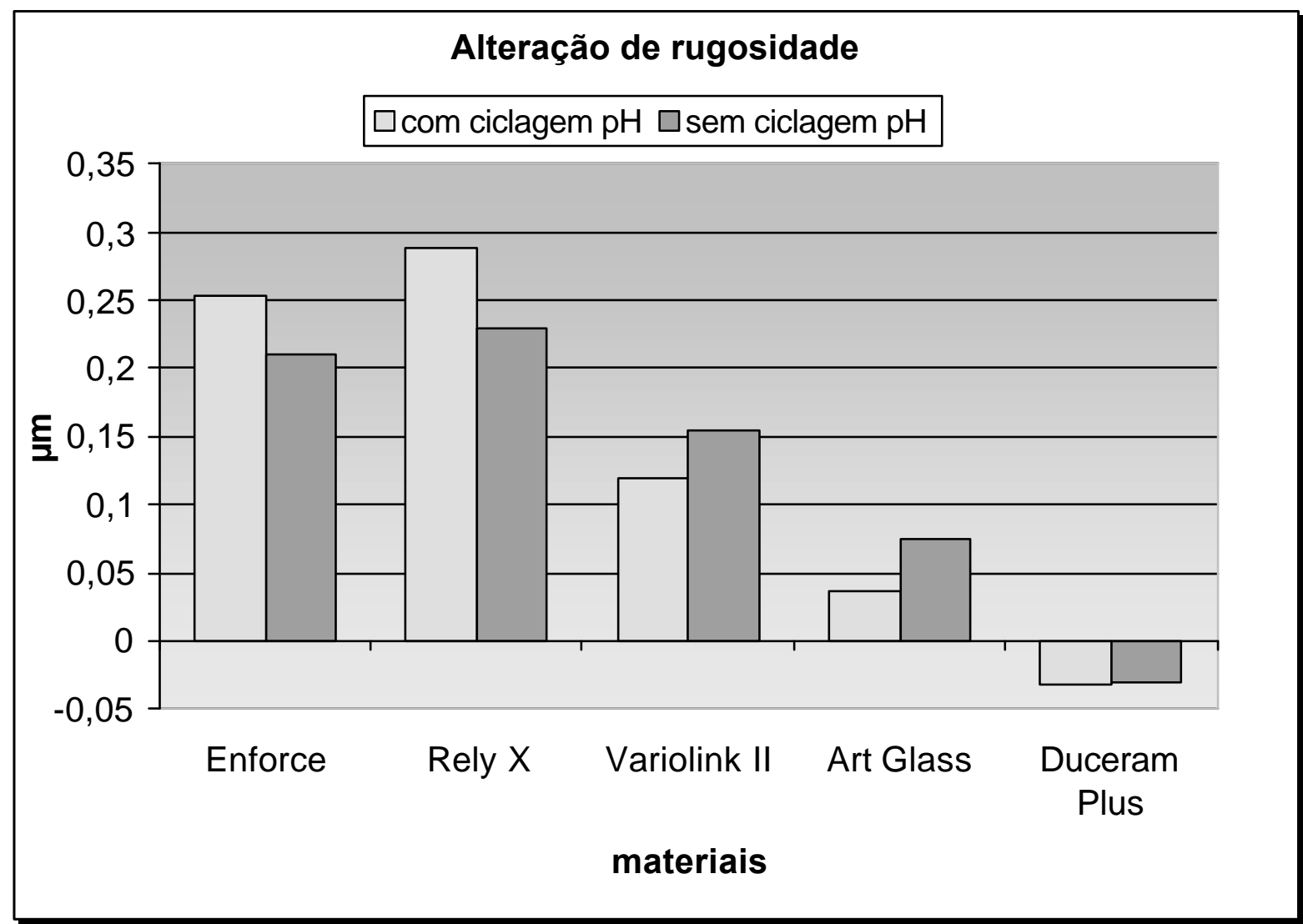

FIGURA 13 - Gráfico representativo da alteração de rugosidade aritmética (Ra) dos materiais avaliados. 
Quando todos os grupos foram submetidos ao teste de correlação de Pearson simultaneamente, verificou-se correlação entre alteração de massa e rugosidade superficial $(p<0,05)$ onde $r=0,602 ; p=0,000$.

\subsection{1- PADRÃO PERFILOMÉTRICO (QUALITATIVO) DE RUGOSIDADE}

\section{SUPERFICIAL}

A seguir serão apresentados os padrões qualitativos do perfil de rugosidade para os materiais e condições testadas.

As figuras 14, 15, 16, 17 e 18 seguem a seqüência, em ordem de material: Enforce, Rely X, Variolink II, Artglass e Duceram Plus.

Para cada figura, três leituras de rugosidade foram observadas em ordem: leitura inicial do material, leitura final após escovação simulada, e leitura final após escovação simulada quando submetidos previamente aos ciclos de $\mathrm{pH}$. 


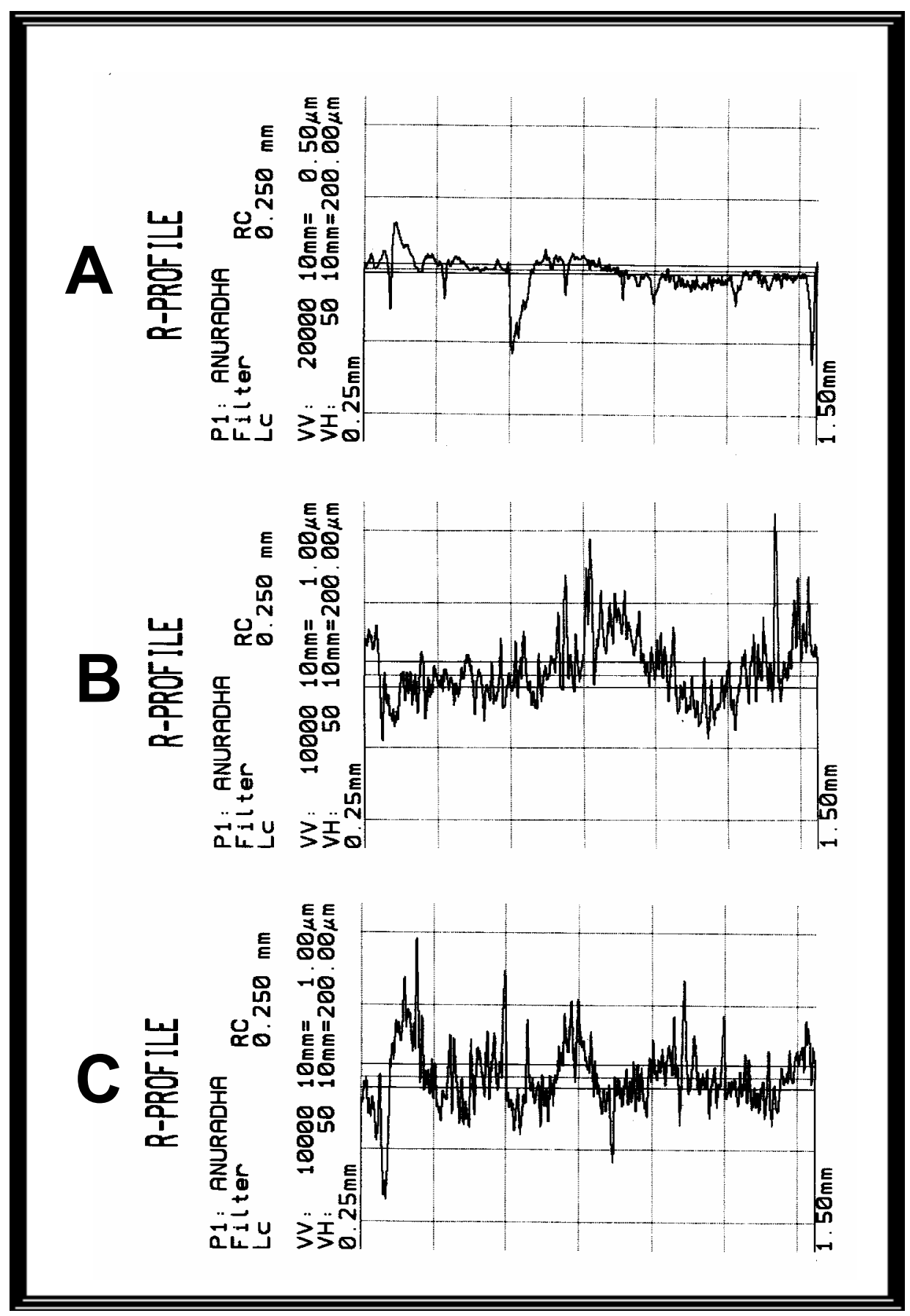

FIGURA 14 - Padrão perfilométrico de rugosidade superficial. Enforce inicial (A), Enforce final sem ciclagem de $\mathrm{pH}(\mathrm{B})$ e Enforce final com ciclagem de $\mathrm{pH}(\mathrm{C})$ 


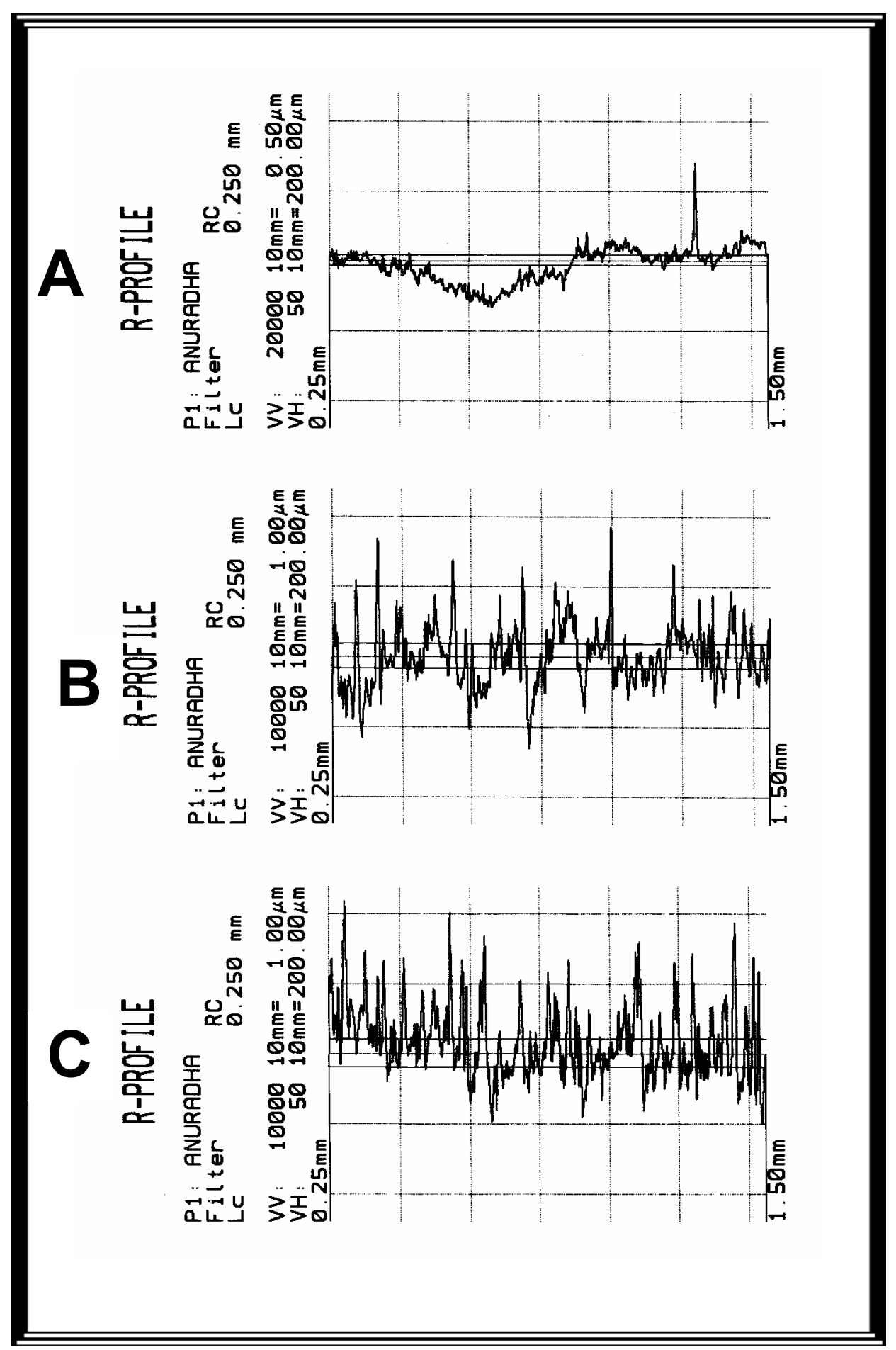

FIGURA 15 - Padrão perfilométrico de rugosidade superficial. Rely $X$ inicial (A), Rely X final sem ciclagem de $\mathrm{pH}$ (B) e Rely X final com ciclagem de $\mathrm{pH}(\mathrm{C})$ 


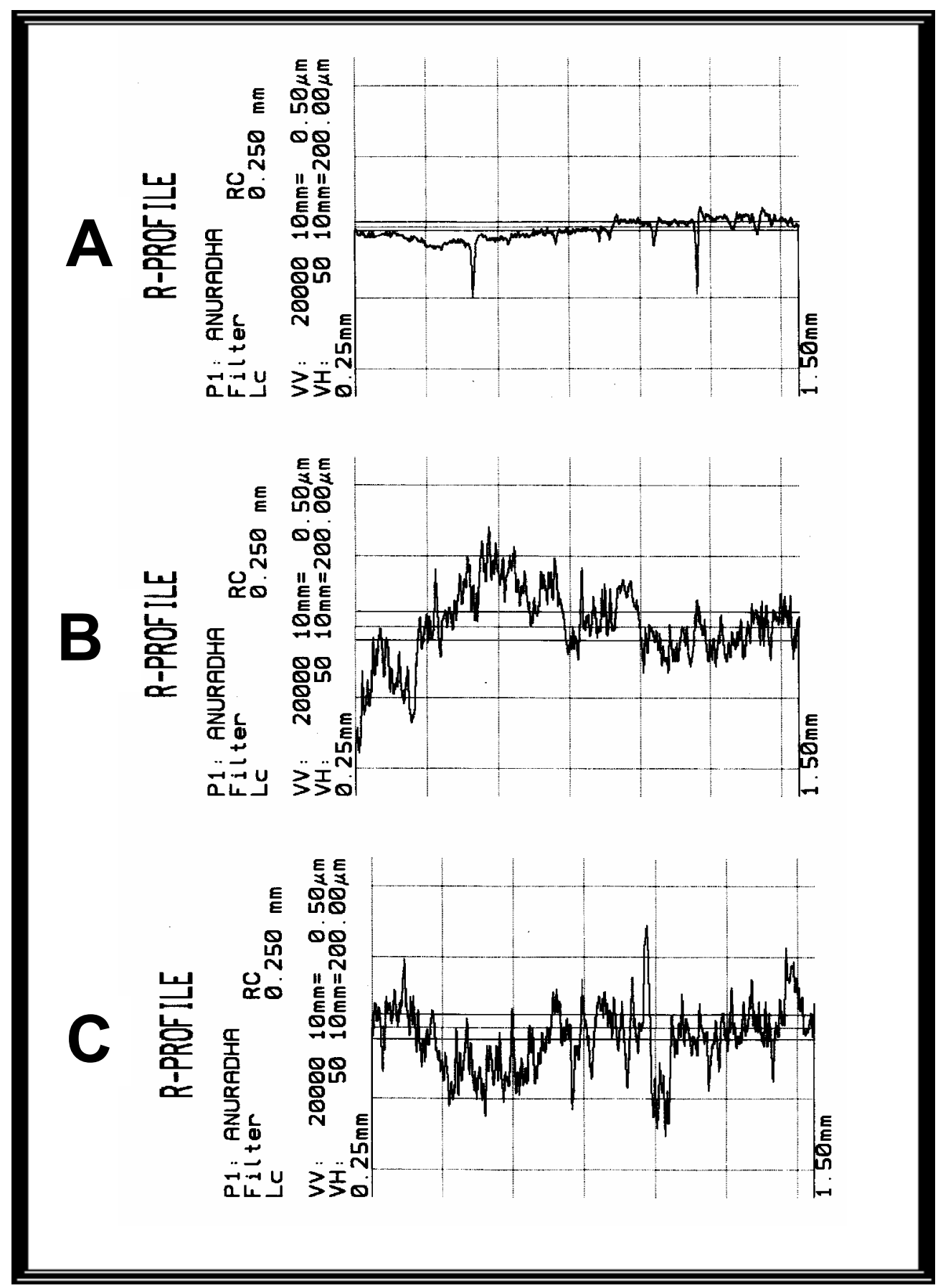

FIGURA 16 - Padrão perfilométrico de rugosidade superficial. Variolink II inicial (A), Variolink II final sem ciclagem de $\mathrm{pH}(\mathrm{B})$ e Variolink II final com ciclagem de $\mathrm{pH}(\mathrm{C})$ 


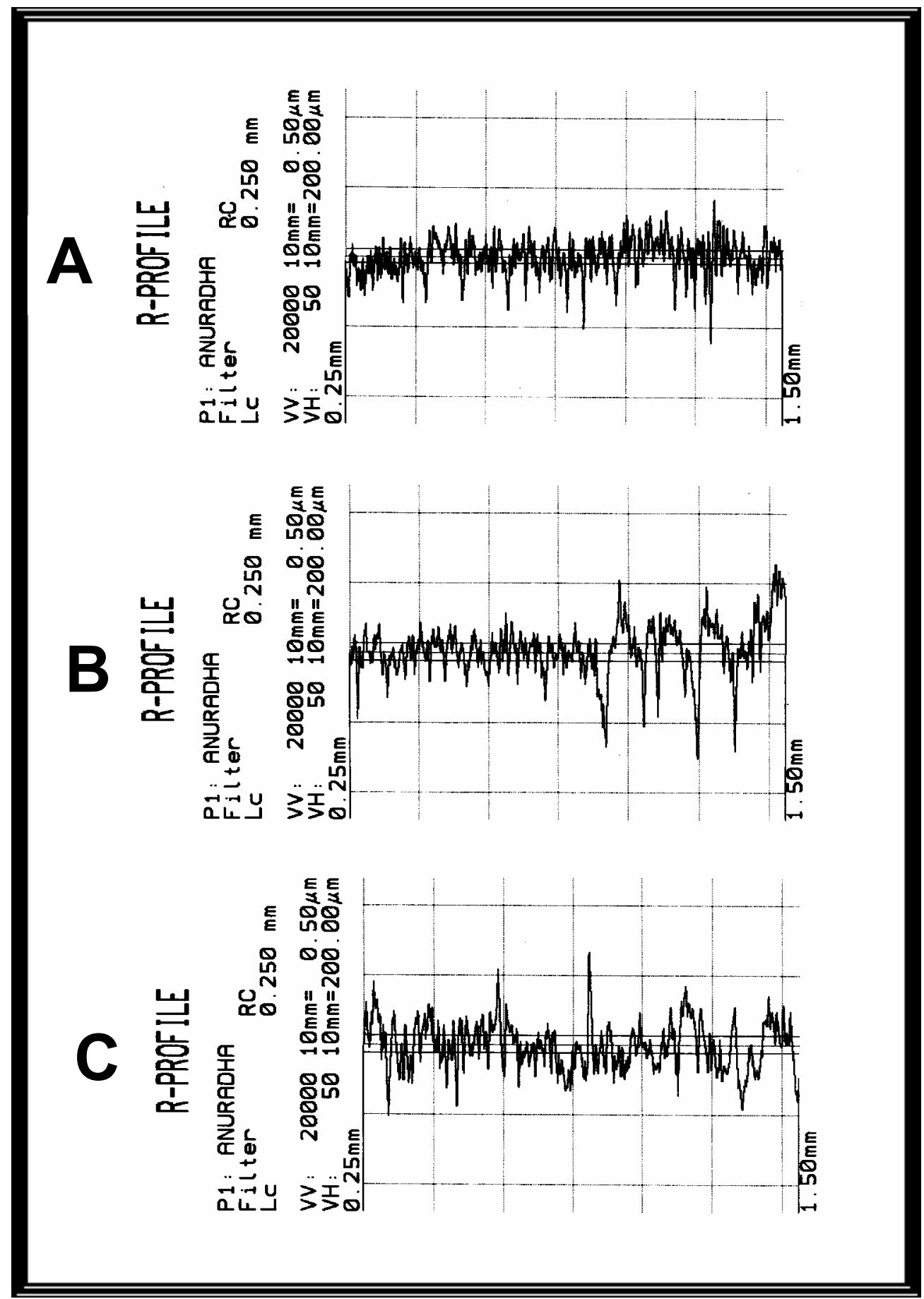

FIGURA 17 - Padrão perfilométrico de rugosidade superficial da resina Artglass inicial (A), Artglass final sem ciclagem de $\mathrm{pH}(\mathrm{B}) \mathrm{e}$ Artglass final com ciclagem de $\mathrm{pH}(\mathrm{C})$ 


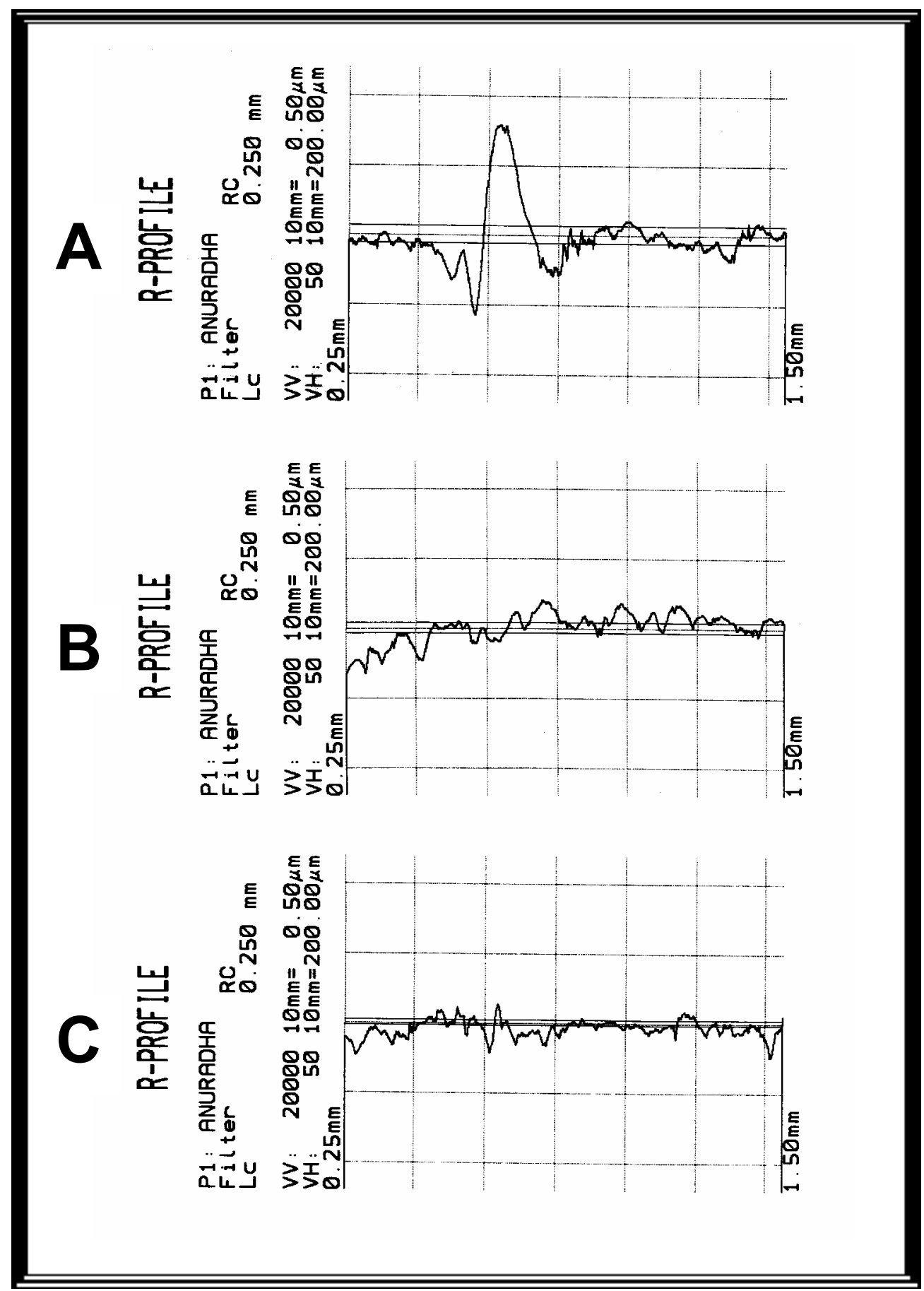

FIGURA 18 - Padrão perfilométrico de rugosidade superficial da porcelana Duceram Plus inicial (A), Duceram Plus final sem ciclagem de $\mathrm{pH}(\mathrm{B})$ e Duceram Plus final com ciclagem de $\mathrm{pH}(\mathrm{C})$ 


\section{Resultados}

\subsection{2- OBSERVACÃO EM MICROSCOPIA ELETRÔNICA DE VARREDURA}
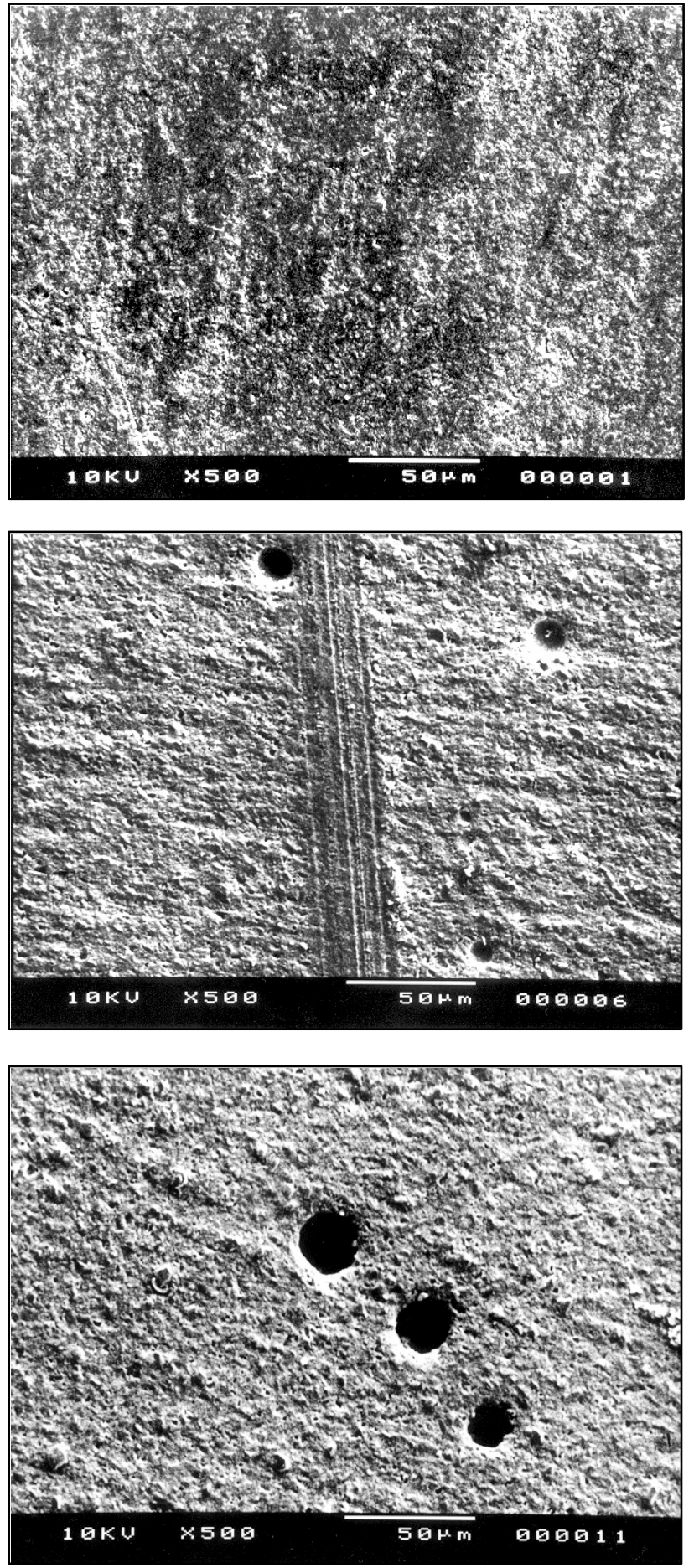

FIGURA $19-$

Fotomicrografia da

superfície do

cimento Enforce

antes da escovação

(MEV original 500X)

FIGURA 20 -

Fotomicrografia da

superfície do

cimento Enforce

após escovação

(MEV original 500X)

FIGURA 21 -

Fotomicrografia da

superfície do

cimento Enforce

após ciclagem de $\mathrm{pH}$

e escovação (MEV

original 500X) 


\section{Resultados}
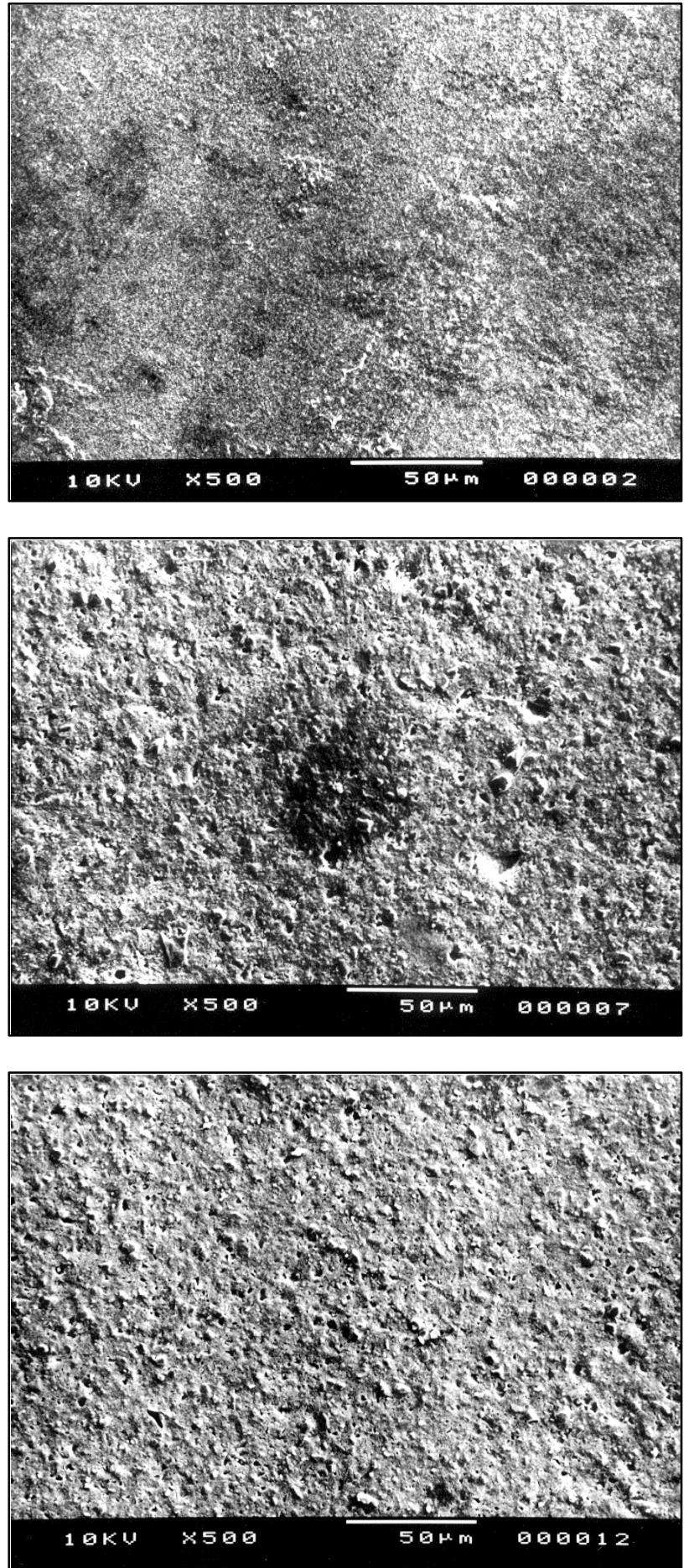

FIGURA 22 -

Fotomicrografia da

superfície do cimento

Rely X antes da

escovação (MEV

original 500X)

FIGURA 23 -

Fotomicrografia da

superfície do cimento

Rely X após

escovação (MEV

original 500X)

FIGURA 24 -

Fotomicrografia da

superfície do cimento

Rely X após ciclagem

de $\mathrm{pH}$ e escovação

(MEV original 500X) 


\section{Resultados}
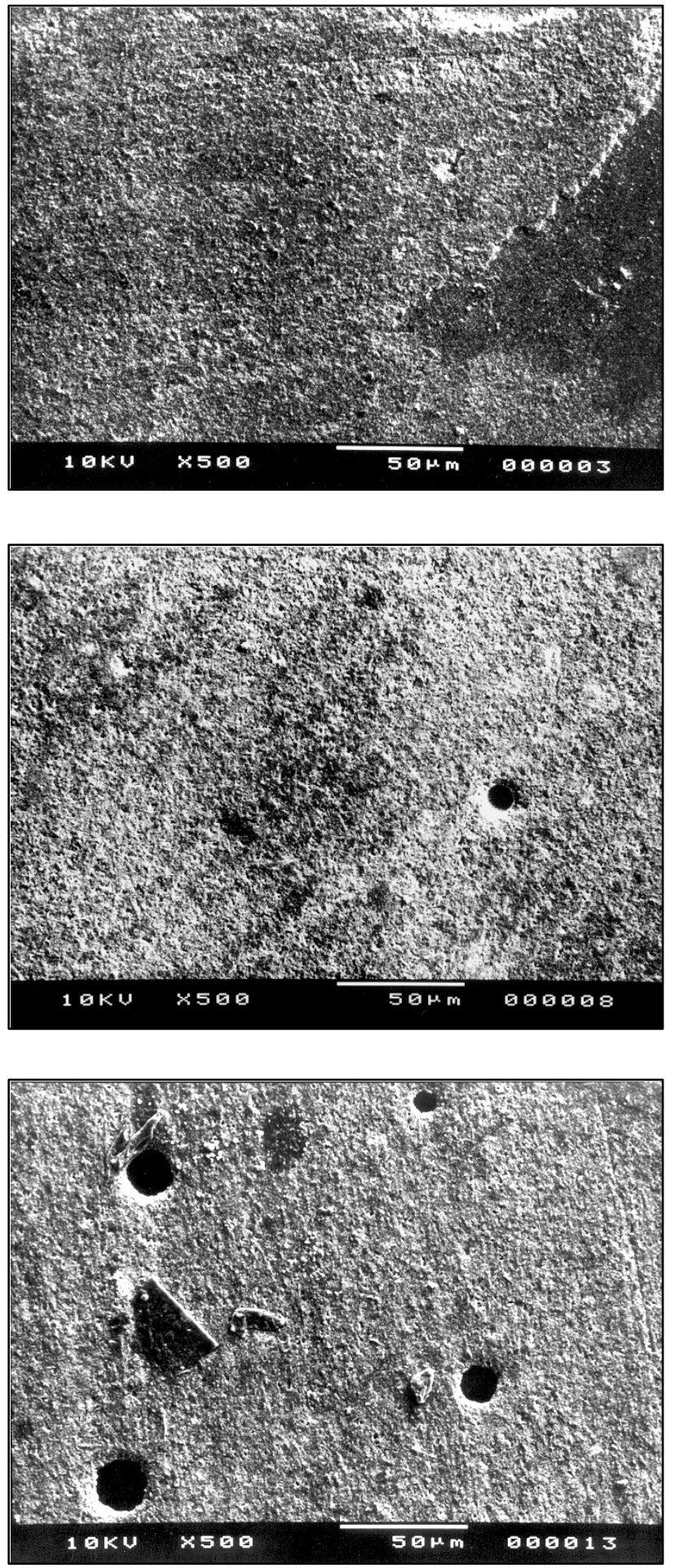

\section{FIGURA 25 -}

Fotomicrografia da

superfície do

cimento Variolink II

antes da escovação

(MEV original 500X)

FIGURA 26 -

Fotomicrografia da

superfície do

cimento Variolink II

após escovação

(MEV original 500X)

\section{FIGURA 27 -}

Fotomicrografia da

superfície do

cimento Variolink II

após ciclagem de pH

e escovação (MEV

original 500X) 


\section{Resultados}
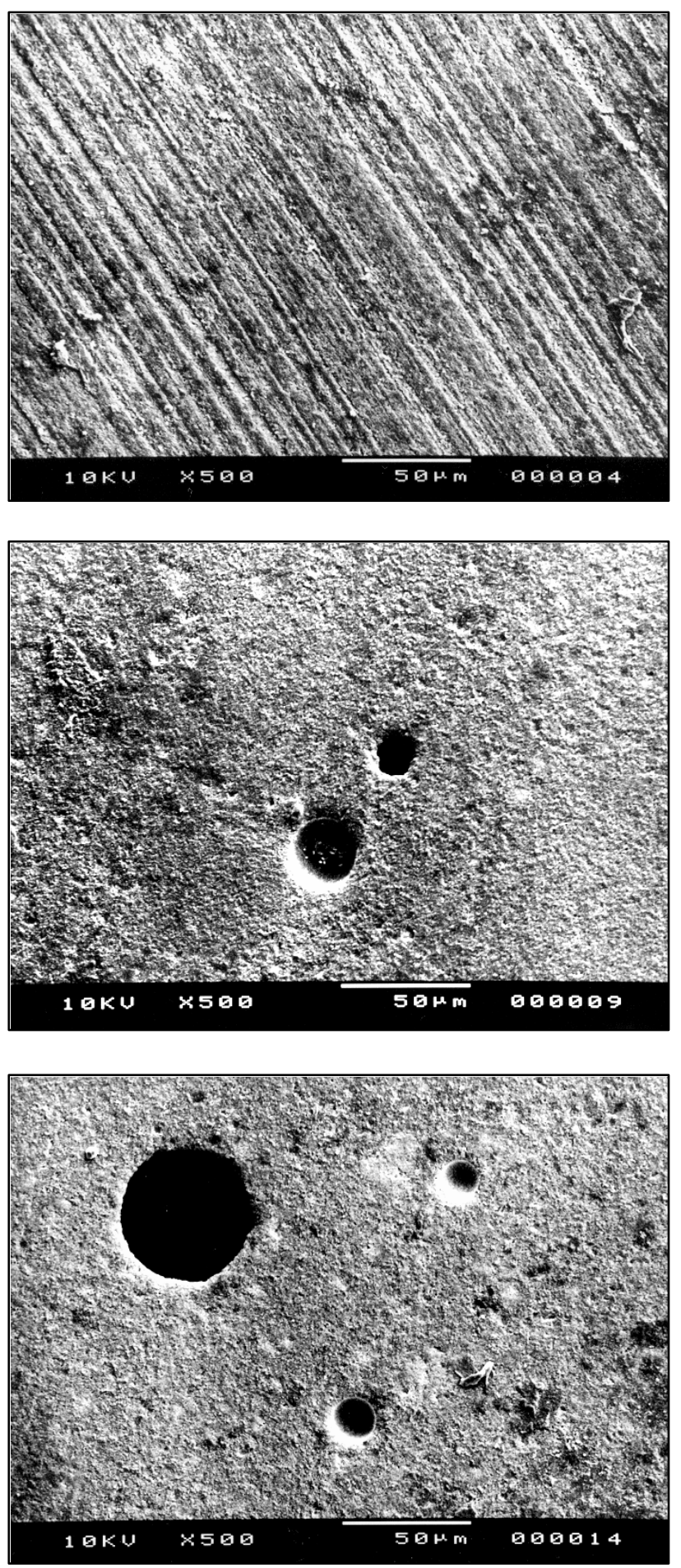

FIGURA 28-

Fotomicrografia do

Art Glass antes da

escovação (MEV

original 500X)

FIGURA 29 -

Fotomicrografia do

Art Glass após

escovação (MEV

original 500X)

FIGURA 30 -

Fotomicrografia do

Art Glass após

ciclagem de $\mathrm{pH}$ e

escovação (MEV

original 500X) 

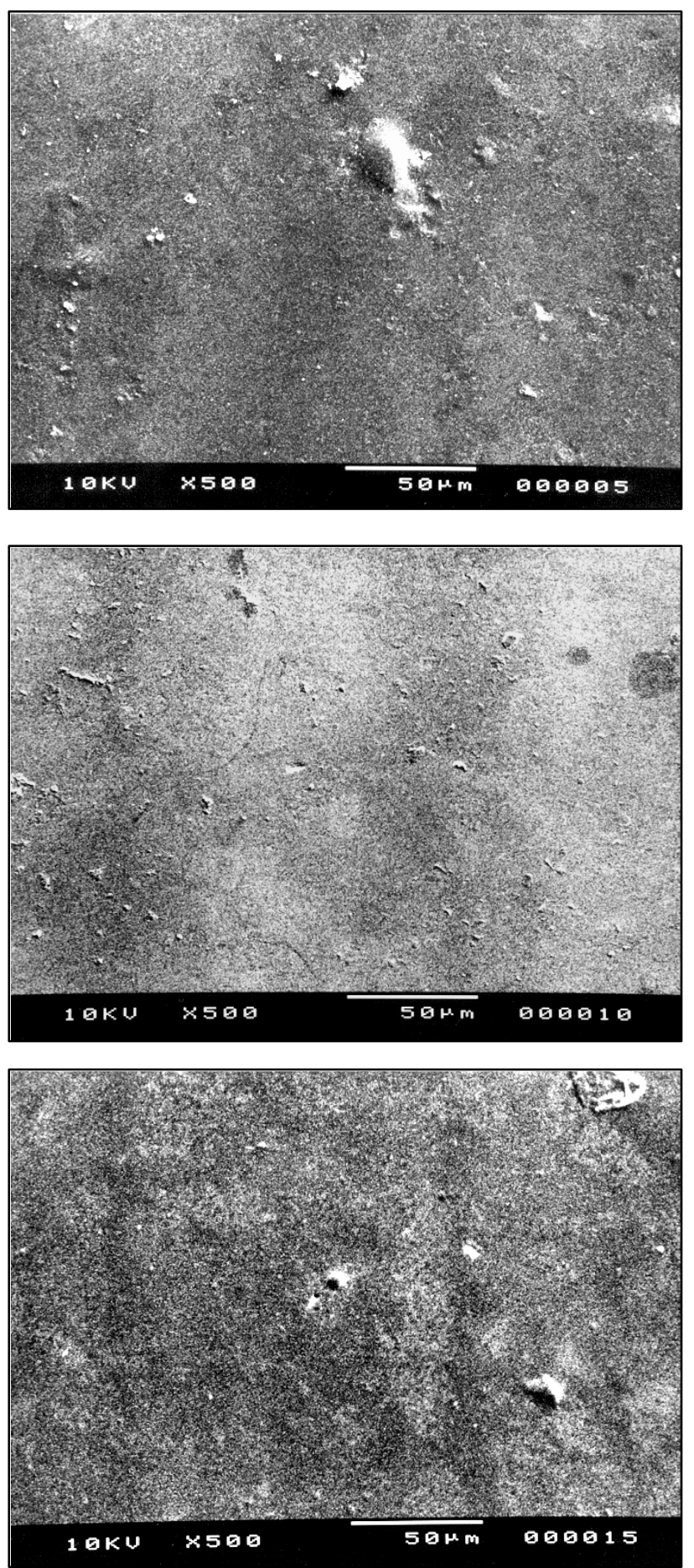

FIGURA 31 -

Fotomicrografia da

Duceram Plus antes

da escovação (MEV

original 500X)

FIGURA 32 -

Fotomicrografia da

Duceram Plus após

escovação (MEV

original 500X)

FIGURA 33 -

Fotomicrografia da

Duceram Plus após

ciclagem de $\mathrm{pH}$ e

escovação (MEV

original 500X) 
6-DISCUSSÃO 


\section{6- DISCUSSÃO}

\section{1-DISCUSSÃO RELACIONADA À METODOLOGIA EMPREGADA}

Durante o processo de confecção dos corpos de prova houve o cuidado no sentido de cobrir os cimentos com tira de poliéster e, sobre esta, uma lâmina de vidro foi colocada para a realização da fotopolimerização através delas. Por se tratar de materiais resinosos, em contato com o oxigênio, parte superficial desses materiais não se polimerizam adequadamente. No caso específico do Variolink II, os fabricantes informam em sua bula que cerca de 50ìm da sua extensão superficial não se polimeriza por ação da inibição do oxigênio.

Apesar de haver trabalhos de resistência ao desgaste, nos quais, as amostras resinosas são estocadas por 24 horas previamente aos ensaios ${ }^{17,18}$, os estudos são praticamente unânimes em indicar estocagem de no mínimo 7 dias $59,51,28,79,47,58,119,39$.

No presente estudo, os espécimes também foram armazenados em água destilada por 7 dias. Trata-se de um procedimento importante uma vez que trabalhos como os de FRAZIER; SARRETT ${ }^{37}$ (1995) e HEATH; WILSON ${ }^{51}$ (1976) afirmam haver influência entre tempo de armazenagem em água e sorção de água pelos materiais resinosos, podendo alterar os valores de massa inicial, sugerindo estocagem mínima de uma semana em água.

Existem relatos na literatura onde a mensuração da massa de materiais a base de resina acontece a seco, sendo que os espécimes são estocados em água, no entanto, antes da pesagem são desidratados em estufa, descartando a influência da sorção de água pelo material| ${ }^{95}$. HEFFEREN ${ }^{52}$ (1976) contra indica este 
procedimento afirmando que a "secagem" pode alterar propriedades do material. Ao comparar a resistência ao desgaste de resinas compostas que tiveram suas massas aferidas a seco e sob umidade, LUGASSY; GREENER ${ }^{74}$ (1972) verificaram diminuição da resistência do material desidratado.

No caso dos cimentos resinosos duais (como os utilizados neste estudo), esta armazenagem dos espécimes em água por tempo superior a 24 horas, antes de serem submetidos a ensaios de desgaste, tem grande importância. Esses materiais associam duas formas de polimerização, a física e a química. A conversão química inicia-se quando as duas pastas (base e catalisador) são misturadas e esta é incapaz de compensar a falta da ativação por luz ${ }^{31}$. Estudos mostram um aumento significante de resistência adesiva após um período de 24 horas da sua polimerização, o que BURROW et al. ${ }^{14}$ (1996) denominam de período de maturação do cimento. BRAGA et al. ${ }^{10}$ (1999) não recomendam nenhum tipo de estresse sobre cimentos resinosos nos primeiros 90 minutos após cimentação, mesmo no caso dos duais, pois a força de adesão neste momento ainda é muito inferior à sua máxima adesão. DARR; JACOBSEN ${ }^{20}$ (1995) também investigaram o grau de conversão dos cimentos duais em comparação aos químicos. Segundo eles, a fotopolimerização atua no sentido de adaptar a peça protética nos instantes iniciais, enquanto a reação química continua ocorrendo nas áreas internas da restauração. Concluem afirmando que até 24 horas da fotoativação a sua resistência é extremamente vulnerável.

Dois critérios foram utilizados para se avaliar a resistência ao desgaste de cimentos resinosos em comparação a uma resina composta indireta e uma porcelana odontológica no estudo atual, sendo eles, a alteração de massa e a alteração da rugosidade superficial. 
A determinação das massas iniciais começou a ser realizada após a obtenção dos corpos de prova, em balança analítica ${ }^{119,39,102}$ com precisão de $0,0001 \mathrm{~g}$. A cada intervalo de 24 horas, uma nova pesagem foi realizada até que não houvesse mais alteração da massa do corpo de prova. Quando foram obtidos valores estáveis após pelo menos quatro pesagens consecutivas, os valores médios iniciais de massa eram registrados. Esta sucessão de pesagens não precisou ser repetida na mensuração da massa final que foi obtida através da média aritmética de quatro pesagens, que se mantiveram constantes.

Antes das pesagens, os espécimes tinham o excesso de umidade removido com um papel absorvente por 5 segundos cada ${ }^{119,39}$. Após a escovação dos corpos de prova houve cuidado na limpeza destes, com água corrente associada à vibração ultra-sônica, para que as partículas de dentifrício fossem removidas e não houvesse interferência nos resultados de massa final. Segundo BULL et al. ${ }^{12}$ (1968) a perda de massa é um dos métodos mais óbvios existentes para se avaliar abrasão. Em seu trabalho, houve forte relação entre a perda de massa de corpos de prova abrasionados com resultados obtidos através de irradiação de isótopos consistindo, portanto, em um critério de confiabilidade. JONES; JONES; WILSON ${ }^{59}$ (1972) acreditam que quando houver condições de se detectar resistência à abrasão por perda de massa deve se aplicá-la.

As medições de rugosidade superficial foram realizadas através do rugosímetro Hommel Tester T1000 - Hommelwerke GmbH. O padrão de leitura utilizado foi rugosidade aritmética $(\mathrm{Ra})$ ou ainda, roughness average, ou seja, a média aritmética entre os picos e vales percorridos pelo instrumento. $O$ valor do cut-off utilizado foi de 0,25mm, este parâmetro determina o filtro utilizado durante a medição, ou seja, 
comprimentos de onda menores que este valor são utilizados para perfil de rugosidade e comprimentos de onda maiores, são utilizados para perfil ondulado.

Para cada superfície do corpo de prova foram realizadas cinco leituras aleatórias, passando sempre pelo seu centro, o valor de rugosidade superficial foi obtido através da sua média aritmética. SUZUKI et al. ${ }^{115}$ (1995) adotaram a realização de 8 leituras de rugosidade por corpo de prova, outros como CORRER SOBRINHO et al. ${ }^{18}$ (2001) e TURSSI $^{18}$ (2001) adotaram a realização de três leituras. No presente trabalho, por se tratar de um número estatisticamente suficiente, adotou-se realizar 5 leituras ${ }^{11,119,39}$.

Conforme KRAMER; FRANKENBERGER ${ }^{66}$ (2000) a utilização de rugosímetro para detectar alteração de superfície é, graças a sua alta resolução, o sistema de maior fidelidade. A forma geométrica da sua ponta ativa, cuja extremidade é de diamante, apresenta-se em formato de triângulo eqüilátero.

Previamente à realização dos ciclos de escovação sumulada, um dos grupos de cada material desta pesquisa foi submetido a ciclos dinâmicos de $\mathrm{pH}$, simulando assim condição de alto desafio cariogênico. O precursor desses modelos de ciclagem de $\mathrm{pH}$ foi FEATHERSTONE ${ }^{34}$ (1986), que se baseava em 6 horas de desmineralização a 37 C em solução contendo 2.0 mM Ca, 2 mM PO4, 74.0 mM acetato pH 4.3. e 17 horas de remineralização a 37 C em solução em saliva artificial, durante 14 dias consecutivos, com exceção do final de semana onde os corpos de prova eram apenas imersos em saliva artificial.

Os modelos de ciclagem de $\mathrm{pH}$ em geral, no entanto, foram extensamente criticados por TEN CATE ${ }^{116}$ (1990). Este desabono se deu, segundo o autor, aos métodos empregados não incluir enzimas, impedindo de se realizar uma correlação 
entre, por exemplo, substâncias como o NaF e que contenham o MFP. Além disso, os modelos se constituem apenas de íons inorgânicos desconsiderando, portanto, efeitos causados pelas proteínas salivares (componentes orgânicos salivares), difusão da película e placa bacteriana, inibição da mineralização e a formação de depósitos de flúor.

Outros trabalhos ${ }^{101,15}$, entretanto, afirmam haver correlação entre modelos de ciclagem de $\mathrm{pH}$, como o estabelecido por FEATHERSTONE ${ }^{34}$ (1996), com o desenvolvimento de lesões cariosas in vivo em situações de alto desafio cariogênico.

Vários outros recursos foram empregados com a finalidade de aproximar a condição experimental de escovação com a condição encontrada na cavidade oral. O equipamento simulador de escovação é dotado de um sensor de temperatura que viabiliza a escovação a uma temperatura de $37 \pm 2$ C através de um monitoramento preciso e livre de interferências externas. A importância do monitoramento da temperatura é explicada por HEATH; WILSON ${ }^{51}$ (1976). Segundo esses autores, os diferentes materiais restauradores (amálgama, ouro e resinas químicas) apresentaram comportamentos diferentes quando submetidos ao desgaste em temperatura ambiente ou a $37 \mathrm{C}$, de forma que sugerem que os testes sejam realizados a $37 \mathrm{C}$ para que se aproximem da condição oral. HARTE; MANL $\mathbf{Y}^{49}$ (1976) também indicam a utilização da temperatura de 37 C, segundo eles, a rigidez das cerdas das escovas dentais diminui em temperaturas mais elevadas quando em comparação à ambiente, por ação do calor, reduzindo em até $28 \%$ a sua capacidade abrasiva.

A amplitude da excursão dos movimentos de escovação varia na literatura de $15 \mathrm{~mm}^{3,51}$ a $85 \mathrm{~mm}^{97}$. A influência entre o comprimento do movimento da escova 
dental com o desgaste é explicada por HEATH; WILSON ${ }^{51}$ (1976). Em seu trabalho, quando utilizaram o comprimento de $45 \mathrm{~mm}$ associado a um dentifrício, o desgaste foi significantemente maior em relação ao comprimento de $15 \mathrm{~mm}$. Por outro lado, na ausência do dentifrício, o desgaste foi menor para o comprimento de $45 \mathrm{~mm}$ em relação ao de $15 \mathrm{~mm}$. Ainda, em percursos de $15 \mathrm{~mm}$, o desgaste foi igual quando o teste foi ou não associado ao dentifrício. Isto porque excursões maiores fazem diminuir o contato entre as cerdas e o espécime e, em excursões menores, desgastam os espécimes por ruptura de partículas. A excursão dos movimentos de escovação, para o presente estudo, foi ajustada em $20 \mathrm{~mm}^{118}$, por se tratar de uma amplitude próxima da condição oral e também compatível com o tamanho do espécime $(5 \mathrm{~mm} \times 3 \mathrm{~mm})$.

A carga aplicada sobre os espécimes durante a escovação também pode exercer forte influência sobre o desgaste, esta correlação é constatada no trabalho realizado por STOOKEY; MUHLER ${ }^{113}$ (1968). Os autores submeteram esmalte e dentina à teste de escovação simulada ao aumento progressivo da carga exercida pela escova, variando de 75 a $300 \mathrm{~g}$, e obtiveram aumento progressivo do desgaste para os dois substratos. Esses dados vêm de encontro aos obtidos por HEATH; WILSON $^{51}$ (1976), onde sugerem que o aumento na carga de escovação leva a uma maior perda de material e que existe um limite de carga até o qual a escova irá exercer a sua função adequadamente, $7 \mathrm{~N}$. Acima deste valor ocorre um declive dos valores de desgaste, provavelmente devido ao "envergamento" das cerdas. O que se nota na literatura é uma margem grande do valor de carga utilizada, variando de $75 g^{113,3}$ a $700 g^{51}$. Valores intermediários foram utilizados por uma série de outros pesquisadores, DE GEE; TEM HARKEL-HAGENAAR; DAVIDSON ${ }^{21}$ (1985) 
utilizaram 125g, WANG ${ }^{119}$ (2001) e GARCIA $^{39}$ (2001) 200g, BUCHALA; ATTIN; HELLWIG $^{11}$ (2000) utilizaram carga de $2.75 \mathrm{~N}$ e TURSSI $^{18}$ (2001), 300g, sendo este último valor o adotado para o presente estudo, uma vez que foram empregadas máquinas de escovação semelhantes.

A preocupação com o tipo de diluente utilizado em associação ao dentifrício iniciou-se em 1972, por ASHMORE; VAN ABBE; WILSON ${ }^{3}$, que testaram a resistência ao desgaste de blocos de dentina ao dentifrício (a base de carbonato de cálcio) associado a dois diluentes, a água e o carboximetilcelulose. O resultado deste estudo demonstrou não haver diferença de desgaste quando da escolha destes dois diluentes. Em 1976, HARTE; MANLY ${ }^{49}$ também avaliaram o diluente utilizado em ensaios de escovação. Concluíram não haver diferença no desgaste entre o uso da saliva artificial e o carboximetilcelulose, entretanto, quando utilizaram a glicerina como diluente, notaram uma queda de $88 \%$ na capacidade de desgaste. Provavelmente, a sua viscosidade inibiu o potencial de abrasão do dentifrício. Quanto à concentração, notaram haver significante relação com a capacidade de desgaste, pois quanto mais diluído o abrasivo, menor o desgaste. GOLDSTEIN; LERNER $^{41}$ (1991) avaliaram a alteração de rugosidade de resinas híbridas quando submetidas à escovação somente com água deionizada e concluíram que, apesar de ter havido uma singela alteração na rugosidade, esta foi em termos estatísticos insignificante.

A suspensão que se utilizou para os testes deste trabalho consistiu de dentifrício dental (Colgate MFP) e água destilada deionizada ${ }^{118}$ na proporção de 1:2 em peso (ISO/TS 14569-1) ${ }^{54}$. Este dentifrício é considerado de média abrasividade ${ }^{8}$. 
Uma das grandes arbitrariedades sobre os testes in vitro de resistência ao desgaste utilizando ciclos de escovação simulada refere-se à sua "equivalência" cronológica in vivo. O número de ciclos que simula 1 ano de escovação na cavidade oral pode variar de $4.320^{61}$ a $16.000^{1}$. De acordo com SEXSON; PHILLIPS ${ }^{102}$ (1951) a cada escovação, o paciente costuma realizar 15 ciclos em uma determinada região. HEATH; WILSON ${ }^{51}$ (1976), testaram a resistência ao desgaste de uma série de materiais, entre eles, ouro, amálgama e resinas químicas. Quando os autores consideraram o maior percentual de desgaste obtido, da resina sem carga Sevriton, calcularam que nesses valores levaria cerca de 1750 anos para se abrasionar $1 \mathrm{~mm}$ de esmalte na cavidade oral ignorando é claro, outras influências como a mastigação. Assim, œncluem afirmando que 20.000 ciclos de escovação simulada equivaleriam a aproximadamente 10 meses in vivo. Esta mesma correlação foi aplicada por DE GEE; TEM HARKEL-HAGENAAR; DAVIDSON ${ }^{21}$ (1985), onde submetem resinas autopolimerizáveis a 2.600 ciclos por hora e relacionam este número a aproximadamente 1 mês de escovação na boca. Já JONES; FISHER; WILSON $^{58}$ (1985) relacionam o número de ciclos utilizados em seus estudos, 60.000 no total, a 18 meses de escovação in vivo. Para HARRINGTON et al. ${ }^{47}$ (1982) 240.000 ciclos equivalem a 4 anos de escovação intra-oral. A correlação mais crível parece ser a estabelecida por BUCHALLA; ATTIN; HELLWIG ${ }^{11}$ (2000). Segundo este trabalho, um paciente costuma realizar em média 4.5 ciclos de escovação por segundo, supondo que cada sextante é escovado por cerca de 20 segundos, 90 ciclos serão realizados até o término do procedimento, de forma que 6.000 ciclos de simulação equivaleriam a aproximadamente 1 a 2 meses na cavidade oral. No 
presente estudo, os materiais foram submetidos a 100.000 ciclos de escovação simulada equivalendo aproximadamente a 2 anos de escovação in vivo.

A comparação dos resultados obtidos através dos diversos trabalhos que utilizaram o teste de escovação simulada fica dificultada em decorrência das variações existentes em cada metodologia, uma vez que não existe uma completa padronização destes ensaios. A velocidade da escovação, amplitude do movimento, valor da carga aplicada, tipo e dureza das cerdas das escovas, controle de temperatura, abrasivo empregado, dentre outros, faz dificultar também a correlação exata entre número de ciclos de escovação e sua equivalência clínica em meses ou anos.

\section{2 - DISCUSSÃO DOS RESULTADOS OBTIDOS}

Os resultados da presente pesquisa indicaram haver influência da composição dos diferentes materiais no desgaste obtido (para alteração de massa e rugosidade superficial), enquanto que a ciclagem de $\mathrm{pH}$ influenciou de forma distinta os materiais avaliados porém, sem significância estatística. Em ordem crescente de alteração de massa o melhor comportamento dos materiais foi: Duceram Plus, Duceram Plus*, Variolink II*, Rely X, Variolink II, Art Glass*, Rely X*, Enforce, Art Glass, Enforce* (onde * indica ciclagem de $\mathrm{pH}$ ).

A porcelana odontológica apresentou o melhor comportamento frente à perda de massa em relação aos demais materiais avaliados (com ou sem ciclagem de pH), apresentando diferença estatisticamente significante. Em relação aos materiais resinosos avaliados, quanto à alteração de massa, pode se observar uma pequena 
superioridade do cimento resinoso Variolink II em relação à resina composta Artglass e o cimento Rely X, enquanto o Enforce apresentou o pior desempenho. Estes resultados podem ser explicados pela porcentagem em peso das suas partículas inorgânicas: Variolink II (73,4\%), Artglass (70,0\%), Rely X (67,5\%) e Enforce (66,0\%). A análise individual para a alteração de massa de cada material permite observar comportamentos distintos quando foram submetidos aos ciclos de $\mathrm{pH}$. A porcelana praticamente não apresentou diferenças, enquanto o cimento Variolink II e a resina composta Artglass apresentaram melhor comportamento quando submetidos a ciclagem de $\mathrm{pH}$. Os cimentos Rely $\mathrm{X}$ e Enforce apresentaram comprometimento maior quando expostos ao desafio cariogênico, o que pode demonstrar importante significado clínico, principalmente em regiões de maior acúmulo de placa na cavidade oral, como regiões proximais e cervicais. A variação dos valores encontrados foi de $0,34 \%$ a $1,85 \%$. Esses valores, de acordo com GOLDSTEIN; LERNER ${ }^{41}$ (1991), são considerados clinicamente insignificantes. Especificamente em relação aos cimentos resinosos, valores de alteração de massa após testes de resistência abrasiva, não foram encontrados na literatura. De acordo com SOLDERHOLM; MUKHERJEE; LONGMATE ${ }^{109}$ (1996) a armazenagem de materiais resinosos em água destilada provoca uma perda maior de massa em comparação à saliva artificial. Isto se explica pela penetração dos íons da saliva artificial para o interior da matriz resinosa. No atual estudo todos os espécimes foram armazenados em água destilada.

A Duceram Plus é uma porcelana odontológica, que graças a sua composição, é altamente friável e também resistente ao desgaste por abrasão ${ }^{105}$. Essas características Ihe conferem, até mesmo, a capacidade de causar desgaste em 
estruturas dentais antagonistas. A composição das porcelanas odontológicas aclara o seu desempenho superior aos demais testados, quanto à perda de massa após a escovação simulada.

No presente trabalho, notourse não haver correlação entre os resultados de alteração de massa e de rugosidade quando a comparação foi feita entre os mesmos grupos. Neste caso, provavelmente o número de amostras foi pequeno para detectar uma estatística confiável. Entretanto, quando todos os grupos (100 corpos de prova) foram comparados simultaneamente, as duas variações (massa e rugosidade) demonstraram correlação através do coeficiente de Pearson, $r=0,602 ; p=0,000$.

A correlação entre perda de massa e alteração da rugosidade superficial nem sempre é válida, pois de acordo com a dureza das partículas inorgânicas dos materiais pode ocorrer diminuição da rugosidade superficial após escovação simulada pelo desgaste concomitante das partículas com a fase orgânica. Outros aspectos diferenciais são a forma, o tamanho, a distribuição e porcentagem das partículas inorgânicas, pois uma vez que se inicia o desgaste, a rugosidade tende a se manter no mesmo patamar, independente da quantidade de estrutura perdida. $O$ tratamento químico das partículas também causa influência sobre o desgaste e rugosidade, uma vez que alguns materiais resinosos que apresentam liberação de flúor e não apresentam tratamento químico de algumas partículas de carga, tendem a apresentar maior desgaste e alteração de rugosidade pelo desprendimento precoce destas $^{* *}$.

KANTER; KOSKI; MARTIN ${ }^{61}$ (1982) fizeram estudos sobre a relação entre a perda de massa e alteração de rugosidade de resinas compostas (Prestige, Isopast, 
Exact, Concise e Profile) submetidas à escovação simulada. Em seus resultados, a resina Prestige apresentou a maior perda de massa e a menor alteração de rugosidade superficial. Também WANG ${ }^{119}$ (2001) e GARCIA ${ }^{39}$ (2001) submeteram materiais odontológicos restauradores a ciclos de escovação simulada e avaliaram seus desgastes através de alteração de massa e rugosidade superficial não encontrando correlação entre os dois critérios de avaliação.

Em ordem crescente de alteração de rugosidade o melhor comportamento dos grupos estudados foi: Duceram Plus, Duceram Plus*, Artglass*, Artglass, Variolink, Variolink*, Enforce, Rely X, Enforce*, RelyX* (onde * indica ciclagem de pH). A variação dos valores encontrados para alteração de rugosidade foi de $-0,031$ ìm a 0,288 ìm. A porcelana odontológica apresentou a menor alteração de rugosidade concatenada a redução do seu valor, seguido dos demais materiais que, apresentaram a rugosidade aumentada. Os cimentos Enforce e Rely X não apresentaram entre si diferença estatisticamente significante para alteração de rugosidade superficial, porém, diferenciaram-se do Variolink II, que apresentou alteração de rugosidade menos acentuada.

A análise individual de cada material quando submetidos ou não aos ciclos de $\mathrm{pH}$ demonstra comportamento distinto para alteração de rugosidade mantendo as mesmas características apresentadas para a alteração de massa.

O aumento de rugosidade superficial para materiais resinosos após serem submetidos a ciclos de escovação simulada é extensamente relatado ${ }^{21,47,119,39,80}$. A preocupação acerca da alteração de rugosidade é explicada por QUIRYNEM; BOLLEN $^{96}$ (1995), que detectaram que a rugosidade em superfícies intra-orais 
influencia definitivamente na colonização inicial de bactérias e também na sua futura estagnação.

As explicações para os diferentes resultados encontrados entre alteração de rugosidade para os materiais estudados e a sua interdependência em relação aos resultados de alteração de massa está diretamente relacionada aos vários vetores da sua composição que podem contribuir para o desgaste ${ }^{115,37,80}$, sendo eles principalmente, a carga inorgânica, a matriz orgânica e a relação entre essas duas fases.

\subsubsection{COMPOSICÃO - CARGA INORGÂNICA}

Testes de resistência ao desgaste de cimentos resinosos mostram que os materiais de micropartículas são mais resistentes à abrasão, devido a sua lisura superficial $^{68,37}$. Segundo FRAZIER; SARRET ${ }^{37}$ (1995) o cimento resinoso DualCement testado com partículas de 0.04 ìm em média apresentou o menor desgaste entre vários outros, a explicação dada pelos autores baseia-se no fato de não ocorrer grande protrusão de partículas (por elas serem pequenas) e estas, conseqüentemente, não rotacionarem através de sua matriz resinosa. O Variolink II, material de menor partículas de carga do presente estudo (0.7 ìm) e maior porcentagem de carga em peso $(73,4 \%)$, apresentou a menor alteração de massa e rugosidade em comparação aos demais avaliados, Enforce (1.0 ìm) e Rely X (1.5 ı̀m).

Através dos padrões perfilométricos obtidos neste estudo, detecta-se qualitativamente um perfil de rugosidade inicial para o material Variolink II (Figura 16) 
menor em relação aos demais cimentos testados, Enforce e Rely X (Figuras 14 e 15).

O presente resultado foi bastante similar ao encontrado por GUZMAN; MOORE; ANDRES ${ }^{44}$ (1997), que ao avaliarem o desgaste de cimentos resinosos (Variolink, Vita Duo e Enforce), em relação à espessura da linha de cimento, obtiveram (para espessura de 240ìm) desgaste maior do cimento Enforce em relação ao Variolink.

SUZUKI; LEINFELDER; SHINKAI ${ }^{15}$ (1995) especulam ainda que quanto menor o tamanho das partículas, o coeficiente de fricção do material apresenta considerável queda, acarretando em menor transferência de estresse para a porção orgânica, resultando em valores inferiores de desgaste.

Por outro lado, os cimentos resinosos de micropartículas de acordo com SUZUKI; LEINFELDER ${ }^{114}$ (1994) não resistem bem ao desgaste causado por contatos localizados (como os oclusais), devido à perda de partículas prépolimerizadas do material.

TORII et al. ${ }^{117}$ (1999) avaliaram a relação entre a porcentagem de carga inorgânica e a sua relação com a resistência ao desgaste de cimentos resinosos. Para tanto, cimentos resinosos híbridos experimentais contendo respectivamente 60 , 70, 72, 74 e 80\% de carga e compostos por partículas de bário e sílica, foram submetidos a teste de resistência ao desgaste. Os autores concluíram que quanto maior a porcentagem de carga maior a resistência ao desgaste do material, o que foi observado neste estudo onde o Variolink II (73,4\%) apresentou a maior resistência ao desgaste quando comparado aos demais cimentos do estudo, Enforce $(66,0 \%)$ e Rely X (67,5\%). 
Outro importante fator deve-se à distância entre as partículas de carga que também é relacionado ao desgaste das resinas compostas ${ }^{60}$. Esse referido trabalho demonstra que a matriz de resina desgasta-se igualmente quando compostas por partículas de variados tamanhos. Apenas quando a distância entre elas é menor que 0,1ìm existe a tendência desta matriz ser protegida pela carga. Neste caso, a explicação para um menor desgaste de materiais de micropartículas relacionourse à homogeneidade de sua superfície.

SUZUKI; LEINFELDER; SHINKAI ${ }^{115}$ (1995) avaliaram a resistência ao desgaste de vários cimentos resinosos em comparação a inlays de resina indireta (Charisma). Nos resultados, a resina indireta apresentou a menor alteração de rugosidade quando comparado a qualquer um dos cimentos testados (Adhesive Cement, Twinlook, DCR, Panavia 21, Fuji II LC). Isto se deu, pelo fato dos cimentos resinosos apresentarem menor quantidade de partículas inorgânicas por volume ${ }^{106}$, condição necessária para aprimorar suas características de manuseio e também reduzir a espessura da linha de cimento. Segundo SOUZA et al. ${ }^{112}$ (1995), o desgaste se dá basicamente na fase orgânica do material, esperando-se portanto, maior desgaste dos cimentos resinosos.

Apesar disso, SODERHOLM et al. ${ }^{10}$ (1984) fizeram uma interessante constatação: materiais que contém zinco, bário e estrôncio são solúveis em solução aquosa assim como os que contêm quartzo e sílica. Os vidros de bário eram especialmente menos estáveis que o quartzo. Ainda segundo o mesmo autor, em outro trabalho ${ }^{108}$, não houve em seis meses degradação significante da sílica e do bário de resinas compostas, porém esta é linearmente correlacionada ao tempo de armazenagem. Em 1996, SOLDERHOLM; MUKHERJEE; LONGNATE ${ }^{109}$ 
confirmaram através de pesquisa que partículas que contém bário são de fato extremamente instáveis, principalmente, quando armazenados em saliva artificial (em comparação à água destilada), suportando a hipótese de haver troca iônica entre o meio e a superfície de carga.

Como mencionado anteriormente, a resistência à abrasão de materiais resinosos depende diretamente dos vários segmentos de sua composição, porção inorgânica, matriz orgânica (que será logo mais discutida) e o que é pouco abordado na literatura, da interface entre partícula inorgânica e matriz orgânica ${ }^{63}$. A propagação de trincas nesses materiais se dá basicamente na sua porção orgânica e este fenômeno está intimamente relacionado ao fato da resistência à fratura da matriz resinosa ser inferior a força de união entre esta matriz e as partículas de $\operatorname{carga}^{63}$

LUO; LANNUTTI; SEGHI ${ }^{75}$ (1998) discorreram sobre a influência do grau de união entre as fases orgânica e inorgânica dos materiais em suas resistências. Segundo eles, o embricamento nanomecânico a partir de nanoporosidades criadas nas partículas inorgânicas demonstram adesão superior ao tratamento químico. SOLDERHOLM et al. ${ }^{110}$ (1984) descreve que o agente silano (entre a carga e a matriz) é passível de sofrer degradação hidrolítica e que esse processo pode ser acentuado pelo tratamento térmico (no caso de resinas indiretas) sendo, portanto, responsável pela ruptura prematura de suas partículas.

O que deve ser endossado em relação aos cimentos adesivos de maior concentração de carga por volume, é que algumas propriedades mecânicas podem ser melhoradas, no entanto, o material passa a ser mais viscoso e, durante a 
cimentação, cuidados em relação à vibração do material devem ser tomados para garantir adequado molhamento sobre a estrutura dental.

Ao se analisar os resultados e o perfil qualitativo do Artglass na figura 17, observa-se que a alteração entre as rugosidades antes e após os procedimentos de abrasão não se diferenciou em demasia. Este material apresentou neste estudo, comparado aos cimentos resinosos, menor alteração de rugosidade, confirmando resultados como os encontrados por SUZUKI; LEINFELDER; SHINKAI ${ }^{15}$ (1995).

Outros resultados foram obtidos por DIJKEN; STADIGH; MEURMAN²7 (1983), onde a escovação de compósitos de partículas médias e grandes, após terem passado por processo de acabamento, apresentaram aumento de rugosidade por exposição das suas partículas inorgânicas.

Entretanto, ao se comparar com resultados de CORRER SOBRINHO et al. ${ }^{18}$ (2001) que avaliaram a rugosidade do Artglass (dentre outras resinas indiretas), submetido a ciclos de escovação nota-se uma pequena discrepância. Os materiais submetidos à escovação (Targis, Artglass e Sculpture) apresentaram valores de rugosidade estatisticamente maiores quando não foram submetidos a qualquer tipo de polimento. No entanto, quando os materiais foram submetidos ao polimento, o Artglass não apresentou diferença estatisticamente significante para alteração de rugosidade. Uma possível explicação está na carga axial empregada pelos autores, de $200 \mathrm{~g}$ durante a escovação, quando comparada às $300 \mathrm{~g}$ empregadas na atual metodologia e ambém no reduzido número de ciclos, 30.000 em comparação a 100.000. HEATH; WILSON ${ }^{51}$ (1976) sugerem que cargas axiais maiores levam a maior perda de material e conseqüentemente maior alteração de rugosidade. 
Como já mencionado, a porcelana odontológica Duceram Plus apresentou, devido a suas características composicionais, resistência ao desgaste bastante aprimorada (Figura 18). No presente estudo, notourse uma irrisória perda de massa, após a escovação, aliado à diminuição da sua rugosidade. Segundo a análise em microscopia eletrônica de varredura sobre formato dos abrasivos que compõe o dentifrício empregado neste trabalho, tem-se que é arredondada e a maior parte apresenta formato irregular ${ }^{87}$. Sua distribuição é heterogênea e varia bastante de tamanho, com algumas partículas apresentando bordas agudas. Ao fim dos ensaios de escovação, constatourse entretanto, um "polimento" da superfície de porcelana causado pelos abrasivos do dentifrício (Figuras 31, 32 e 33).

Em trabalho de revisão de literatura realizado por BOLLEN; LAMBRECHTS; QUIRYNEN $^{9}$ (1997) sobre a rugosidade dos diferentes materiais restauradores, tiveram que as cerâmicas que apresentavam rugosidade inicial em torno de 3.0ìm e eram submetidos as mais diversas formas de polimento apresentavam decréscimo acentuado desses valores. Também quando WARD; TATE; POWERS ${ }^{120}$ (1995) avaliaram a rugosidade superficial de porcelanas após diversos procedimentos de acabamento e polimento, sendo eles: glazeamento; pontas diamantadas $135 \mathrm{~F}$ (30ìm), 135 EF (15ìm) e 135 UF (8ìm); sistema Enhance; sistema Flexi disc; sistema de polimento de porcelana Shofu dental; tiveram em todos os casos redução significante de rugosidade superficial. Os autores concluem, com base em seus resultados estatísticos, que as marcas comerciais e os tipos de porcelana não importaram para os resultados de rugosidade final, sendo que a realização do polimento foi o fator significante. 
Entretanto, RELDMAN; RIDÉM ${ }^{97}$ (1979) quando submeteram uma porcelana à escovação simulada por 10 horas, não perceberam mudanças significantes de intensidade de luz refletida, significando provavelmente a não alteração da sua rugosidade superficial, enquanto PATTERSON et al. ${ }^{89}$ (1992) verificaram aumento na rugosidade de porcelana desgastada e polida.

\subsubsection{COMPOSICÃOO-CARGA ORGÂNICA:}

A degradação da carga orgânica é definida como um processo de divisão onde polímeros se convertem em oligômeros e, em alguns casos, em monômeros. A degradação dos polímeros pode ocorrer por fatores térmicos, mecânicos ou químicos. Na química, a degradação da matriz resinosa pode ocorrer pela ação da água (hidrólise) ou de enzimas ${ }^{42}$. Esta água ou solventes penetram por fendas dos polímeros e provocam uma degradação química, ou seja, ocorre a perda de material dos polímeros, sendo esse processo classificado como erosão ${ }^{42}$. A progressiva degradação provoca "poros" na sua microestrutura por onde oligômeros ou monômeros residuais, enfim, produtos da degradação são liberados, levando à erosão e à perda de massa dos polímeros. Concomitantemente, o pH no interior desses poros passa a ser controlado por esses produtos de degradação.

WU; McKINNEY'124 (1982) avaliaram a influência química do etanol e ciclohexanona sobre as resinas por duas semanas e constataram a ocorrência de amolecimento da matriz de Bis-GMA diminuindo a sua resistência ao desgaste. Especula-se que isto tenha ocorrido pelo fato dos solventes terem penetrado e causado uma expansão da rede polimérica, facilitando a difusão de monômeros 
livres por ela. O mais preocupante é que a simples estocagem da matriz resinosa em água por um longo período pode interferir na sua resistência ao desgaste ${ }^{124}$.

FERRACANE; CONDON ${ }^{36}$ (1990) avaliaram o efeito da estocagem de compósitos em água e água + etanol. De acordo com seus achados em 3 horas a água foi capaz de remover $50 \%$ dos seus produtos de degradação e a água + etanol, 75\%. Após sete dias, 1.5 a $2.0 \%$ da massa inicial dos espécimes foi reduzida. Quando LEE; GREENER; MENIS ${ }^{70}$ (1995) armazenaram resinas compostas em 75\% etanol + água e em saliva artificial, perceberam não ter havido degradação dos materiais na saliva artificial mesmo após um período de 30 dias, no entanto, uma série de produtos foi detectada na segunda solução. GEURTSEN ${ }^{40}$ (1998) pressupõe que a difusibilidade da saliva artificial pela cadeia de polímeros seja inferior à do etanol.

FRAZIER; SARRETT ${ }^{37}$ (1995) não encontraram aumento significante de desgaste em alguns cimentos resinosos (Insure, Dualcement, Porcelite Dual Cure e Chameleon Mirage FLC) após estocá-los em água deionizada por períodos de 6 e 12 meses, no entanto, o Optec Luting Cement apresentou aumento de desgaste relacionado à esta estocagem por longo período. Os pesquisadores atribuem ao fato desse cimento ter pequena quantidade de carga por volume $(52 \%)$, associado ao tamanho médio de partícula relativamente grande $(1,4 \mathrm{ìm})$, esta combinação de fatores pode resultar em uma baixa proporção entre superfície de carga inorgânica e o volume de carga. Condição que gera aumento do espaço entre as cargas facilitando a difusão da água pela matriz orgânica. Esta degradação hidrolítica parece, segundo os autores, ocorrer mais intensamente nas proximidades das partículas de carga sendo, portanto, responsável pela sua ruptura. 
De acordo com DE GEE; HAGENAAR; DAVIDSON ${ }^{21}$ (1985), uma mesma matriz apresenta resistência ao desgaste superior quando incorporados por carga inorgânica, em relação à matriz pura. Isto também devido a sua superior eficiência de polimerização causada pela melhor dissipação de calor e luz para o interior do material.

Convém salientar que pelo fato de cimentos resinosos serem materiais caracterizados por apresentarem menor percentual volumétrico de partículas à resina aglutinante, quando comparados à resina composta restauradora, as características de desgaste da matriz orgânica devem ser especialmente consideradas.

KAWAI; IWAMI; EBISU ${ }^{63}$ (1998) compararam a resistência a abrasão de 7 resinas compostas experimentais, que tiveram seus monômeros resinosos modificados e obtidos através de misturas entre Bis-GMA, UDMA, TMPT, TEGDMA, quando submetidos à escovação simulada, através da perda de massa. Seus resultados demonstraram que os materiais a base de Bis-GMA exibiram maior desgaste quando comparados com UDMA ou TMPT, e que, este desgaste tende a diminuir com o aumento da proporção de TEGDMA na sua associação.

Este mesmo trabalho afirma ainda que o grau de polimerização dos materiais a base de Bis-GMA aumentou quando se aumentou a proporção de TEGDMA. Sabese que quanto menor o grau de polimerização de um material resinoso, inferior as suas propriedades físicas e, conseqüentemente, mais susceptíveis à abrasão63. Esses achados vêm de encontro com os de ASMUSSEN; PEUTZFELDT ${ }^{7}$ (1998) que demonstraram haver influência da matriz orgânica nas propriedades mecânicas dos compósitos, apresentando de forma geral maior resistência quando compostos, 
neste caso, por UEDMA. Afirmam também haver dificuldade em se interpretar resultados de resistência abrasiva de diversos materiais por existir outras características, principalmente relacionadas à carga inorgânica, que interferem no resultado final.

Todos os cimentos do presente estudo possuem matriz orgânica formada basicamente por Bis-GMA e TEGDMA. A relação de concentração entre esses dois monômeros não foi fornecida pelos respectivos fabricantes. Poder-se-ia especular que fatores relacionados à carga inorgânica tiveram influência na resistência ao desgaste dos materiais aqui estudados assim como, as diferentes concentrações entre seus monômeros resinosos (Bis-GMA e TEGDMA).

Segundo CARVALHO et al. ${ }^{16}$ (1996) ao inserirmos a resina composta em uma cavidade e polimerizá-la, dá-se início ao duelo entre a contração de polimerização e estrutura dental. O relaxamento desse estresse é atenuado através da posterior sorção de água pela resina, uso de resinas de polimerização mais lenta (químicas) e pela manutenção do Fator-C o mais baixo possível. A configuração cavitária em procedimentos de cimentação adesiva é extremamente desfavorável tanto para que ocorra a sorção de água como em relação ao fator configuração cavitária, uma vez que a superfície livre restringe-se à ínfima linha de cimento.

Por esse raciocínio, mais uma vez cabe endossar para o fato de que aparentemente concentrações mais elevadas de TEGDMA em relação ao Bis-GMA parecem aprimorar algumas características mecânicas do material resinoso, porém, uma concentração muito elevada desse monômero (TEGDMA) está associada à descoloração intrínseca ${ }^{5}$ e também ao maior índice de contração de polimerização ${ }^{4}$. Assim, os monômeros resinosos e suas concentrações, especificamente no caso 
dos cimentos resinosos, devem ser criteriosamente avaliados de forma que equilibrem as características mecânicas, físicas e biológicas necessárias.

Em relação ao desempenho do Artglass quanto a alteração de rugosidade, trata-se de um polividro cuja parte orgânica é composta de metacrilatos multifuncionais em combinação a monômeros bifuncionais, formando uma matriz entrelaçada (crosslinked). É um material que utiliza uma unidade de conversão que combina uma intensa luz visível (320 a 500nm) ao calor ${ }^{64}$. Para elevar o potencial de polimerização, essa unidade utiliza pulsos de alta intensidade de luz visível (20ms) aliada a intervalos de ausência de luz (80ms), o que de acordo com o fabricante, permite um relaxamento do material aumentando a disponibilidade para que grupos metacrilatos não reagidos sofram a conversão. Mais, além dos dimetacrilatos bifuncionais o Artglass contém metacrilatos multifuncionais que oferecem até 6 grupos reativos.

\section{3 - INFLUÊNCIA DOS CICLOS DE pH}

Embora a realização da ciclagem de $\mathrm{pH}$ não tenha apresentado influência estatística para os materiais avaliados, a análise dos resultados numéricos para perda de massa e alteração de rugosidade, determinou comportamentos distintos dos materiais. A porcelana Duceram Plus apresentou a menor influência para os dois testes quando submetida ou não à ciclagem de $\mathrm{pH}$, enquanto a resina Artglass e o cimento Variolink II apresentaram melhores comportamentos quando foram ciclados $(\mathrm{pH})$. Por outro lado, Os cimentos Rely X e Enforce apresentaram influência negativa quando submetidos aos ciclos de $\mathrm{pH}$. 
No trabalho de ASMUSSEM ${ }^{6}$ (1984), onde polímeros experimentais a base de Bis-GMA e TEGDMA foram testados em relação a condições ácidas de armazenamento, notou-se considerável queda na dureza desses monômeros.

Esta alteração na dureza dos materiais relaciona-se, segundo o autor, com os parâmetros de solubilidade das matrizes. Em outras palavras, o ácido láctico que não influenciou na alteração da dureza dos polímeros tem seu parâmetro de solubilidade em diferente margem. Em relação ao TEGDMA, quando atinge até 50\% da concentração do polímero, este se mostrou menos suscetível à ação dos ácidos. Isto se deve à mudança do seu parâmetro de solubilidade, causado pela presença do diluente.

Os resultados do presente trabalho demonstraram não ter havido relação estatisticamente significante entre a resistência à abrasão dos materiais estudados quando, previamente à escovação simulada, foram ou não submetidos a ciclos dinâmicos de $\mathrm{pH}$. Isto pode ser notado através da silhueta dos seus traçados qualitativos (Figuras 14,15,16,17 e 18).

Estes resultados estão de acordo com os encontrados por PEREIRA et al. ${ }^{91}$ (2002), que ao avaliar a alteração de rugosidade em materiais restauradores, entre eles, as resinas compostas A110 e Suprafill submetidos à ciclagem de pH não apresentaram diferenças significantes quando comparados ao baseline. Também BUCHALLA; ATTIN; HELLWIG ${ }^{11}$ (2000) ao avaliar a resistência ao desgaste de diversos cimentos (quando submetidos a condições de acidez), concluíram que os cimentos resinosos, com exceção do C\&B Metabond que apresentou pequena alteração, foram os únicos materiais não afetados pela influência de condição de acidez. De acordo com os resultados encontrados, esses autores concluem que 
apenas os materiais que apresentam reação ácido-base (ionômeros de vidro, compômeros e ionômeros modificados por resina) têm desgastes mais acentuados aos baixos valores de pH. EISENBURGER; ADDY; ROBBACH ${ }^{29}$ (2003) avaliaram a susceptibilidade de um cimento resinoso (Dual Cement) se desintegrar na presença do ácido cítrico (pH 3,0). Concluíram não haver diferença estatisticamente significante na alteração de rugosidade após 7 dias de imersão em ácido cítrico quando comparado à 7 dias de imersão em soro fisiológico.

Quando OLEA et al. $^{83}$ (1996) analisaram a liberação de produtos de degradação de resinas compostas, concluíram que o bisfenol - A e os oligômeros foram amplamente liberados pela hidrólise tanto em meio alcalino $(\mathrm{pH} 13)$ como em meio ácido $(\mathrm{pH} 1)$.

PANZERI et al. ${ }^{87}$ (1978) recomendam valores de $\mathrm{pH}$ para dentifrícios entre 5,0 e 10,5. Segundo esses autores, o pH pode interferir de maneira acentuada na ação do dentifrício, principalmente quanto à ação dos detergentes, que são componentes básicos desses produtos. Esses detergentes podem ser de 4 tipos ${ }^{86}:$ 1) aniônico desenvolve sua atividade quando o meio é alcalino. 2) catiônico - desenvolve sua atividade em meio ácido 3) não iônico - não ionozáveis e 4) anfótero - comportamse em função do meio. Como propriedade característica, os detergentes aniônicos são excelentes agentes de limpeza, os catiônicos usados como anti-sépticos e os não iônicos, como espumantes.

No dentifrício utilizado para este trabalho, Colgate, apresenta-se em sua composição o Lauril Sulfato de Sódio, que baseado no trabalho de PANZERI et al. ${ }^{86}$ (1978) é do tipo aniônico e, portanto, suas potencialidades são desenvolvidas em 
meio alcalino. Essas características provavelmente não influenciaram nos resultados do presente trabalho.

\section{4- OBSERVACÕES MICROSCÓPICAS OBTIDAS}

A microscopia eletrônica de varredura indicou diferenças entre as características das superfícies dos cimentos resinosos antes e após a escovação simulada. Estas características parecem estar principalmente relacionadas às partículas de carga dos materiais em estudo.

No caso do cimento Enforce (Figura 19) nota-se, após a escovação (Figura 20), a presença de estrias, fruto dos repetitivos e unidirecionais movimentos de vai e vem, realizada pela cerda de escovas dentais ${ }^{1}$, sendo verificada também o desprendimento de partículas inorgânicas (Figuras 20 e 21).

O Rely X (Figura 22) apresenta-se após a escovação (Figuras 23 e 24), com uma matriz mais irregular expondo parcialmente algumas das suas partículas inorgânicas e também desprendimento das mesmas.

Também o Variolink II (Figura 25) apresentou alteração superficial qualitativa após ciclos de escovação (Figuras 26 e 27), o desprendimento parcial de carga inorgânica pode ser observado pelas suas fotografias finais. Constata-se inexpressiva alteração na aparência da matriz orgânica principalmente quando comparados aos demais cimentos deste estudo.

A presença de bolhas pôde ser observada para os três cimentos resinosos avaliados. A explicação se dá pelo fato de tratar-se de materiais que foram 
manipulados através do sistema pasta a pasta, ficando impossível impedir a incorporação de bolhas durante esse procedimento.

A resina composta indireta (Figura 28) apresentou ruptura e desprendimento de algumas partículas inorgânicas (Figuras 29 e 30). Ao comparar a foto inicial com as finais, observa-se na primeira, uma aparência rachurada da matriz orgânica obtida presumivelmente através do processo de acabamento.

Acredita-se que o desgaste dos compósitos se dá basicamente em duas distintas fases: inicialmente, a matriz resinosa sofre uma abrasão seletiva, que leva à exposição e protrusão das suas partículas inorgânicas e, posteriormente, ao permanecer o processo abrasivo, a ruptura definitiva dessas partículas ${ }^{76}$. Esses padrões parecem ter sido descritos nas análises das fotografias aqui obtidas.

A análise microscópica da porcelana revelou uma superfície homogênea e lisa, antes e principalmente após os procedimentos de abrasão (Figuras 31, 32 e 33), justificando os baixos valores de Ra que foram encontrados em relação aos demais grupos do estudo (Figura 18). Ao se observar imagens onde ocorreu e não a ciclagem de $\mathrm{pH}$, não se detecta qualitativamente diferença significante entre as superfícies. WARD; TATE; POWERS ${ }^{120}$ (1995) também constataram através da análise microscópica (MEV 350X) superfície extremamente lisa após procedimento de polimento.

HAYASHI et al. ${ }^{50}$ (2000) e KRAMER; FRAKENBERGER ${ }^{66}$ (2000) encontraram em suas fotomicrografias de porcelanas (de pacientes) a manifestação de uma série de trincas e rachaduras ao longo da superfície, após apenas alguns meses de acompanhamento; esta característica não foi apresentada nas figuras do presente 
trabalho, uma vez que estas superfícies não foram submetidas à carga mecânica, como usualmente ocorre na cavidade oral.

\section{5 - DISCUSSÃO COM TRABALHOS IN VIVO}

Nota-se uma certa (e justificável) inquietação, por parte dos pesquisadores, em aceitar que testes laboratoriais possam reproduzir o complexo processo de desgaste que ocorre na cavidade oral ${ }^{72}$. HARRINGTON et al. ${ }^{47}$ (1982) já indagavam sobre os diferentes processos de desgaste que ocorrem in vivo e afirmavam que estes poderiam variar de indivíduo para indivíduo e também de localização para localização dentro de uma mesma cavidade oral. Por exemplo, abrasão por escovação deve ter efeito maior em dentes anteriores enquanto que a carga mastigatória atua mais enfaticamente na região posterior.

Assim, as principais dificuldades em se realizar trabalhos clínicos relacionamse: ao tempo envolvido para a finalização do experimento ${ }^{51}$; à cooperação do paciente e sua concordância com o estudo ${ }^{84}$; e à dificuldade de interpretação dos dados diante de inúmeras variáveis que se pode encontrar (como hábitos dos pacientes) ${ }^{84}$.

Talvez diante dos contratempos citados, poucos trabalhos clínicos e principalmente longitudinais foram encontrados sobre cimentos resinosos e os materiais utilizados como controle no presente trabalho.

Em 1992, WENDT; LEINFELDER ${ }^{123}$ publicaram uma avaliação clínica de 3 anos de inlays de resinas compostas indiretas. As avaliações foram feitas através de inspeções clínicas diretas, fotografias e moldagens com silicona de adição que foram 
posteriormente avaliados em microscopia eletrônica de varredura. A maior parte das restaurações apresentou avaliação excelente ou aceitável ao longo de 36 meses. Não houve neste período diferenças estatísticas entre o desgaste de inlays fotopolimerizadas e inlays que, além de fotopolimerizadas, também receberam tratamento térmico.

Em análises microscópicas de 1 e 3 anos, esses autores perceberam um desgaste da matriz orgânica para inlays fotoativadas. Em contraste, as inlays foto e termoativadas também apresentaram desgaste, no entanto, a sua matriz orgânica se mostrou mais contígua.

Esses achados se relacionam com trabalhos laboratoriais ${ }^{121}$ onde a microdureza de resinas fotoativadas se mostrou inferior às que foram foto e termoativadas. Também, DE GEE et al. ${ }^{22}$ (1990) propõe que o tratamento térmico provoca um processo de enrijecimento reduzindo o estresse entre a carga e a matriz, o que contribui para o aumento da sua resistência ao desgaste.

No atual trabalho, o comportamento da resina indireta Artglass (ativada por luz e calor) se mostrou, em termos de alteração de rugosidade, superior aos cimentos resinosos de ativação física e química.

Recentemente, HAYASHI et al. $^{50}$ (2000) publicaram seus resultados de avaliação clinica (moldagens em MEV e visualização direta) de inlays de cerâmica após acompanhamento de 8 anos. Após 1 ano de controle, já se notava microfraturas da porcelana. Em 2 anos, outras fraturas foram se propagando e em 4 anos, as irregularidades na porcelana se tornaram mais severas e as trincas começaram a se unir. Os autores perceberam que em seis anos (através da MEV) haviam microfraturas nas margens das restaurações em $55 \%$ dos casos, desgaste 
do material restaurador em $19 \%$ e desgaste do cimento resinoso em $41 \%$ das restaurações. Depois de mais 2 anos (ou seja, após 8 anos de acompanhamento), houve desgaste em $36 \%$ das restaurações e no cimento resinoso em $74 \%$ dos casos (ao longo de toda a margem). Houve um acentuado desgaste no período de 6 a 8 anos acompanhado pelo aumento das microfraturas das restaurações. A longevidade das restaurações caiu de 92\% para 80\% em 2 anos (de 6 para 8 anos).

Os autores desse trabalho especulam que a adesão dos cimentos foi se tornando fraca por constantes forças mastigatórias e alertam dizendo ser indispensável o acompanhamento dos procedimentos clínicos. ISIDOR; BRONDUM $^{57}$ (1995) também publicaram um controle de 57 meses de inlays de porcelana e constataram que cerca de $50 \%$ das restaurações avaliadas (25 no total) falharam durante o período de observação. Dessas falhas, a maior parte por fratura do material.

O trabalho clínico de OSBORNE et al. ${ }^{84}$ (1978) comprovou haver significante diferença na deterioração de diversos cimentos quando observado em diferentes pacientes. A perda de material foi consideravelmente maior para alguns indivíduos. Além disso, os resultados clínicos apresentaram desgaste muito maior dos cimentos quando comparados aos trabalhos in vitro. Os autores atribuem isso às falhas em se detectar constituintes orgânicos que também são lançados sobre os cimentos. KRAMER; FRANKEMBERGER ${ }^{66}$ (2000) que avaliaram o desempenho clínico de cimentos resinosos sob inlays de cerâmica por 6 anos obtiveram como resultados: desgaste na margem em 32\% das restaurações após 6 meses e em 65\%, após 72 meses. A abrasão do cimento foi mais intensa no primeiro ano de avaliação. 
Especificamente no caso dos cimentos resinosos, quando se comparam resultados de trabalhos laboratoriais e clínicos, percebe-se um desempenho menos promissor desses materiais in vivo.

Segundo DE GEE et al. ${ }^{23}$ (1996) e LARSEN; MUNKSGAARD ${ }^{69}$ (1991) esterazes e enzimas da saliva também parecem atacar a matriz de resina de compósitos liberando ácido metracrílico. Estas causam amolecimento das superfícies de compósitos após $48 \mathrm{~h}$ à sua exposição, o que pode explicar o aumento dos desgastes in vivo. MAIR ${ }^{77}$ (1989) assegura que mudanças de temperatura de 6 a $60^{\circ} \mathrm{C}$, que são características das condições intrabucais, aumentaram a incidência de microtrincas nas resinas composta, esse mecanismo pode promover maior difusão dos fluidos intraorais pelos polímeros resinosos podendo acelerar a sua degradação.

SOLDRHOLM; MUKHERJEE; LONGNATE ${ }^{109}$ (1996) por sua vez, encontraram maior troca iônica entre partículas de carga de compósitos com saliva artificial em relação à água destilada (comumente utilizada nos testes laboratoriais). Ainda, os autores afirmam ter trocado as soluções mensalmente (tempo total do controle 12 meses) e alertam dizendo que em condições orais a saliva é continuamente produzida. A saliva artificial difere da saliva in vivo, principalmente na composição de proteínas, contribuindo para a formação de película adquirida e placa, o que poderia agravar os resultados. Mais, a relação entre o efeito de proteínas salivares em relação à interação da rugosidade superficial e sua energia livre de superfície também tem sido discutida. Baseado em QUIRINEM; BOLLEN ${ }^{96}$ (1995), mudanças de até 0,1ìm no Ra (roughness average) de superfícies de estruturas intra -orais não se relaciona com a alteração do seu ângulo de contato. Entretanto, variações 
maiores que $0,1 \mathrm{ìm}(\mathrm{Ra})$ se relacionam diretamente ao ângulo de contato inicial do material: se o ângulo de contato inicial é menor que $60^{\circ}$ (como o esmalte), o aumento de rugosidade causará diminuição deste ângulo; se o ângulo de contato inicial é maior que $86^{\circ}$, o aumento de rugosidade acarretará no aumento deste ângulo; entre os ângulo de $60^{\circ}$ e $86^{\circ}$, o aumento de rugosidade não provoca efeito na mudança do ângulo de contato.

A importância clínica desses parâmetros está no fato de justificarem as diferenças entre quantidades de placa encontradas em diferentes porções de polímeros em uma mesma cavidade oral $^{96}$, podendo acelerar o desgaste de uma área em detrimento a outra.

Por outro lado, os cimentos resinosos de partículas menores, que na maior parte dos ensaios laboratoriais de resistência abrasiva demonstram resultados superiores aos híbridos, como nos resultados do presente estudo, não resistem bem ao desgaste causado por contatos localizados (como os oclusais), devido à perda de partículas pré-polimerizadas do material ${ }^{114}$. Este fator também poderia clinicamente contribuir para a aceleração do seu desgaste.

Além dos fatores externos de desgaste dos cimentos, ação de ácidos, enzimas salivares, escovação, abrasão pelo bolo alimentar, hábitos do paciente e mastigação, clinicamente a hidrólise desses materiais e por conseqüência disso, a degradação de cimentos resinosos, pode acontecer também por fatores "internos", contribuindo para a discrepância entre resultados in vivo e in vitro. Sabe-se que os cimentos resinosos são associados aos sistemas de união (adesivos dentinários) quando empregados clinicamente. A compatibilidade entre sistemas de união 
autocondicionantes e resinas de polimerização lenta, como os cimentos resinosos químicos ou duais, também é alvo de discussão na literatura ${ }^{100}$.

De acordo com estudos de SANARES et al. ${ }^{99}$ (2000) e SANARES et al. ${ }^{100}$ (2001) ocorre uma interação entre monômeros ácidos não polimerizados da camada superficial do adesivo, provavelmente inibida pelo oxigênio, com as aminas terciárias presentes nesses materiais resinosos, iniciando-se uma reação ácido-base. Quando esses dois componentes reagem, forma-se compostos de amina quaternária que não são ativos para a formação de radicais livres, prejudicando a conversão dos cimentos $^{81}$. Além disso, as aminas quaternárias são solúveis em água.

Como já foi visto, a conversão inadequada dos cimentos resinosos é um dos fatores que causa aumento da sua susceptibilidade à degradação, por enfraquecer as suas características físicas e mecânicas.

Sem dúvida, uma das vantagens em se realizar estudos laboratoriais está na maior simplicidade em se isolar uma determinada condição, por exemplo, testar resistência ao desgaste por ação da escovação. Entretanto, JONES; JONES; WILSON$^{59}$ (1972) enfatizam sabiamente que os resultados de qualquer teste laboratorial servem para predizer o comportamento de um determinado material sob uma determinada condição, mas os resultados só podem ser confirmados depois de avaliados por longos períodos em cavidade oral. 
7-CONCLUSÕES 


\section{7-CONCLUSÕES}

De acordo com os resultados obtidos no estudo proposto, conclui-se que:

1- A porcelana Duceram Plus não foi influenciada pela ciclagem de $\mathrm{pH}$ e, apresentou o melhor comportamento frente à alteração de massa e rugosidade superficial após teste de escovação simulada.

2- Entre os materiais resinosos, o Artglass e o Variolink II apresentaram os melhores comportamentos para alteração de massa e rugosidade superficial, seguido do Rely X e Enforce.

3- A ciclagem de pH não apresentou diferenças significativas nos resultados intramateriais porém, determinou comportamentos distintos intermateriais. 
ANEXOS 
ANEXO 1 - Quadro das médias das massas iniciais, médias das massas finais, diferença entre MF e MI, porcentagem da alteração de massa, médias das rugosidades iniciais, médias das rugosidades finais e a diferença entre $R F$ e $R I$ de todos os materiais e condições testadas

\begin{tabular}{|c|c|c|c|c|c|c|c|c|}
\hline$M$ & $\mathrm{CpH}$ & $M M I / g$ & $M M F / g$ & MF-MI & $M \%$ & MRI/ im & MRF/ìm & RF-RI \\
\hline$E$ & $\mathrm{~N}$ & 0,1258 & 0,1238 & $-0,0020$ & $-1,589$ & 0,098 & 0,313 & 0,215 \\
\hline$E$ & $\mathrm{~N}$ & 0,1182 & 0,1169 & $-0,0013$ & $-1,099$ & 0,114 & 0,288 & 0,174 \\
\hline$E$ & $\mathrm{~N}$ & 0,1161 & 0,1135 & $-0,0026$ & $-2,239$ & 0,065 & 0,271 & \begin{tabular}{|l|}
0,206 \\
\end{tabular} \\
\hline $\mathrm{E}$ & $\mathrm{N}$ & 0,1156 & 0,1134 & $-0,0022$ & $-1,903$ & 0,086 & 0,280 & 0,194 \\
\hline$E$ & $\mathrm{~N}$ & 0,1142 & 0,1118 & $-0,0024$ & $-2,101$ & 0,045 & 0,443 & 0,398 \\
\hline$E$ & $\mathrm{~N}$ & 0,1128 & 0,1106 & $-0,0022$ & $-1,950$ & 0,057 & 0,384 & \begin{tabular}{|l|}
0,327 \\
\end{tabular} \\
\hline$E$ & $\mathrm{~N}$ & 0,1177 & 0,1162 & $-0,0015$ & $-1,274$ & 0,062 & 0,232 & \begin{tabular}{|l|}
0,170 \\
\end{tabular} \\
\hline$E$ & $\mathrm{~N}$ & 0,1127 & 0,1112 & $-0,0015$ & $-1,330$ & 0,066 & 0,240 & 0,174 \\
\hline$E$ & $\mathrm{~N}$ & 0,1293 & 0,1274 & $-0,0019$ & $-1,469$ & 0,110 & 0,130 & 0,020 \\
\hline$E$ & $\mathrm{~N}$ & 0,1219 & 0,1201 & $-0,0018$ & $-1,476$ & 0,075 & 0,309 & \begin{tabular}{|l|}
0,234 \\
\end{tabular} \\
\hline$E$ & S & 0,1045 & 0,1033 & $-0,0012$ & $-1,148$ & 0,053 & 0,372 & 0,319 \\
\hline$E$ & S & 0,1319 & 0,1299 & $-0,0020$ & $-1,516$ & 0,049 & 0,276 & 0,227 \\
\hline$E$ & $\mathrm{~S}$ & 0,1102 & 0,1081 & $-0,0021$ & $-1,905$ & 0,042 & 0,316 & \begin{tabular}{|l|}
0,274 \\
\end{tabular} \\
\hline$E$ & S & 0,1190 & 0,1171 & $-0,0019$ & $-1,596$ & 0,055 & 0,271 & 0,216 \\
\hline$E$ & S & 0,1171 & 0,1140 & $-0,0031$ & $-2,647$ & 0,057 & 0,326 & 0,269 \\
\hline$E$ & $\mathrm{~S}$ & 0,1258 & 0,1228 & $-0,0030$ & $-2,384$ & 0,057 & 0,443 & \begin{tabular}{|l|}
0,386 \\
\end{tabular} \\
\hline$E$ & S & 0,1221 & 0,1194 & $-0,0027$ & $-2,211$ & 0,063 & 0,291 & 0,228 \\
\hline$E$ & S & 0,1168 & 0,1150 & $-0,0018$ & $-1,541$ & 0,063 & 0,327 & 0,264 \\
\hline $\bar{E}$ & $\mathrm{~S}$ & 0,1178 & 0,1159 & $-0,0019$ & $-1,612$ & 0,050 & 0,236 & \begin{tabular}{|l|}
0,186 \\
\end{tabular} \\
\hline$E$ & S & 0,1132 & 0,1110 & $-0,0022$ & $-1,943$ & 0,084 & 0,253 & 0,169 \\
\hline $\mathrm{R}$ & $\mathrm{N}$ & 0,1108 & 0,1088 & $-0,0020$ & $-1,805$ & 0,128 & 0,381 & 0,253 \\
\hline $\bar{R}$ & $\mathrm{~N}$ & 0,1094 & 0,1083 & $-0,0011$ & $-1,005$ & 0,138 & 0,394 & \begin{tabular}{|l|}
0,256 \\
\end{tabular} \\
\hline $\mathrm{R}$ & $\mathrm{N}$ & 0,1090 & 0,1077 & $-0,0013$ & $-1,192$ & 0,043 & 0,337 & 0,290 \\
\hline $\mathrm{R}$ & $\mathrm{N}$ & 0,1105 & 0,1088 & $-0,0017$ & $-1,538$ & 0,054 & 0,347 & 0,293 \\
\hline $\bar{R}$ & $\mathrm{~N}$ & 0,1152 & 0,1143 & $-0,0009$ & $-0,781$ & 0,117 & 0,252 & \begin{tabular}{|l|}
0,135 \\
\end{tabular} \\
\hline $\mathrm{R}$ & $\mathrm{N}$ & 0,1019 & 0,1008 & $-0,0011$ & $-1,079$ & 0,075 & 0,270 & 0,195 \\
\hline $\mathrm{R}$ & $\mathrm{N}$ & 0,1201 & 0,1188 & $-0,0013$ & $-1,082$ & 0,153 & 0,318 & 0,165 \\
\hline $\mathrm{R}$ & $\mathrm{N}$ & 0,1545 & 0,1526 & $-0,0019$ & $-1,229$ & 0,188 & 0,276 & \begin{tabular}{|l|}
0,088 \\
\end{tabular} \\
\hline $\mathrm{R}$ & $\mathrm{N}$ & 0,1042 & 0,1031 & $-0,0011$ & $-1,055$ & 0,174 & 0,415 & \begin{tabular}{|l|}
0,241 \\
\end{tabular} \\
\hline $\mathrm{R}$ & $\mathrm{N}$ & 0,1116 & 0,1101 & $-0,0015$ & $-1,344$ & 0,044 & 0,418 & 0,374 \\
\hline $\mathrm{R}$ & $\mathrm{S}$ & 0,1148 & 0,1130 & $-0,0018$ & $-1,567$ & 0,093 & 0,406 & 0,313 \\
\hline $\mathrm{R}$ & $\mathrm{S}$ & 0,1113 & 0,1093 & $-0,0020$ & $-1,796$ & 0,060 & 0,423 & \begin{tabular}{|l|}
0,363 \\
\end{tabular} \\
\hline $\mathrm{R}$ & S & 0,1126 & 0,1118 & $-0,0008$ & $-0,710$ & 0,119 & 0,391 & 0,272 \\
\hline $\mathrm{R}$ & $\mathrm{S}$ & 0,1192 & 0,1180 & $-0,0012$ & $-1,006$ & 0,063 & 0,240 & \begin{tabular}{|l|}
0,177 \\
\end{tabular} \\
\hline $\mathrm{R}$ & $\mathrm{S}$ & 0,1110 & 0,1083 & $-0,0027$ & $-2,432$ & 0,121 & 0,424 & \begin{tabular}{|l|}
0,303 \\
\end{tabular} \\
\hline $\mathrm{R}$ & S & 0,1105 & 0,1083 & $-0,0022$ & $-1,809$ & 0,058 & 0,420 & 0,362 \\
\hline $\mathrm{R}$ & S & 0,1150 & 0,1132 & $-0,0020$ & $-1,739$ & 0,043 & 0,372 & 0,329 \\
\hline$R$ & $S$ & 0,1118 & 0,1103 & $-0,0015$ & $-1,341$ & 0,156 & 0,395 & \begin{tabular}{|l|}
0,239 \\
\end{tabular} \\
\hline $\mathrm{R}$ & S & 0,1273 & 0,1252 & $-0,0021$ & $-1,649$ & 0,143 & 0,277 & 0,134 \\
\hline $\mathrm{R}$ & S & 0,1101 & 0,1083 & $-0,0018$ & $-1,634$ & 0,042 & 0,436 & 0,394 \\
\hline V & $\mathrm{N}$ & 0,1390 & 0,1369 & $-0,0021$ & $-1,510$ & 0,052 & 0,210 & 0,158 \\
\hline $\mathrm{V}$ & $\mathrm{N}$ & 0,1294 & 0,1273 & $-0,0021$ & $-1,622$ & 0,095 & 0,217 & 0,122 \\
\hline
\end{tabular}




\begin{tabular}{|c|c|c|c|c|c|c|c|c|}
\hline $\bar{V}$ & $\mathrm{~N}$ & 0,1305 & 0,1284 & $-0,0021$ & $-1,609$ & 0,083 & 0,208 & 0,125 \\
\hline$\overline{\mathrm{V}}$ & $\mathrm{N}$ & 0,1470 & 0,1455 & $-0,0015$ & \begin{tabular}{|l|}
$-1,020$ \\
\end{tabular} & 0,069 & 0,166 & 0,097 \\
\hline $\mathrm{V}$ & $\mathrm{N}$ & 0,1286 & 0,1273 & $-0,0013$ & $-1,010$ & 0,049 & 0,266 & 0,217 \\
\hline $\mathrm{V}$ & $\mathrm{N}$ & 0,1333 & 0,1320 & $-0,0013$ & $-0,975$ & 0,039 & 0,265 & 0,226 \\
\hline$\overline{\mathrm{V}}$ & $\mathrm{N}$ & 0,1425 & 0,1406 & $-0,0019$ & \begin{tabular}{|l}
$-1,333$ \\
\end{tabular} & 0,068 & 0,190 & 0,122 \\
\hline $\bar{V}$ & $\mathrm{~N}$ & 0,1356 & 0,1338 & $-0,0018$ & \begin{tabular}{|l|}
$-1,327$ \\
\end{tabular} & 0,030 & 0,151 & 0,121 \\
\hline $\mathrm{V}$ & $\mathrm{N}$ & 0,1320 & 0,1302 & $-0,0018$ & \begin{tabular}{|l|}
$-1,363$ \\
\end{tabular} & 0,060 & 0,247 & 0,187 \\
\hline$\overline{\mathrm{V}}$ & $\mathrm{N}$ & 0,1361 & 0,1338 & $-0,0023$ & \begin{tabular}{|l|}
$-1,689$ \\
\end{tabular} & 0,027 & 0,193 & 0,166 \\
\hline $\mathrm{V}$ & $S$ & 0,1394 & 0,1384 & $-0,0010$ & $-0,717$ & 0,034 & 0,166 & 0,132 \\
\hline $\mathrm{V}$ & $S$ & 0,1502 & 0,1484 & $-0,0018$ & \begin{tabular}{|l|}
$-1,198$ \\
\end{tabular} & 0,038 & 0,150 & 0,112 \\
\hline$\overline{\mathrm{V}}$ & $S$ & 0,1364 & 0,1351 & $-0,0013$ & \begin{tabular}{|l|}
$-0,953$ \\
\end{tabular} & 0,043 & 0,133 & 0,090 \\
\hline V & $S$ & 0,1422 & 0,1403 & $-0,0019$ & $-1,336$ & 0,026 & 0,131 & 0,105 \\
\hline $\mathrm{V}$ & $S$ & 0,1360 & 0,1348 & $-0,0012$ & \begin{tabular}{|l|}
$-0,882$ \\
\end{tabular} & 0,087 & 0,222 & 0,135 \\
\hline$\overline{\mathrm{V}}$ & $\mathrm{S}$ & 0,1411 & 0,1396 & $-0,0015$ & \begin{tabular}{|l|}
$-1,063$ \\
\end{tabular} & 0,069 & 0,195 & 0,126 \\
\hline V & $S$ & 0,1546 & 0,1536 & $-0,0010$ & $-0,646$ & 0,116 & 0,236 & 0,120 \\
\hline$\overline{\mathrm{V}}$ & $\mathrm{S}$ & 0,1396 & 0,1391 & $-0,0005$ & \begin{tabular}{|l|}
$-0,358$ \\
\end{tabular} & 0,032 & 0,159 & 0,127 \\
\hline$\overline{\mathrm{V}}$ & $\mathrm{S}$ & 0,1282 & 0,1261 & $-0,0021$ & \begin{tabular}{|l|}
$-1,638$ \\
\end{tabular} & 0,037 & 0,193 & 0,156 \\
\hline V & $S$ & 0,1372 & 0,1359 & $-0,0013$ & $-0,947$ & 0,137 & 0,233 & 0,096 \\
\hline $\bar{A}$ & $\mathrm{~N}$ & 0,1164 & 0,1155 & $-0,0009$ & \begin{tabular}{|l|}
$-0,773$ \\
\end{tabular} & 0,081 & 0,103 & 0,022 \\
\hline $\bar{A}$ & $\mathrm{~N}$ & 0,1101 & 0,1076 & $-0,0025$ & \begin{tabular}{|l}
$-2,270$ \\
\end{tabular} & 0,078 & 0,210 & 0,132 \\
\hline A & $\mathrm{N}$ & 0,1012 & 0,0983 & $-0,0029$ & $-2,865$ & 0,099 & 0,190 & 0,091 \\
\hline A & $\mathrm{N}$ & 0,0905 & 0,0888 & $-0,0017$ & \begin{tabular}{|l|}
$-1,878$ \\
\end{tabular} & 0,110 & 0,296 & 0,186 \\
\hline $\bar{A}$ & $\mathrm{~N}$ & 0,1195 & 0,1174 & $-0,0021$ & \begin{tabular}{|l}
$-1,757$ \\
\end{tabular} & 0,079 & 0,150 & 0,071 \\
\hline A & $\mathrm{N}$ & 0,0914 & 0,0902 & $-0,0012$ & \begin{tabular}{|l|}
$-1,312$ \\
\end{tabular} & 0,125 & 0,125 & 0,000 \\
\hline A & $\mathrm{N}$ & 0,1069 & 0,1042 & $-0,0027$ & \begin{tabular}{|l|}
$-2,525$ \\
\end{tabular} & 0,084 & 0,115 & 0,031 \\
\hline $\bar{A}$ & $\mathrm{~N}$ & 0,1059 & 0,1036 & $-0,0023$ & \begin{tabular}{|l|}
$-2,171$ \\
\end{tabular} & 0,134 & 0,147 & 0,013 \\
\hline $\mathrm{A}$ & $\mathrm{N}$ & 0,1008 & 0,0996 & $-0,0012$ & $-1,190$ & 0,085 & 0,192 & 0,107 \\
\hline A & $\mathrm{N}$ & 0,0948 & 0,0934 & $-0,0014$ & $-1,476$ & 0,089 & 0,176 & 0,087 \\
\hline $\bar{A}$ & S & 0,1043 & 0,1025 & $-0,0018$ & $-1,725$ & 0,081 & 0,118 & 0,037 \\
\hline $\mathrm{A}$ & $\mathrm{S}$ & 0,0933 & 0,0923 & $-0,0010$ & \begin{tabular}{|l|}
$-1,071$ \\
\end{tabular} & 0,086 & 0,140 & 0,054 \\
\hline A & $\mathrm{S}$ & 0,1045 & 0,1035 & $-0,0010$ & $-0,956$ & 0,076 & 0,087 & 0,011 \\
\hline $\bar{A}$ & $S$ & 0,1018 & 0,1004 & $-0,0014$ & \begin{tabular}{|l}
$-1,375$ \\
\end{tabular} & 0,106 & 0,113 & 0,007 \\
\hline $\mathrm{A}$ & $\mathrm{S}$ & 0,1059 & 0,1039 & $-0,0020$ & $-1,888$ & 0,117 & 0,165 & 0,048 \\
\hline A & $\mathrm{S}$ & 0,0995 & 0,0976 & $-0,0019$ & $-1,909$ & 0,091 & 0,209 & 0,118 \\
\hline $\bar{A}$ & S & 0,1033 & 0,1017 & $-0,0016$ & $-1,548$ & 0,098 & 0,116 & 0,018 \\
\hline A & $\mathrm{S}$ & 0,0916 & 0,0908 & $-0,0008$ & \begin{tabular}{|l}
$-0,873$ \\
\end{tabular} & 0,100 & 0,125 & 0,025 \\
\hline A & $\mathrm{S}$ & 0,1058 & 0,1043 & $-0,0015$ & $-1,417$ & 0,113 & 0,123 & 0,010 \\
\hline $\bar{A}$ & $\mathrm{~S}$ & 0,0951 & 0,0941 & $-0,0010$ & \begin{tabular}{|l|}
$-1,051$ \\
\end{tabular} & 0,077 & 0,112 & 0,035 \\
\hline $\mathrm{D}$ & $\mathrm{N}$ & 0,1549 & 0,1546 & $-0,0003$ & \begin{tabular}{|l|l}
$-0,193$ \\
\end{tabular} & 0,281 & 0,194 & $-0,087$ \\
\hline $\bar{D}$ & $\mathrm{~N}$ & 0,1406 & 0,1402 & $-0,0004$ & \begin{tabular}{|l|}
$-0,284$ \\
\end{tabular} & 0,074 & 0,052 & $-0,022$ \\
\hline $\bar{D}$ & $\mathrm{~N}$ & 0,1196 & 0,1191 & $-0,0005$ & \begin{tabular}{|l|}
$-0,418$ \\
\end{tabular} & 0,144 & 0,112 & $-0,032$ \\
\hline $\mathrm{D}$ & $\mathrm{N}$ & 0,1305 & 0,1299 & $-0,0006$ & \begin{tabular}{|l}
$-0,459$ \\
\end{tabular} & 0,125 & 0,118 & $-0,007$ \\
\hline $\bar{D}$ & $\mathrm{~N}$ & 0,1430 & 0,1430 & 0,0000 & 0,000 & 0,108 & 0,090 & $-0,018$ \\
\hline $\bar{D}$ & $\mathrm{~N}$ & 0,1232 & 0,1223 & $-0,0009$ & \begin{tabular}{|l|l}
$-0,730$ \\
\end{tabular} & 0,197 & 0,256 & 0,059 \\
\hline $\mathrm{D}$ & $\mathrm{N}$ & 0,1341 & 0,1335 & $-0,0006$ & $-0,447$ & 0,238 & 0,165 & $-0,073$ \\
\hline $\bar{D}$ & $\mathrm{~N}$ & 0,1305 & 0,1300 & $-0,0005$ & \begin{tabular}{|l|}
$-0,383$ \\
\end{tabular} & 0,112 & 0,067 & $-0,045$ \\
\hline $\bar{D}$ & $\mathrm{~N}$ & 0,1470 & 0,1465 & $-0,0005$ & \begin{tabular}{|l|}
$-0,340$ \\
\end{tabular} & 0,363 & 0,297 & $-0,066$ \\
\hline $\mathrm{D}$ & $\mathrm{N}$ & 0,1364 & 0,1362 & $-0,0002$ & $-0,146$ & 0,089 & 0,067 & $-0,022$ \\
\hline $\mathrm{D}$ & $\mathrm{S}$ & 0,1451 & 0,1443 & $-0,0008$ & \begin{tabular}{|l}
$-0,551$ \\
\end{tabular} & 0,176 & 0,084 & $-0,092$ \\
\hline $\bar{D}$ & $\mathrm{~S}$ & 0,1435 & 0,1430 & $-0,0005$ & $-0,348$ & 0,100 & 0,113 & 0,013 \\
\hline $\mathrm{D}$ & S & 0,1350 & 0,1345 & $-0,0005$ & $-0,370$ & 0,163 & 0,135 & $-0,028$ \\
\hline $\bar{D}$ & $\mathrm{~S}$ & 0,1454 & 0,1451 & $-0,0003$ & \begin{tabular}{|l|}
$-0,206$ \\
\end{tabular} & 0,219 & 0,181 & $-0,038$ \\
\hline $\bar{D}$ & $\mathrm{~S}$ & 0,1378 & 0,1368 & $-0,0010$ & $-0,725$ & 0,157 & 0,192 & 0,035 \\
\hline $\mathrm{D}$ & $\mathrm{S}$ & 0,1305 & 0,1300 & $-0,0005$ & \begin{tabular}{|l}
$-0,383$ \\
\end{tabular} & 0,210 & 0,221 & $-0,011$ \\
\hline
\end{tabular}




\begin{tabular}{|l|l|l|l|l|l|l|l|l|}
\hline $\mathrm{D}$ & $\mathrm{S}$ & 0,1638 & 0,1636 & $-0,0002$ & $-0,122$ & 0,099 & 0,086 & $-0,013$ \\
\hline $\mathrm{D}$ & $\mathrm{S}$ & 0,1651 & 0,1651 & 0,0000 & 0,000 & 0,187 & 0,099 & $-0,088$ \\
\hline $\mathrm{D}$ & $\mathrm{S}$ & 0,1242 & 0,1238 & $-0,0004$ & $-0,322$ & 0,152 & 0,089 & $-0,063$ \\
\hline $\mathrm{D}$ & $\mathrm{S}$ & 0,1361 & 0,1353 & $-0,0008$ & $-0,587$ & 0,095 & 0,049 & $-0,046$ \\
\hline
\end{tabular}

Onde $\mathrm{N}$ indica que não foi realizada a ciclagem de $\mathrm{pH}$ e $\mathrm{S}$ indica a sua realização

ANEXO 2 - Teste estatístico para alteração de massa (ANOVA e Tukey)

\begin{tabular}{|l|l|l|l|l|l|l|}
\hline \multicolumn{6}{|l|}{ Summary of all effects; design: 1 - Material; 2-pH cycles } \\
\hline Effect & df Effect & MS effect & df Error & MS Error & F & p=level \\
\hline 1 & 4 & 6,032958 & 90 & 0,152460 & 39,57074 & 0,000000 \\
\hline 2 & 1 & 0,051257 & 90 & 0,152460 & 0,33620 & 0,563480 \\
\hline 1 and 2 & 4 & 0,616474 & 90 & 0,152460 & 4,04351 & 0,004626 \\
\hline Tukey test; variable M\%; á=0,05; Interaction: 1 X2 & \multicolumn{5}{l|}{} \\
\hline Material & pH & Mean & 1 & 2 & 3 & 4 \\
\hline E & S & $-1,85030$ & XXXX & & & \\
\hline A & N & $-1,82170$ & XXXX & & & \\
\hline E & N & $-1,64300$ & XXXX & XXXX & & \\
\hline R & S & $-1,56830$ & XXXX & XXXX & & \\
\hline A & S & $-1,38130$ & XXXX & XXXX & XXXX & \\
\hline V & N & $-1,34580$ & XXXX & XXXX & XXXX & \\
\hline R & N & $-1,21100$ & & $X X X X$ & XXXX & \\
\hline V & S & $-0,97380$ & & & XXXX & \\
\hline D & S & $-0,36140$ & & & & XXXX \\
\hline D & N & $-0,34000$ & & & & XXXX \\
\hline
\end{tabular}

ANEXO 3 - Teste estatístico para alteração de Rugosidade (ANOVA e Tukey)

\begin{tabular}{|c|c|c|c|c|c|c|c|}
\hline \multicolumn{8}{|c|}{ Summary of all effects; design: 1 - Material; 2-pH cycles } \\
\hline \multicolumn{2}{|l|}{ Effect } & df Effect & MS effect & df Error & MS Error & $\mathrm{F}$ & $\mathrm{p}=$ level \\
\hline \multicolumn{2}{|c|}{1} & 4 & 0,295279 & 90 & 0,003864 & 76,41162 & 0,000000 \\
\hline \multicolumn{2}{|c|}{2} & 1 & 0,000812 & 90 & 0,003864 & 0,210190 & 0,647722 \\
\hline \multicolumn{2}{|l|}{1 and 2} & 4 & 0,009748 & 90 & 0,003864 & 2,522650 & 0,046394 \\
\hline \multicolumn{8}{|c|}{ Tukey test; variable M\%; á $=0,05$; Interaction: 1 X2 } \\
\hline Material & $\mathrm{pH}$ & Mean & 1 & 2 & 3 & 4 & 5 \\
\hline $\bar{D}$ & $\mathrm{~S}$ & $-0,033100$ & $\overline{X X X X}$ & & & & \\
\hline $\mathrm{D}$ & $\mathrm{N}$ & $-0,031300$ & $\mathrm{XXXX}$ & & & & \\
\hline A & $\mathrm{S}$ & 0,036300 & $\overline{X X X X}$ & $\overline{X X X X}$ & & & \\
\hline $\bar{A}$ & $\mathrm{~N}$ & 0,074000 & & $\overline{X X X X}$ & $\overline{X X X X}$ & & \\
\hline $\mathrm{V}$ & $\mathrm{S}$ & 0,119900 & & $\mathrm{XXXX}$ & XXXX & & \\
\hline $\mathrm{V}$ & $\mathrm{N}$ & 0,154100 & & & $\overline{X X X X}$ & $\overline{X X X X}$ & \\
\hline $\mathrm{E}$ & $\mathrm{N}$ & 0,211200 & & & & $\overline{X X X X}$ & $\overline{X X X X}$ \\
\hline $\mathrm{R}$ & $\mathrm{N}$ & 0,229000 & & & & XXXX & XXXX \\
\hline$E$ & $S$ & 0,253800 & & & & & $\mathrm{XXXX}$ \\
\hline $\mathrm{R}$ & $S$ & 0,288600 & & & & & $X X X X$ \\
\hline
\end{tabular}


REFERÊNCIAS BIBLIOGRÁFICAS 


\section{REFERÊNCIAS BIBLIOGRÁFICAS*}

1) AKER, J.R. New composite resins: comparison of their resistance to toothbrush abrasion and characteristics of abraded surfaces. J. Amer. dent. Ass., v.105, n.4, p.633-35, Oct. 1982.

2) ANUSAVICE, K. J. Philips science of dental materials. 10 ed. W.B, Saunders Co, 1996.

3) ASHMORE, H.; VAN ABBE, N.J.; WILSON, S.J. The measurement in vitro of dentine abrasion by toothpaste. Brit. dent. J., v.133, n.2, p.60-6, July 1972.

4) ASMUSSEN, E. Composite restorative resins. Composition versus wall-to-wall polymerization contraction. Acta Odont. Scand., v.33, p.337-44, 1975.

5) ASMUSSEN, E. Factors affecting the color stability of restorative resins. Acta Odont. Scand., v.41, p.11-8, 1983.

6) ASMUSSEN, E. Softening of Bis-GMA - based polymers by ethanol and by organic acids of plaque. Scand. J. dent. Res., v.92, p.257-61, 1984.

7) ASMUSSEN, E.; PEUTZFELDT, A. Influence of UEDMA BisGMA and TEGDMA on selected mechanical properties of experimental resin composites. Dent. Mater., v.14, n.1, p.51-6, 1998.

8) BASTOS, J. R. M. et al. Contribuição à posologia de dentifrícios pelo cirurgião - dentista no Brasil. Rev. gaúcha Odont., v.33, n.3, p.202-5, jul../set. 1985. 


\section{Referências Bibliográficas}

9) BOLLEN, C.M.; LAMBRECHTS, P.; QUIRYNEN, M. Comparison of surface roughness of oral hard materials to the treshold surface roughness for bacterial plaque retention: a review of the literature. Dent. Mater., v.13, n.4,p.258-68,1997.

10) BRAGA, R. R. et al. Pilot study on the early shear strength of porcelain - dentin bonding using dual - cure cements. J. prosth. Dent., v.81, n.3, p.285-9, 1999.

11) BUCHALLA, W.; ATTIN, T.; HELLWIG, E. Brushing abrasion of luting cements under neutral and acidic conditions. Oper. Dent, v.25, p.482-7, 2000.

12) BULL, W.H. et al. The abrasion and cleaning properties of dentifrices. Brit. dent. J., v.125, n.8, p.331-7, Oct. 1968.

13) BUONOCORE, M. G. A simple method of increasing the adhesion of acrylic filling materials to enamel surfaces. J. dent. Res., v.34, n. p.849-53, 1955.

14) BURROW, M. F. et al. Early bonding of resin cements to dentin - effect of bonding environment. Oper. Dent, v.21, n.5, p.196-202, 1996.

15) CARVALHO, A.S.; CURY, J.A. Fluoride release from some dental materials in different solutions. Oper. Dent, v.24, p.14-9, 1999.

16) CARVALHO, R.M. et al. A Review of Polymerization Contraction. The influence of stress development versus stress relief. Oper. Dent., v.21, p.17-22, 1996.

17) CONDON, J.R.; FERRACANE, J.L. Evaluation of composite wear with a new multi-mode oral wear simulator, Dent. Mat., v.12, n.4, p.218-26, 1996. 


\section{Referências Bibliográficas}

18) CORRER SOBRINHO, L. et al. Influência da escovação na rugosidade de superfície de materiais restauradores estéticos. Pós grad. Rev., v.4, n.1, p.47-55, 2001.

19) DALY, C.G.; CHAPPLE, C.C.; CAMERON, A.C. Effect of toothbrush wear on plaque control. J. clin. Periodont., v.23, n.1, p.45-9, Jan. 1996.

20) DARR, A. H.; JACOBSEN, P. H. Conversion of dual cure luting cement. J. oral Rehab., v.22, n.1, p.43-7, 1995.

21) DE GEE, A.J.; HARKEL-HAGENAAR, H.C.; DAVIDSON, C.L. Structural and physical factors affecting the brush wear of dental composites. J. Dent., v.13, n.1, p.60-70, Mar. 1985.

22) DE GEE, A. J. et al. Annealing as a mechanism of increasing wear resistance of composites. Dent. Mat., v.6, p.266-70, 1990.

23) DE GEE, A J. et al. Influence of enzymes and plaque acids on in vitro wear of dental composites. Biomaterials, v.17, p.1327-32, 1996.

24) DE GOES, M. F. Cimentos resinosos. In: CHAIN, M. C.; BARATIERI, L. N. Restaurações estéticas com resina composta em dentes posteriores. São Paulo, Artes Médicas, 1998. Cap.6, p.176.

25) Dental Advisor plus, v.7, n.3, p.1-2, 1997.

26) DERAND, P.; VEREBY, P. Wear of low fusing dental porcelains. J. prosth. Dent., v.81, n.4, p.460-3, 1999. 


\section{Referências Bibliográficas}

27) DIJKEN, J. W. V.; STADIGH, J.; MEURMAN, J. H. Appearance of finished and unfinished composite surfaces after tooth brushing. Acta Odont. Scand., v.41, n.4, p.337-46, Aug. 1983.

28) EHRNFORD, L. et al. An abrasion test for composite resins. J. dent Res., v.59, n.4, p.716-20, Apr. 1980.

29) EISENBURGER, M.; ADDY, M.; ROBBACH, A; Acidic solubility of luting cements. J. Dent, v.31, p.137-42, 2003.

30) EICK, J.D.; WELCH, F.H. Polymerization shrinkage of posterior composite resins and its possible influence on postoperative sensitivity. Quintessence Int. v.17, p.103-11, 1986.

31) EL-MOWAFY, O.M.; RUBO, M.H.; EL-BADRAWY, W.A. Hardening of new resin cements cured through a ceramic inlay. Oper. Dent, v.24, p.38-44, 1999.

32) ERDRICH, A. J. Artglass: a unique polyglass technology for prosthetic and restorative dentistry. Laboratory Digest, p. 1-17, Summer, 1996.

33) FANUSCU M.I.; SORENSEN, J.A. Pre and post-cementation fit of ceramic crown systems. J. dent. Res., v.71, p.320, 1992. Special issue. / Abstract 1717/

34) FEATHERSTONE, J.D. et al. Enhancement of remireralization in vitro and in vivo. In: Leach S.A. Factors relating to demineralization and remineralization of the teeth. Oxford, IRL, 1986. p.23-34.

35) FERRACANE, J. L. Materials in dentistry: principles and applications. Baltimore, Lippincott Williams \& Wilkins, 2001. p. 14. 
36) FERRACANE, J. L.; CONDON, J. R. Rate of elution of leachable components from composite. Dent. Mat., v.6, p.282-7, 1990.

37) FRAZIER, K.B.; SARRETT, D.C. Wear resistance of dual cured resin luting agents. Amer. J. dent., v.8, n.4, p.161-4, 1995.

38) GARCEZ, R.M.V.B. Avaliação da liberação de flúor de resinas compostas em água e em ciclagem de pH. Bauru, 2001. Dissertação (Mestrado) Faculdade de Odontologia de Bauru, Universidade de São Paulo.

39) GARCIA, F.C.P. Avaliação comparativa das resinas compostas fluidas em relação à resistência à abrasão (escovação simulada). Bauru, 2001. Dissertação (Mestrado) - Faculdade de Odontologia de Bauru, Universidade de São Paulo.

40) GEURTSEN, W. Substances released from dental resin composites and glass ionomer cements. Eur. J. oral Sci., v.105, p.687-95, Apr. 1998.

41) GOLDSTEIN, G. R.; LERNER, T. The effect of toothbrushing on hybrid composite resin. J. prosth. Dent., v.66, n.4, p.498-500, Oct. 1991.

42) GOPFERICH, A. Mechanisms of polymer degradation and erosion. Biomaterials, v.17, p.103-14, 1996.

43) GRABENSTETTER, R. J. et al. The measurement of the abrasion of human teeth by dentifrice abrasives: a test utilizing radioactive teeth. J. dent. Res., v.37, n.6, p.1060-8, Nov./Dec. 1958. 


\section{Referências Bibliográficas}

44) GUZMAN, A.F.; MOORE, B.K.; ANDRES, C.J. Wear resistance of four luting agents as a function of marginal gap distance, cement type, and restorative material. Int. J. prosth., v.10, n.5, p.415-25, 1997.

45) HACHIYA, Y. et al. Relation of finish to discoloration of composite resins. J. prosth. Dent., v.52, n.6, p. 811-4, Dec. 1984.

46) HARRISON, A.; LEWIS, T.T. The development of an abrasion testing machine for dental materials. J. Biomed. Mater. Res., v.9, n.3, p.341-53, May 1975.

47) HARRINGTON, E. et al. Toothbrush-Dentifrice Abrasion. Brit. dent. J., v.153, n.135, p.135-8, 1982.

48) HARTE, D.B.; MANLY, R.S. Effect of toothbrush variables on wear of dentine produced by four abrasives. J. dent. Res., v.54, n.5, p.993-8, Sept./Oct. 1975.

49) HARTE, D.B.; MANLY, R.S. Four variables affecting magnitude of dentifrice abrasiveness. J. dent. Res., v.55, n.3, p.322-7, May/June 1976.

50) HAYASHI, M. et. al. Eight year clinical evaluation of fired ceramic inlays. Oper. Dent., v.25, p.473-81, 2000.

51) HEATH, J.R.; WILSON, H.J. Abrasion of restorative materials by toothpaste. J. oral Rehab., v.3, n.2, p.121-38, Apr. 1976.

52) HEFFEREN, J.J. A laboratory method for assessment of dentifrice abrasivity. J. dent. Res., v.55, n.4, p.563-73, July/Aug. 1976.

53) INOKOSHI, S. et al. Dual cure luting composites. Part I: Filler particle distribution. J. oral Rehab., v.20, n.2, p.133-46, 1993. 


\section{Referências Bibliográficas}

54) INTERNATIONAL ORGANIZATION FOR STANDIZATION. Technical specification 14569-1. Dental materials - guidance on testing of wear resistance - Part 1: wear by tooth brushing. Switzerland, ISO, 1999.

55) IRIE, M.; SUZUKI, K. Current luting cements: marginal gap formation of composite inlay and their mechanical properties. Dent. Mat., v.17, n.4, p.34753, 2001.

56) ISENBERG, B. I.; KAWAI, K.; LEINFELDER, K. F. Effect of gap dimension on composite cement wear. J. dent. Res., v.71, p.691, 1992. Special issue. /Abstract 1402/

57) ISIDOR, F.; BRONDUM, K. A clinical evaluation of porcelain inlays. J. prosth. Dent., v.74, n.2, p.140-4, Aug. 1995.

58) JONES, P.A.; FISHER, S.E.; WILSON, H.J. Abrasivity of dentifrice on anterior restorative materials. Brit. dent. J., v.158, n.3, p.130-3, Feb. 1985.

59) JONES, D.W.; JONES, P.A.; WILSON, H.J. A simple abrasion test for composites. J. Dent., v.1, n.1, p.28-34, Oct. 1972.

60) JORGENSEN, K. D.; ASMUSSEN, E. Occlusal abrasion of a composite restorative resin with ultra fine filler - an initial study. Quintessence Int., v.9, n.6, p.73-8, June 1978.

61) KANTER, J.; KOSKI, R. E.; MARTIN, D. The relationship of weight loss to surface roughness of composite resins from simulated tooth brushing. J. prosth. Dent., v.47, n.5, p.505-13, May 1982. 


\section{Referências Bibliográficas}

62) KAWAI, K.; ISENBERG, B.P.; LEINFELDER, K.F. Effect of gap dimension on composite resin cement wear. Quintessence Int., v.24, p.53-9, 1993.

63) KAWAI, K.; IWAMI, Y.; EBISU, S. Effect of resin monomer composition on toothbrush wear resistance. J. oral Rehab., v.25, n.4, p.264-8, Apr. 1998.

64) KNOBLOCH, L. A. et al Two body wear resistance and degree of conversion of laboratory processed composite materials. Int. J. Prosthod., v.12, n.5, p.432-38, Sept./Oct. 1999.

65) KNUDSEN, M. B.; JORGENSEN, K.D. Abrasion of microfill restorative resins in class 1 cavities. Scand. J. dent. Res., v.91, n.2, p.159-61, Apr. 1983.

66) KRÄMER, N.; FRANKENBERGER, R. Leucite reinforced glass ceramic inlays after six years: Wear of luting composites. Oper. Dent., v.25, p.466-72, 2000.

67) KREJCI, I. et al. Wear of ceramic inlays, their enamel antagonists, and luting cements. J. prosth. Dent, v.69, n.4, p.425-30, 1993.

68) LAMBRECHTS, P. et al. Quantitative evaluation of the wear resistance of posterior dental restorations: A new three-dimensional measuring technique. J. Dent, v.12, p.252-67, 1984.

69) LARSEN, L. B.; MUNKSGAARD, E. C. Effect of saliva on surface degradation of resin composites. Scand. J. dent Res., v.99, p.254-61, 1991.

70) LEE, S. Y.; GREENER, E. H.; MENIS, D. L. Detection of leached moieties from dental composites in fluids simulating food and saliva. Dent Mat., v.11, p.348-53, 1995. 


\section{Referências Bibliográficas}

71) LEINFELDER, K.F. A Report on a new condensable composite resin. Compendium, v.19, n.3, p.230-7, 1998.

72) LEINFELDER, K. F.; BEAUDREAU, R. W.; MAZER, RB. An in vitro device for predicting clinical wear. Quintessence Int., v.20, n.10, p.755-61, Oct. 1989.

73) LENTZ, D.L. et al. Toothbrush abrasion caused by different dentifrices. Quintessence Int., v.22, n.12, p.985-8, 1991.

74) LUGASSY, A. A.; GREENER, E. H. Anabrasion resistance study of some dental resins. J. dent. Res., v.51, n.4, p.967-89, July/Aug. 1972.

75) LUO, J.; LANNUTTI, J. J.; SEGHI, R. R. Effect of filler porosity on abrasion resistance of nanoporous silica gel/polymer composites. Dent. Mat., v.14, n.1, p.29-36, Jan. 1998.

76) LUTZ, F. et al. Potential posterior composites. An in vitro and in vivo comparison for wear. J. dent. Res., v.63, p.914, 1984.

77) MAIR, L. H. Surface permeability and degradation of dental composites resulting from oral temperature changes. Dent Mat., v.5, p.247-55, 1989.

78) MANDIKOS, M. N. et al. A comparison of the wear resistance and hardness of indirect composite resins. J. prosth. Dent, v.85, n.4, p.386 -95, 2001.

79) Mc CABE, J.F.; SMITH, B.H. A method for measuring the wear of restorative materials in vivo. Brit. dent. J., v.151, n.3, p.123-6, Aug. 1981.

80) MENDONÇA, C. et al. Surface roughness evaluation of flowable composite resins before and after brushing. J. dent. Res., v.81, p.339, 2002. Special Issue. / Abstract 2702/ 


\section{Referências Bibliográficas}

81) MESQUITA, I. Compatibilidade entre sistemas adesivos simplificados e resinas compostas. Efeito da acidez do adesivo e modo de polimerização da resina. Bauru, 2002. Monografia (Especialização) Faculdade de Odontologia de Bauru, Universidade de São Paulo.

82) MILLER, W.D. Experiments and observations on the wasting of tooth tissue variously designated as erosion, abrasion, chemical abrasion, denudation, etc. Dent. Cosmos, v.49, n.1, p.1-23, Jan. 1907.

83) OLEA, N. et al. Estrogenicity of resin - based composites and sealants used in dentistry. Enviornm. Health Perspectives, v.104, p.298-305, 1996.

84) OSBORNE, J.W. et al. A method for assessing the clinical solubility and disintegration of luting cements. J. prosth. Dent., v.40, n.4, p.413-7, 1978.

85) PAMElJeR, C. H.; STANLEY, H. R. Pulp reactions to resin cements. Amer. J. Dent., v.5, n.1, p.81-7, 1992.

86) PANZERI, H. et al. Avaliação de dentifricios $1^{\circ}$ parte - consistência, densidade, pH, "vida útil" e perda de água. Odont. Mod., v.5, n.3, p.4-10, maio/jun. 1978.

87) PANZERI, H. et al. Avaliação de dentifricios $2^{\circ}$ parte - forma de distribuição de partículas abrasivas. Odont. Mod., v.5, n.4, p.5-18, jul./ago. 1978.

88) PASHLEY, E. L. et al. Dentin permeability: Sealing the dentin in crown preparations. Oper. Dent, v.17, p. 13-20, 1992. 
89) PATTERSON, C. J. W. et al. Efficacy of a porcelain refinishing system in restoring surface finish after grinding with fine and extra-fine diamond burs. J. prosth. Dent., v.68, n.3, p.402-6, Sept. 1992.

90) PAUL, S.J. Adhesive luting procedures. Berlin, Quintessenz Verlags $\mathrm{GmbH}$, 1997.

91) PEREIRA, L.C.G. et al. Avaliação da rugosidade superficial de materiais restauradores submetidos à simulação de alto desafio cariogênico. Pesq. Odontol. Bras., v.16, p.194, 2002.

92) PEUTZFELDT, A. Dual cure resin cements: in vitro wear and effect of quantity of remaining double bonds, filler volume, and light curing. Acta odont. Scand., v.53, n.1, p.29-34, 1995.

93) POWELL, J.M.; PHILIPS, R.W.; NORMAN, R.D. In vitro wear response of composite resin, amalgam, and enamel. J. dent. Res. v.54, n.6, p.1183-95, Nov./Dec. 1975.

94) PRAKKI, A.; CARVALHO, R.M. Cimentos resinosos duais: características e considerações clínicas. Pós Grad. Rev., v.4, n.1, p.21-6, 2001.

95) PRAMPERO, A.L. et al. Relação das escovas com dentifricios. Rev gaúcha Odont, v.40, n.4, p.298-302, jul./ago. 1992.

96) QUIRYNEN, M.; BOLLEN, C.M.L. The influence of surface roughness and surface free energy on supra and subgingival plaque formation in man. $\mathbf{J}$. clin. Periodont, v.22, n.1, p.1-14, 1995. 


\section{Referências Bibliográficas}

97) REDMALM, G.; RYDÉN, H. Dentifice abrasivity. Swed. Dent. J., v.3, p.91-100, 1979.

98) REES, J.S.; JACOBSEN, P.H. Stresses generated by luting resins during cementation of composite and ceramic inlays. J. oral Rehab., v.19, p.11522, 1992.

99) SANARES, A M. E. et al Chemical cured composite weakens bonding of adhesives by surface interaction. J. dent. Res. v.79, n.1700, p.356, 2000 Special Issue. /Abstract 1700/

100) SANARES, A M. E. et al. Adverse surface interactions between one bottle light cured adhesives and chemical cured composites. Dent. Mat., v.17, n.6, p.542-56, Nov. 2001.

101) SERRA, M.C.; CURY, J.A. The in vitro effect of glass ionomer cement restoration on enamel subjected to a demineralization and remineralization model. Dent. Res., v.23, p.143-7, 1992.

102) SEXSON, J. C.; PHILLIPS, R. W. Studies on the effect of abrasives on acrylic resins. J. prosth. Dent., v.1, n.4, p. 454-71, July 1951.

103) SHINKAI, K. et al. Effect of surface penetrating sealant on wear resistance of luting agents. Quintessence Int., v.25, n.11, p.767-71, 1994.

104) SHINKAI, K. et al. Effect of gap dimension on wear resistance of luting agents. Amer. J. Dent., v.8, n.3, p.149-51, 1995. 
105) SILVA E SOUZA JUNIOR, M. H. da. Procedimentos restauradores estéticos em resina e porcelana para dentes posteriores. Rev. dent. Rest., v.1, n.1, Jan./mar. 1998.

106) SILVA E SOUZA JUNIOR, M. H da.; CARVALHO, R. M.; MONDELLI, R. F. L. Restaurações estéticas. Fundamentos para aplicação clínica. Restaurações com resinas compostas. São Paulo, Ed. Santos, 2000.

107) SILVA E SOUZA JUNIOR, M. H da. et al. Odontologia estética. Fundamentos e aplicações clínicas. Restaurações indiretas sem metal: resinas compostas e cerâmica. São Paulo, Ed. Santos, 2001.

108) SODERHOLM, K. J. M. Filler leachability during water storage of six composite materials. Scand. J. dent. Res., v.98, p.82-8, 1990.

109) SOLDERHOLM, K. J. M.; MUKHERJEE, R.; LONGNATE, J. Filler leachability of composites stored in destilled water or artificial saliva. J. dent. Res., v.75, n.9, p.1692-99, Sept. 1996.

110) SODERHOLM, K. J. et al. Hydrolytic degradation of dental composites. J. dent. Res., v.63, p.1248-54, 1984.

111) SORENSEN, J.A.; MUNKSGAARD, E.C. Ceramic inlay movement during polymerization of resin luting agents. Eur. J. oral Sci., v.103, p.186-9, 1995.

112) SOUZA, E. H. A et al. Effect of topical fluoride application on the surface roughness of composites. Braz. dent. J., v.6, n.1, p.33-9, Jan. 1995. 
113) STOOKEY, G.K.; MUHLER, J.C. Laboratory studies concerning the enamel and dentine abrasion properties of common dentifrice polishing agents. J. dent. Res., v.47, n.4, p.524-32, 1968.

114) SUZUKI, S.; LEINFELDER, K.F. An in vitro evaluation of a copolymerizable type of micro filled composite resin. Quintessence Int., v.25, p.59-64, 1994.

115) SUZUKI, S.; LEINFELDER, K.F.; SHINKAI, K. Wear resistance of resin cements. Amer. J. Dent., v.8, n.2, p.83-7, 1995.

116) TEN CATE, J.M. In vitro studies on the effects of fluoride on De and Remineralization. J. dent. Res., v.69, p.614-9, 1990. Special issue.

117) TORII, Y. et al. Influence of filler content and gap dimension on wear resistance of resin composite luting cements around a CAD/CAM ceramic inlay restoration. Dent. Mat., v.18, n.4, p.453-61, 1999.

118) TURSSI, C.P. Micromorfologia superficial de materiais estéticos submetidos a diferentes processos de degradação. Piracicaba, 2001. Dissertação (mestrado). Faculdade de Odontologia de Piracicaba - Universidade Estadual de Campinas.

119) WANG, L. Avaliação comparativa da resistência à abrasão de resinas compostas condensáveis, submetidas à escovação simulada, através da alteração de massa e da rugosidade superficial. Bauru, 2001. Dissertação (mestrado) - Faculdade de Odontologia de Bauru, Universidade de São Paulo. 
120) WARD, M. T.; TATE, W. H.; POWERS, J. M. Surface roughness of opalescent porcelains after polishing. Oper. Dent, v.20, n.3, p.106-10, May/June 1995.

121) WENDT, S. L. A laboratory and clinical evaluation of a heat cured composite resin inlay. Alabama, 1988. Thesis - University of Alabama at Birmingham.

122) WENDT JUNIOR, S. L.; LEINFELDER, K.F. The clinical evaluation of heattreated resin composite inlay. J. Amer. dent Ass., v.120, p.177-81, 1990.

123) WENDT JUNIOR, S. L.; LEINFELDER, K.F. Three year evaluation of a heattreated resin composite inlay. Amer. J. Dent., v.5, p.258-62, 1992.

124) WU, W.; McKINNEY, J. E. Influence of chemicals on wear of dental composites. J. dent. Res., v.61, n.10, p.1180-3, Oct. 1982.

125) XU, X.; XIN, X.; WEATHERSBY, J.; BURGUESS, J. O. In vitro wear and toothbrush abrasion of flowable and posterior dental composites. J. dent. Res., v.81, p.258, 2002. Special Issue. /Abstract 1997/ 
ABSTRACT 


\section{ABSTRACT}

\section{RESIN CEMENTS WEAR RESISTANCE EVALUATION UNDER BRUSHING ABRASION PRECEDED BY PH CYCLING SIMULATIONS}

Indirect aesthetic restorations have been found to have a wide variation on its adaptation, subjecting consequently, the luting material to the oral environment degradation provided by physical, mechanical or chemical processes. Thus, their wear resistances still worry researchers. In this context, the objective of this work was to evaluate the wear resistance of three resin luting cements, Enforce (Dentsply), Rely X (3M) and Variolink II (Vivadent) when compared to the following indirect restorative materials, Artglass (Heraeus Kulzer) and Duceram Plus (Ducera). All the material was subjected to dynamic $\mathrm{pH}$ cycles and to brushing simulation and the wear was detected by their weight and surface roughness changes.

A hundred specimens were obtained, twenty for each material, half of them (ten for each material) was submitted to dynamic $\mathrm{pH}$ cycles before the brushing strokes. For the abrasion test, the specimens were subjected to 100.000 cycles of brushing with soft bristles tips (Oral B) containing dentifrice solution (Colgate) and deionized water. The weight loss was detected by the difference between the initial (before brushing strokes) and final measurements (after brushing strokes). The evaluation of surface roughness was obtained by the difference between initial and final means after five roughness readings in a Hommel Tester T 1000 testing machine. The results (ANOVA and Tukey) showed significant differences of weight loss and surface roughness among the tested materials. 
Duceram Plus was not influenced by $\mathrm{pH}$ cycling and presented the best performance after tooth brushing test. Among composite materials, Artglass and Variolink II presented better results for weight and roughness alterations followed by Rely $\mathrm{X}$ and Enforce. PH cycling did not influence statistically on tested materials wear resistance. 